\title{
G. DARGENTY
}

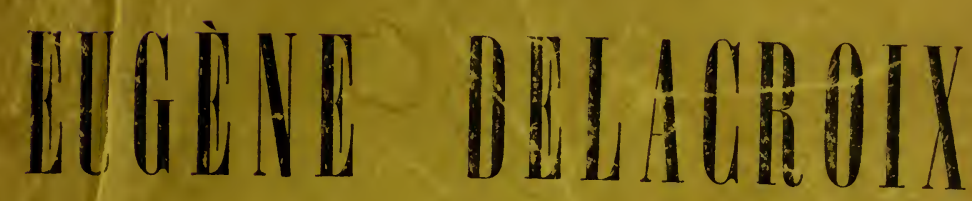

$$
L U I-M \hat{E} M E
$$

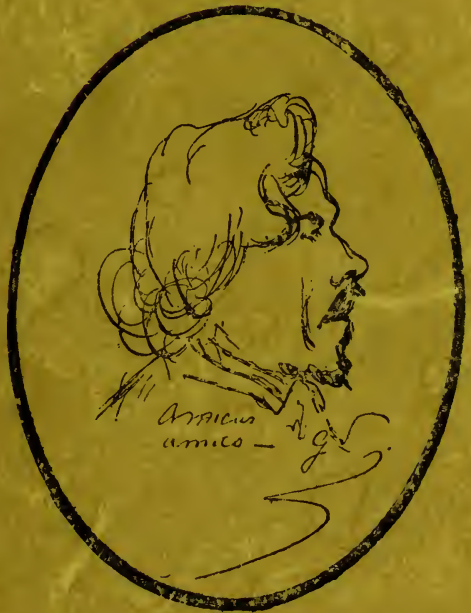

LIBRAIRIE DE L'ART

T. ROUAM, ÉDITEUR 29, CITÉ D'ANTIN, PAFIS

1885 
Les nexper fo Ct

$$
p+p^{p r} 8^{2}-8^{r f}
$$




\title{
EUGĖNE DELACROIX
}

PA R

\author{
LUI - M $\hat{E} \mathbf{M E}$
}




\section{PARIS. - IMPRIMERIE DE L'ART}

E. MÉNARD ET J. AUGRY, 4I, RUE DE I. A VICTOIRE. 



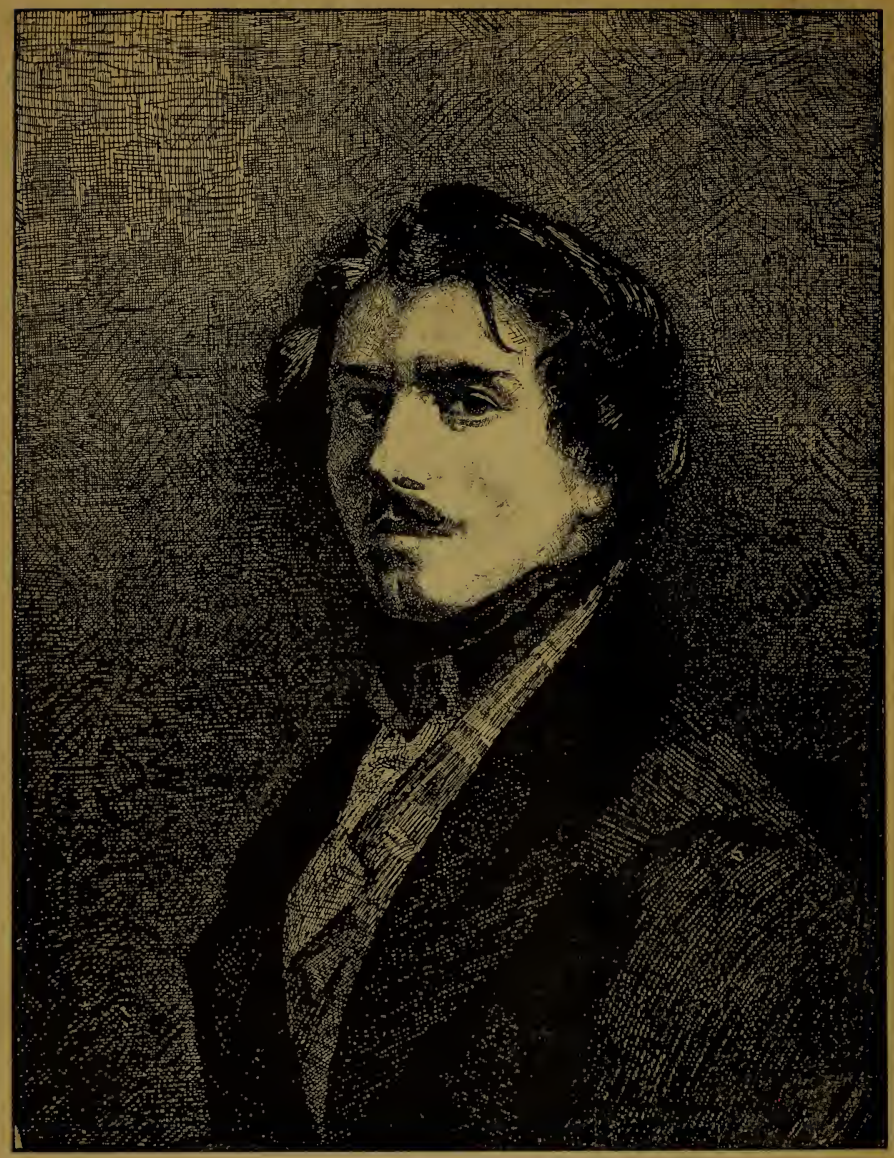

I'ORTRAIT W'ELGEXE WELACROIX

par lui-mêmə. - (Musḱe de I.ouve.) 
G. DARGENTY
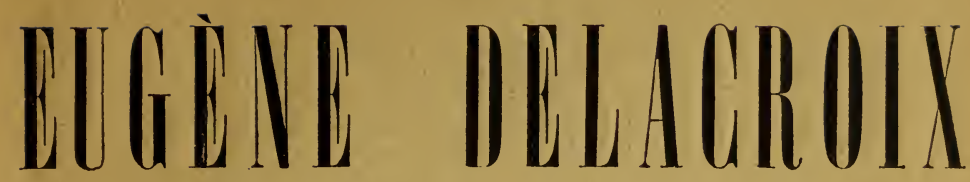

PAR

\section{U I - M E M E}

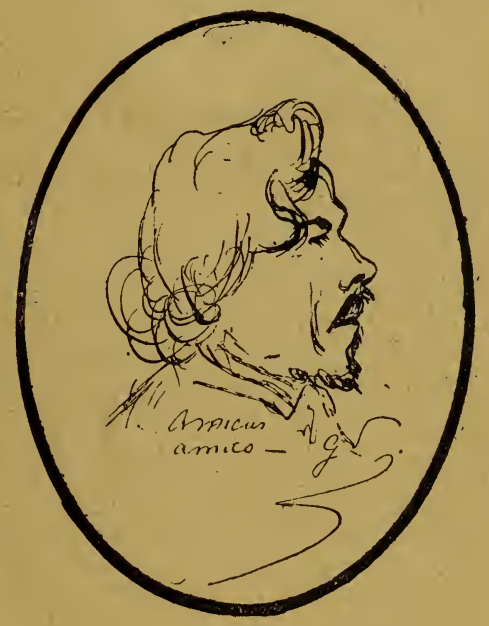

LIBRAIRIE DE L'ART

.J. ROUA M, ÉDITEUR

29, CITE D'ANTIN, PARIS

1885 



\title{
EUGÈNE DELACROIX
}

\author{
PAR LUI-MÊME
}

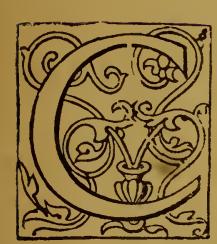

E livre n'est ni une œuvre critique, ni une simple biographie; c'est un résumé de la vie, des mœurs, des tendances, des impressions, des joies, des déboires, des efforts et des sentiments généraux du plus grand peintre de notre époque, d'un des chefs de l'école moderne, d'un admirable poète, d'un homme de génie enfin, dont la personnalité rayonnante illumine la première partie de ce siècle.

Il nous a paru intéressant, au moment où on se préoccupe de rendre au maître un tardif hommage, de montrer Delacroix sous toutes ses faces, de le mettre pour ainsi dire à nu devant le public, afin que ce public puisse connaître à fond 
le merveilleux artiste, le juger par ses grands et ses petits côtés, le suivre dans son évolution intellectuelle, partager ses joies, ses espérances et ses douleurs; voir enfin ce que peut une volonté ferme mal secondée par une santé chancelante, lorsqu'elle est doublée d'une foi inébranlable et d'un amour absolu de l'art.

C'est Delacroix lui-même qui va nous conter sa vie. Cette vie ainsi envisagée sera d'un grand enseignement surtout pour les artistes d'aujourd'hui, dont la majeure partie a perdu non seulement les traditions du grand art mais avec elles aussi la foi et les hautes vertus qui permettent de conserver, l'œil fixé sur le but, une impassibilité sereine, une attitude ferme et une marche droite au milieu des dégoûts, des chagrins, des impatiences, des désenchantements, et surtout des succès et des adulations qui, les uns comme les autres, sont les compagnons obligés d'une carrière artistique. Cette vie fut extérieurement calme et presque terne. On ne la trouve traversée par aucun épisode dramatique, aucun incident aigu pourant donner plus tard un aliment à la légende. C'est une vie concentrée, 
prosaïcque en apparence. Il faut pénétrer au plus profond de l'âme du peintre pour rencontrer la houle intime qui battit incessamment les parois de son crâne comme elle ne manque jamais de battre la boite osseuse de tout grand homme. Delacroix confie à ses seuls amis ses préoccupations, ses tourments; eux seuls sarent ce qu'endure sa nature mélancolique, souffretcuse et hypocondriaque. Il ne fait point d'éclat, ne prend pas l'univers à témoin de ses peines, ne monte pas sur les toits pour crier à la foule ce qu'il souffre. Le monde le croit heureux et riche; il est pauvre et tourmenté sans trêve; mais hormis Soulier, Pierret, Félix G. et quelques rares intimes, camarades de la première enfance, nul ne soupçonnera le feu interne qui le consume, nul ne connaîtra ses doutes, ses espérances, ses ambitions, sa confiance en lui et sa méfiance de lui.

Les lettres de Delacroix si heureusement réunies par les soins de M. Burty nous fourniront un des éléments les plus précieux de cette étude. Elles seules contiennent l'artiste tout entier. A côté d'elles cependant une longue 
suite de morceaux critiques dus à Paul de SaintVictor, à Th. Gautier, à Ernest Chesneau, à Baudelaire, à M. Jal, à M. Vitet, à Charles Blanc, à Th. Silvestre, à Thoré, à M. Rivet, et surtout les souvenirs intimes contenus dans les publications de MM. Moreau, Piron, Cantaloube et Jean Gigoux, fourmillent de renseignements précieux. Nous avons tout consulté et c'est de cet ensemble considérable que nous tirerons le texte de ce volume, qui n'est, comme on le voit, qu'une sorte de compilation ainsi que l'indique son titre, du reste.

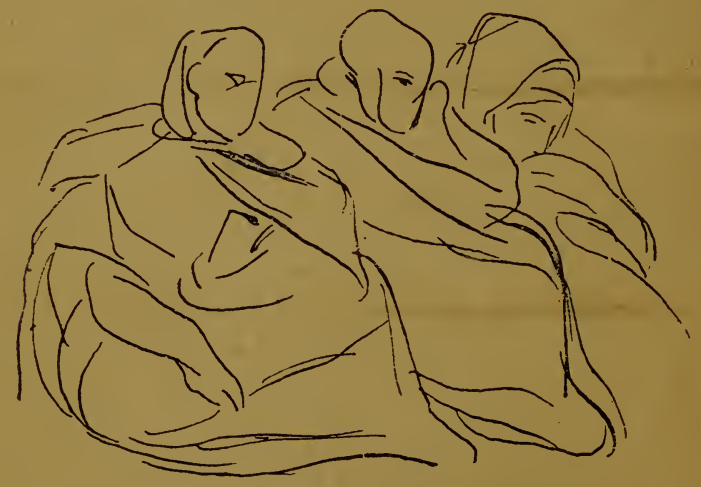




\section{Généalogie}

Ferdinand-Eugène Delacroix est né à Charenton, le 8 floréal de l'an VI de la Rẻpublique. Il était fils de Victoire Oëben et de Charles Delacroix, ministre de la République française près la République batave, suivant son acte de naissance transcrit sur les registres de la commune de Charenton.

Charles Delacroix, dit M. Piron dans le livre précieux qu'il a consacré à la vie et aux cuvres d'Eugène Delacroix, avait été d'abord avocat au Parlement, puis secrétaire de Turgot; il avait accompagné celui-ci dans son intendance de Limoges; il avait été ensuite élu membre de la Convention. Les Directeurs lui avaient plus tard confié le ministère des affaires étrangères. Deux ans après la naissance d'Eugène, il fut compris dans l'organisation des préfectures et désigné par le premier consul pour occuper celle de Marseille. Enfin, de là il passa préfet de Bordeaux, où il mourut entouré de l'estime publique. 
Victoire Oëben, morte en 1814, appartenait à une famille d'artisans-artistes honorables. L'ébéniste Oëben est qualifié fameux dans les catalogues des grandes ventes du siècle dernier, il fut élève de Boulle.

Charles Delacroix eut de son mariage avec Victoire Oëben quatre enfants : le général Charles-Henri, baron Delacroix, né le 11 janvier 1779, mort à Bordeaux, le 30 décembre 1840 ; $M^{\text {me }}$ de Verninac, née en 1780 , morte en 1827 ; Henri Delacroix, tué à Friedland à vingt-trois ans; enfin, Ferdinand-Victor-Eugène, qui était le plus jeune.

Nous croyons utile de transcrire ici textuellement les détails que nous donne M. Piron sur la famille d'Eugène Delacroix, parce qu'ils montrent, sans toucher à cette question cependant, dans quelles conditions de relations si opposées à ses aspirations et à ses instincts vécut le grand artiste pendant le cours de sa jeunesse, privéc de toutes les douceurs des épanchements familiaux dont sa nature était si avide pourtant, à en juger par la correspondance qu'il entretenait avec ses amis. 
“ Le fils aîné (Charles-Henri), général Delacroix, eut une carrière glorieuse mais traverséc comme toutes celles des militaires de cette époque. Il mourut à Bordeaux à l'âge de soixante-sept ans, instituant pour son légataire universel son plus jeune frère Eugène, mais ne lui laissant presque rien. Il vivait du revenu que lui attribuait son titre de commandeur de la Légion d'honneur, celui de baron de l'Empire, sa pension de général, enfin d'une autre pension que lui faisait la maison du prince Eugène, et tout cela devait s'éteindre avec lui.

" Dans un voyage qu'Eugène fit aux EauxBonnes, en 1845, il ne put rejoindre son frère, qui était alors à Mestras près de Gujan. Ils se virent peu pendant le cours de leur vie : ils s'aimaient, les liens du sang ne perdirent jamais de leur force; mais les rapports d'esprit, d'éducation et de monde ne les réunissaient pas, et de longs intervalles s'écoulèrent sans qu'ils eussent occasion de s'écrire et de se visiter.

“ $\mathrm{M}^{\text {me }}$ de Verninac, sœur d'Eugène, était une femme très belle et d'une grande distinction. Elle avait épousé M. de Verninac Saint-Maur, 
ambassadeur de France à Constantinople. Elle eut de ce mariage un seul fils, Charles de Verninac, qui fut envoyé comme vice-consul en Amérique et qui mourut en quarantaine à New-York, en 1834, de la fièvre jaune qu'il avait contractée à Vera-Cruz, à son retour de Valparaiso.

" Il existe un portrait de $\mathrm{M}^{\mathrm{me}}$ de Verninac, peint par David, et grand comme nature, qu'Eugène Delacroix conservait précieusement dans son salon. Son admiration pour le talent du peintre se mêlait dans le culte qu'il avait pour cette peinture à la tendresse qu'il portait à la mémoire de sa sœur. Il a, par testament, légué ce portrait à M. de Verninac, son cousin, président du tribunal de Tulle.»

Le troisième enfant, le jeune Henri Delacroix, mourut à Friedland. " La bataille venait de finir, chacun se retirait : il rencontra son frère, depuis le général ; ils se jetèrent dans les bras l'un de l'autre et se félicitèrent réciproquement. Henri donna à Charles moitié d'un morceau de pain qu'il avait caché, chose précieuse à ce qu'il paraît, à ce moment, et à peine 
s'étaient-ils séparés qu'un dernier boulet de canon emportait ce malheureux Henri. »

On voit, par les lignes qui précèdent, que Delacroix fut à peu près complètement sevré de ces doux liens de famille qui soutiennent, consolent et aident à vivre la première période de la vie, période semée d'écueils où l'expérience, l'amour des siens sont choses si précieuses. Il avait perdu sa mère à seize ans; il vivait éloigné, par la nécessité des circonstances, de son frère et de sa sœur; il était seul enfin, et débordait d'ardeur et d'enthousiasme juvéniles. S'il eût vécu en famille, sa mère, son frère et sa sœur eussent été les confidents nés de ses projets et de ses espérances; mais, ces amis naturels lui faisant défaut, son cœur s'est accroché aux camarades de collège, aux amis de sa jeunesse qui se sont substitués à sa véritable famille absente, et auxquels il a livré tous les secrets de son àme avec la verve de la vingtième année. L'amitié, la sainte amitié comme il l'appelle, de ses condisciples enthousiastes et bons comme ui, ce fut le cordial qui le réconforta dans l'abandon cruel où ses deuils le plongeaient. 
Le vide affreux que la mort fit prématurément autour de lui, ses amis seuls le comblèrent. Aussi éprouva-t-il toujours le besoin de rester en constante communion avec eux et de leur tendre la main à distance lorsque les exigences de la vie le forçaient à s'éloigner. On est dunc tenté de s'applaudir égoïstement de ce douloureux état de choses qui nous vaut la série de lettres où cet esprit abondant et expansif s'est répandu naïvement et sans apprêt, avec la confiance absolue d'un homme loyal qui se livre à de loyaux camarades. 


\section{Portrait de Delacroix}

“ Eugène Delacroix, dit M. Piron, était assez grand, maigre et un peu frêle, mais bien pris dans sa taille, élégant de tournure et distingué de manières. Il avait les cheveux d'un noir de jais, les yeux vifs, la bouche bien ornée, le sourire aimable et spirituel; son teint était pâle et bilieux et sa figure paraissait petite sous ses cheveux touffus et soyeux; son œil éprouvait quelquefois une légère contraction, semblable à celle d'un homme qui interrogerait le soleil et qui se mettrait en mesure d'en supporter l'éclat.

" Il se plaçait ainsi, debout, en face et assez rapproché de son interlocuteur, renversait ensuite légèrement le corps pour augmenter la distance qui le séparait de lui et comme pour mieux examiner son homme; c'est alors que, dans son sourire, on voyait briller sous sa moustache noire ses dents blanches, plates et bien rangées.

" Il avait, a dit quelqu'un, des petites mains 
nerveuses, adroites et plus aiguisées que celles d'un chat. Sa mise était soignée, il recherchait les habitudes d'un homme du monde; on voyai clairement qu'il ne voulait pas ètre confondu avec ces héros d'ateliers qui arrivent à la célébrité par l'excentricité de leur costume. Il était réservé de maintien, sobre de gestes, jetant dans la conversation quelques mots comme un aliment et sans prétention à la dominer. Je ne lui ai jamais entendu faire de longs discours; son opinion s'énonçait par quelques phrases coupées, et il concluait presque toujours dès les premiers mots. Avec une timidité naturelle et visible, il avait cependant confiance dans son propre jugement, et l'on ne peut pas dire qu'il manquât d'une certaine bonne opinion de lui-même. Son esprit était fin, sa forme caressante et son cœur sincère et fidèle en amitié. Il était très impressionnable, légèrement craintif, quelque peu défiant; en somme, bon et généreux envers tous et surtout sans ressentiment ni longue rancune à l'égard de personne.

- “ Homme bien élevé, et l'esprit très cultivé, il était recherché dans le monde, qu'il a fui 
souvent par raison de santé et par instinct de conservation. »

Voici un portrait brossé de main de maitre : l'homme y est tout entier, au physique et au moral. Voyons maintenant l'artiste. C'est M. Th. Silvestre qui va faire la synthèse de ses défauts et de ses qualités, éclairer sa figure d'un jour intense et lui donner un relief unique, grâce à l'extraordinaire vigueur de son talent.

Il sera temps ensuite d'aborder l'artiste par le détail.

“ Delacroix se fortifie par la solitude et le recueillement; il est à son chevalet mystérieux et incessant comme l'alchimiste à ses fourneaux. Bien des gens n'ont trouvé que hauteur et misanthropie dans la retraite un peu farouche qu'il s'est imposée, mais un tel artiste dévoré du besoin de produire sent l'existence courte et n'est guère porté à sacrifier aux plus intéressantes relations. Selon l'expression du poète: il cache sa vie et répand son esprit. L'homme studieux qui connaît le monde ne s'ennuie jamais; l'isolement est un droit pour son égoïsme, un devoir pour son intelligence. 
Libre et fort par lui-même, que gagnerait-il aux affections vulgaires? le dégoût. Celui qui connaît le prix de son âme et des vérités éternelles appartient à la solitude.

“Delacroix tressaille comme un coupable toutes les fois cu'il entend les pas d'un visiteur; un coup de sonnette jette l'alarme dans si maison; deux gouvernantes accourent à la porte, semblables à des sentinelles réveillées par un coup de feu, et défendent la consigne. si, par une rare tolérance, il vous arrive d'entrer aux heures du travail dans cet atelier si bien gardé, le peintre est arrêté court, quelquefois même pour le reste de la journée, dans ces moments de verve et d'entrain qui le prennent par intervalles, soyez certain qu'il vous maudit intérieurement, tout en vous disant mille choses charmantes. C'est qu'il est arrivé à cette jalouse et inflexible distribution du temps qui décuple la fécondité des hommes supérieurs, leur permet de prêter à la spécialité de leur art l'appui de toutes les connaissances, et d'arriver enfin, par l'habitude d'un travail solitaire et obstiné, à la fermeté de l'expérience sans préjudice des 
qualités natives. L'écrivain même qui, dans toute l'ardeur de la jeunesse et du sentiment, est confus et désordonné, c'est-à-dire médiocre et même mauvais, peut devenir, comme le vin, excellent en vieillissant et se trouver dans toute sa puissance au moment où il n'a plus ni clents ni souffle. Non seulement alors les idées se pressent dans son cerveau comme autrefois, mais encore a-t-il rejeté les paillettes du faux luxe en gagnant des qualités solides, l'enchaînement, la proportion qu'il ne soupconnait même pas et qui lui viennent à cette heure avec la conception, naturellement, spontanément. Malgré leur vivacité, leur imprévu et cette saveur amère des fruits verts que les enfants font tomber des arbres à coups de pierres, les ouvrages de la jeunesse manquent de substance et de fermeté.

"D'où vient, me disait un jour Delacroix, qu'à présent je ne m'ennuie pas un seul instant quand j'ai le pinceau à la main? J'éprouve même que, si mes forces pouvaient y suffire, je ne cesscrais de peindre que pour manger ou dormir. Autrefois, dans cet âge prétendu l'âg̣e 
de la verve et de l'imagination, j'étais arrêté à chaque pas et souvent dégoûté; aujourd'hui je n'hésite plus : la maturité est complète; l’imagination est aussi fraîche, aussi active que jamais, et délivrée des passions folles; mais les forces physiques manquent, les sens usés demandent le repos, et pourtant quelle consolation je trouve encore dans le travail! J'ai le bonheur de ne plus être heureux comme je l'entendais autrefois. A quelle tyrannie sauvage l'affaiblissement du corps ne m'a-t-il pas arraché? Il faut donc faire comme on peut: si la nature nous refuse le travail au delà d'un certain nombre d'instants, ne lui faisons pas violence; contentons-nous de ce qu'elle nous laisse; jouissons du travail pour le travail lui-même et des heures délicieuses qui le suivent; ce repos a été acheté par une salutaire fatigue qui entretient la santé du corps, agit sur celle de l'âme et empêche la rouille des années de clévorer notre intelligence.

"Mais ne vous fiez pas à ces paroles de résignation : l'artiste a des rages de travail qui le jaunissent et le clessèchent. Il prend tour à tour, par passades, avec rapidité et furie, dix à clouze 
toiles qui se succèdent sur son chevalet comme les apparitions de la lanterne magique. Je me trouvais un soir chez lui vers les quatre heures; on lui demandait un Christ en croix que je vis entièrement esquissé le lendemain : Christ, larrons, saintes femmes, peuple, soldats et bourreaux, tout était déjà rendu avec autant d'énergie que si le tableau eût été fini; seulement, la scène se passait encore un peu confusément à travers les chaudes fumées de l'inspiration.

"Cet homme subtil et impressionnable vibre au moindre choc, s'agite au moindre souffle; il voit, entend, saisit tout au vol, un mot, un geste, un nuage qui passe sur votre physionomie; mais sa défiance développée à l'excès par l'expérience du monde et de ses hypocrisies dépasse quelquefois sa perspicacité naturelle; il lui arrive de manquer de franchise, sans rien laisser paraître de cette dissimulation, parce qu'il est à peu près le maitre de ses attitudes et de sa langue. Je crois qu'il n'excepte que très peu d'hommes de son indifférence; la philosophie pratique lui suggère quelques complaisances mondaines doublées d'ironie. 
“ Delacroix est un caractère violent, sulfureux, mais plein d'empire sur lui-même : il se tient en prison dans son éducation d'homme du monde qui est parfaite. Rusé, attentif quand on lui parle, il est prompt, aiguisé, prudent dans ses répliques. Comme il connait à fond l'escrime de la vie, il enferre proprement son homme sans avancer d'une ligne. Né au cœur de la diplomatie, bercé sur les genoux de Talleyrand qui fut le successeur de son père au ministère des affaires étrangères, il remplirait à la Rubens la plus brillante ambassade : il ne pourrait sans doute déployer le faste, l'ampleur du Flamand, mais quel goût, quelle finesse il montrerait! Son maintien est élégant et supérieurement aisé : gestes sobres, fort expressifs, et une langue d'or. 11 a l'habileté, les manières caressantes, les insinuations, les grâces, les manières de la femme. Ses petits yeux vifs clignotants, enfoncés sous l'arcade de ses sourcils noirs et rudes, l'abondance magnificue de sa chevelure, me rappellent les plus vivants portraits à l'eauforte que Rembrandt nous ait laissés de luimême. Delacroix est du reste le parent de 
Rembrandt par la ténacité, la fougue, la divination. Son humeur est spirituelle et sarcasticque plutôt qu'enjouée. Il a le sourire profond et mèlancolique. La coupe carrée de ses mâchoires inégales et proéminentes, la mobilité de ses narines largement ouvertes at frémissantes, expriment à outrance l'ardeur de ses passions et de sa volonté. Parfois, ses airs de tête sont d'une fierté et d'un cynisme souverains. Son front carré s'avance en bosses intelligentes. Sa bouche, d'un dessin redoutable, tendue comme un arc, lance des flèches acérées sur ses contradicteurs et porte des jugements exquis. Il n'est pas beau dans les conditions bourgeoises et sa physionomie rayonne. Toutes ses figures ont quelque chose de lui : l'air pensif et souffrant; mais il donne à l'homme énormément de muscles par amour pour la force et l'activité. Les femmes surtout lui ressemblent par la noblesse, l'élégance des attitudes, l'ardeur du tempérament et la fatale beauté de l'expression.

“La frêle constitution de l'artiste est relevée par la vigueur de ses nerfs : il a la résistance et la souplesse de l'acier fin; il respire feu et 
flamme comme ce petit cheval cabré clans le Massacre de Scio, sublime ouvrage de sa jeunesse. Il parle avec mesure, mais, à ses attitudes impatientes, on voit qu'il refrène son impétuosité. Il étonne par tant de fougue mêlée à tant de sang-froid, et par cette surexcitation de l'esprit qui pétille toujours en lui comme la flamme. "I,artiste qui, clans la folle émulation de la jeunesse, aurait peint sur la pointe d'un clocher, comme il le dit lui-même, et qui a fait à la diable le Massacre de Scio dans un petit atelier humide du quartier de la Sorbonne, a besoin aujourd'hui de beaucoup de précautions et de soins : l'atmosphère de son atelier est tellement chaude que les couleurres y vivraient heureuses; cet homme ardent et frileux se tient toujours enveloppé comme le python des galeries zoologiques; on croirait qu'il est né à Java et non sous le ciel de Paris. Les sensations qui courent dans ses veines, plus rapides que l'électricité sur les fils télégraphiques, le bouleversent vingt fois par jour.

“ Il y a vingt ans, m'écrivait George Sand, que je suis liée avec lui, et par conséquent 
heureuse de pouvoir dire qu'on doit le louer sans réserve, parce que rien, dans la vie de l'homme, n'est au-dessous de la mission si largement remplie du maître; et je n'ai probablement rien à vous apprendre sur la constante noblesse de son caractère et l'honorable fidélité de ses amitiés.

"Il jouit également des diverses faces du beau par les côtés multiples de son intelligence. Delacroix, vous pouvez l'affirmer, est un artiste complet. Il goûte et compreñd la musique d'une manière si supérieure, qu'il eût été très probablement un grand musicien, s'il n'eût pas choisi d'être un grand peintre. Il n'est pas moins bon juge en littérature, et peu d'esprits sont aussi ornés et aussi nets que le sien. Si son bras et sa vue venaient à se fatiguer, il pourrait encore dicter, dans une très belle forme, des pages qui manquent à l'histoire de l'art et qui resteraient comme des archives à consulter, pour tous les artistes de l'avenir.

“ Ne craignez pas d'être partial, en lui portant une admiration sans réserve. La vôtre, comme la mienne, a dû commencer avec son 
talent, et grandir avec sa puissance, année par année, œuvre par œuvre.

" Tant de qualités brillantes et variées n'ont fait qu'embellir les études spéciales de l'artiste: le public sera bien surpris, après sa mort, si la collection innombrable et précieuse de ses essais en tous genres passe entière sous ses yeux avides. »

Elle y est passée, depuis, cette collection, sous les yeux du public, et le résultat des enchères a prouvé que Théophile Silvestre avait bien jugé. 


\section{Amour de Delacroix pour la musique.}

Et maintenant, pourcuoi Delacroix se fit-il peintre? car, ainsi qu'il nous l'apprend lui-même, il avait un goût très prononcé pour la musique, goût qui ne se démentit pas, ainsi que le prouve la citation qui vient après, tirée du livre de M. Ed. Moreau. Laissons-lui la parole d'abord : “ J'ai eu, de très bonne heure, un grand goût pour le dessin et pour la musique. Un vieux musicien, qui était organiste de la cathédrale de Bordeaux, où mon père est encore préfet, donnait des leçons à ma sœur. Pendant que je faisais mes gambades dans le salon où ces leçons se donnaient, ce brave homme, qui d'ailleurs avait beaucoup de mérite et avait, par parenthèse, été l'ami de Mozart, remarquait que j'accompagnais le chœur avec les basses et des agréments de ma façon, dont il admirait la justesse, et qui annonçaient une véritable aptitude musicale. Il tourmenta même ma mère, pour qu'il fit de moi un musicien. » 
Delacroix, affirme M. Ed. Moreau, aimait également la peinture et la musique. "Il aimait cette dernière avec passion. Dans un de ses croquis, nous le voyons debout, devant une cheminée, jouant du violon, de ce violon chéri cqu'il cultivait déjà en 1824, tout en peignant le Massacre de Scio. Ce qu'il jouait alors, c'étaient les partitions des Nozze, de Tancrède et de Don Juan, entendues la veille au théâtre, et dont les illustres interprètes, la Pasta, Guichetti et la Bonsignori, avaient ravi son âme en extase. A cette époque, c'est-à-clire de 1822 à 1830, il aimait aussi à exercer sa voix, qui, sans avoir une bien grande étendue, ne laissait pas que d'être douée d'un timbre profondément sympathique et lui valait, comme chez M. de Conflans un certain soir, des succès de salon auxquels il n'était pas tout à fait insensible. Bientôt, les exigences de la peinture, décidément son art favori, ne lui laissent plus le temps de se livrer à l'étude sérieuse de la musique: le pinceau l'emportant, le violon resta dans son étui cette fois pour n'en plus sortir, et sa voix, qui déjà se voilait sous les premières atteintes de sa maladie 
de larynx, cessa désormais de se faire entendre, même aux amis; mais s'il n'est plus un exécutant, il n'en demeure pas moins un mélomane, et, jusqu'à son dernier jour, il restera un dilettante accompli.

"En musique, cependant, comme en toutes choses, sa vive et délicate organisation n'admet rien que d'exquis: les chefs-d'œuvre des maîtres ont seuls le privilège de l'émouvoir; encore faut-il que l'exécution en soit parfaite, car il a l'oreille exercée et le goût difficile: il est du Conservatoire un auditeur assidu; il ne manque pas une soirée d'Halévy ou de Berlioz; ravi, transporté, quand c'est l'ouverture de Coriolan, ou celle de la Flûte enchantée, qui figure au programme.

" S’il entend Franchome ou Chopin, Allard, Prudent, Delsarte ou Alcan, ou bien encore quelques-unes de ces individualités du grand monde, que le talent a su élever à la hauteur des véritables artistes; si leurs doigts merveilleux rendent, comme il le comprend, la musique de ses maitres favoris, oh! alor's son bonheur n'a pas d'égal; que s'il voit au théâtre 
la Pasta dans Roméo, la Malibran dans Miaric Stuart, la Grisi dans Norma, la Cruvelli dans Sémiramis, l'Alboni dans la Cenerentola, Marin dans Lucrèce Borgia, ou que, dans un salon, la comtesse Potocka chante devant lui le Moulin de Nohant, que Mariette Lablache vocalise son adorable Chiquita, que $M^{\text {me }}$ Viardot lui fasse connaître un vieil air de Glück, il en rêvera des semaines entières, et le résultat de chacune de ces soirées sera, pour le lendemain, une journée de travail productif, où son pinceau électrisé puisera dans un souvenir purement musical de sublimes inspirations.

“ Il nous souvient, à ce propos, qu’un jour du mois d'août 18ว6, visitant avec Delacroix ses fresques de Saint-Sulpice, encore enveloppées de leur chemise de planches, il nous montrait avec complaisance cet ange magnifique qui, dans le tableau d'Héliodore, frappe le profanateur de sa verge vengeresse. Le morceau venait à peine d'être achevé, et le maître attribuait sa réussite exceptionnelle à cet état indéfinissable de la pensée, dans lequel l'avaient plongé les chants de l'orgue, jouant le Dies iræ. 
“ Delacroix, cependant, n'étudia pas la musique et fut mis au lycée impérial, à l'âge de neuf ans..... ) 


\section{Pourquoi Delacroix se fit peintre.}

\section{Entrée à l'atelier.}

“.... Beaucoup de circonstances devaient le conduire à prendre cet état, dit M. Piron. Considérons d'abord qu'au moment de se choisir une carrière, il dut s'apercevoir que le nom de son père lui fermait l'entrée aux emplois publics sous le gouvernement des Bourbons; qu'il se trouvait en outre, être le cousin de M. de la Valette, qui venait d'être arraché à la mort par le noble dévouement de sa femme, et dont le gouvernement poursuivit le nom avec grande passion, pendant plusieurs années.

"Pour tenter une carrière industrielle ou commerciale, il fallait des capitaux qu'il n'avait pas, et d'ailleurs son aptitude ne le portait pas là.... Que faire alors? Ce qu'il fit, se laisser aller à ses instincts d'indépendance et de liberté personnelle, donner un libre essor aux élans de son imagination et prendre sérieusement et résolument la carrière des arts. 
" Au collège, il dessinait déjà, et je me rappelle qu'il avait fait, étant jeune, deux caricatures pour le journal le Nain jaune, qui traitaient de ce qu'on appelait en 1814 les Voltigeurs de Louis XIV. M. Riesener, oncle de sa mère, était un peintre distingué, et l'opinion de celui-ci ne fut sans doute pas, non plus, sans influence sur la détermination qu'adopta son neveu.

" Mais, quand il eut pris cette résolution, Delacroix ne balança plus et nous ne trouvons rien dans sa vie qui puisse nous faire supposer qu'il ait jamais songé à changer de parti. A dater de ce moment, toute sa volonté, toutes ses facultés, toute son ambition, ont appartenu à l'art, comme à un maître exigeant et jaloux, qui n'admet ni faiblesse, ni partage. ”

Il entra dans l'atelier de Guérin vers 1816, et il y entra avec l'intention bien arrêtée de se livrer exclusivement à la peinture. Bientôt après, son goût devint une passion et son jeune talent devint du génie.

Il nous a raconté lui-même les premiers événements de sa vie. 
"Vers la fin de 1815, j'entrai chez Guérin pour y étudier la peinture. Je ne sais s'il s'est aperçu que je promisse quelque talent, mais il ne m’a jamais encouragé. Quand je fis en 1822 le premier tableau que j'osai exposer et qui représentait le Dante et Virgile, je le fis venir chez moi, par déférence, pour le lui soumettre; il n'en fit guère que des critiques, et si je ne pus jamais tirer de lui son assentiment à mon désir de l'exposer, il est juste de dire que, quelque temps après l'ouverture de l'exposition, m’ayant retrouvé à l'académie, où j'allais encore étudier en élève, sur les derniers bancs, il voulut bien me dire que ces messicurs, c'esta-dire les professeurs, avaient remarqué mon tableau. » 


\section{Relations avec Gros.}

Son admiration pour le maitre.

"Le succès capital de ma carrière date de cette époque lointaine. Je ne parle pas de celui que j'eus dans le public, malgré mon obscurité, ou peut-être à cause d'elle, mais de la manière flatteuse dont Gros me parla de mon tableau. J'idolâtrais le talent de Gros, qui est cncore pour moi, à l'heure où je vous écris, et après tout ce que j’ai vu, un des plus notables de l'histoire de la peinture. Le hasard me fit rencontrer Gros, qui, apprenant que j'étais l'auteur du tableau en question, me fit, avec une chaleur incroyable, des compliments qui pour la vie m'ont rendu insensible à toute flatterie. Il finit par me dire, après m'en avoir fait ressortir tous les mérites, que c'était du Rubens châtié. Pour lui qui adorait Rubens et qui avait été élevé à l'école sévère de David, c'était le plus grand des éloges. Il me demanda s'il pouvait faire quelque chose pour moi. Je lui 
demandai incontinent de me laisser voir ses fameux tableaux de l'Empire qui dans ce moment étaient dans l'ombre de son atelier, ne pouvant être exposés au grand jour, à cause de l'époque et des sujets. Il m'y laissa quatre heures seul ou avec lui, au milieu de ses esquisses, de ses préparations; en un mot il me donna les marques de la plus grande confiance, et Gros était un homme très inquiet et très soupçonneux. S'il faut mêler à un assentiment si complet un grain de motif particulier de la part du grand peintre, je crus entrevoir ensuite, à une certaine aigreur qui entra dans les procẹdés de Gros à mon égard, qu'il avait pensé à me prendre près de lui pour me faire avoir le prix de Rome dans son école. J'avais dès lors, malgré ma simplicité, tracé ma route d'un autre côté, et je déclinai cette protection. Cependant, lorsque, par la suite, ses élèves, apparemment pour le flatter, critiquaient devant lui mes tableaux, il les arrêtait, non pas en prenant le parti de mon talent, mais en disant que j'étais un jeune homme parfaitement honnête et bon élève. » 
Il fallut assurément à Delacroix une singulière force de volonté pour résister aux propositions ou aux insinuations si flatteuses de l'homme éminent qui le distinguait et qui se trouvait être le peintre pour lequel il professait la plus absolue admiration. Le jeune homme sentit qu'on se mettant entre les griffes d'un tel maître, il serait forcé d'abdiquer toute initiative et que sa personnalité irait se fondre en celle de son professeur. Un instinct secret lui dit que son indépendance valait mieux que le plus attrayant des servages. Aussi persévéra-t-il à copier le modèle chez Guérin, sûr de ne pas être entamé par la neutralité des préceptes généraux qu'on y professait. Mais, pendant qu'il étudiait la nature à l'Académie, il cherchait ailleurs sa voie.

Il demandait à Raphael, à Velazquez, à Véronèse, et surtout à Rubens, les secrets de leur splendide peinture. Il passait au Jardin des plantes des journées entières, pendant lesquelles, observant les animaux dans toutes leurs postures, il se pénétrait de leurs mouvements, de leur galbe, cherchait la dominante 
de leur caractère, saisissant au vol les inflexions spéciales des fauves, leurs glissements, leurs rampements sur le sol, les ramassements qui procèdent leurs bonds, la torsion de leurs queues, le rictus féroce de leurs lèvres, et jusqu'au feu de leur prunelle qui se fait jour sous la paupière demi-close de leurs yeux félins. Ce sont ces observations répétées, faites avec la sagacité, la conscience, la volonté et la suprême compréhension du génie, qui ont fait de

7 Delacroix le premier de tous les animaliers. Ce sont elles qui, appliquées aux grands ensembles de la nature, en ont fait le prodigieux paysagiste qu'il est. 


\section{La santé.}

L'enfance d'Eugène Delacroix fut très difficile. Il était d'une nature fort délicate et, pendant tout le cours de son existence, nous le verrons entravé par des défaillances physiques que son tempérament nerveux, vaillant et passionné, arrivera toujours à dominer, non sans lui inspirer pourtant de légitimes doléances causées par le regret amer de ne point voir ses forces seconder suffisamment son courage.

"Il fut toute sa vie, personne ne l'ignore, dit M. Ed. Moreau, sinon malade, au moins toujours souffrant : à diverses époques, sa frêle organisation, gravement éprouvée déjà par des fièvres contractées dans son extrême jeunesse, reçut de sérieuses atteintes qui, sans mettre l'existence en danger, imposèrent à sa santé des précautions continuelles. " Et nous lisons dans M. Piron : " Sa constitution était délicate, et cet état de santé, qui a commencé par de longues fièvres en $18: 0$ et qui s'est terminé par une maladie de poitrine en 1863, a beaucoup 
influé sur l'ensemble de ses idées pendant le cours de sa vie, d'ailleurs si bien remplic. ")

Il écrit, en effet, au général Delacroix, son frère, en 1819, une lettre datée de la forêt d'Axe, une lettre qui marque l'époque de cet envahissement par la fièvre qui eut sur son existence entière une si capitale influence : “ .....Je te dirai maintenant ce qui m'a si fort retardé. De SaintMaur, j'ai gaiement entrepris ma route; je fis très bien une longue traite, mais la chaleur du jour devint trop forte; je me reposai dans un cabaret; j'eus la sottise d'y prendre une espèce de refroidissement qui dégénéra presque aussitòt en une petite fièvre. J'arrivai à Châtellerault malade, et, pour comble de douleur, je demeurai plusicurs grands jours dans cette ville inconnue, dans une auberge, à attendre la diligence ou malle-poste qui pût me conduire jusqu'ici. Je ne conseille pas à M. le curé de Loreau de s'en rapporter beaucoup au passage de toutes ces voitures, dont il me flattait si fort, le ventre tranquillement à table. Rien n'est si facile à dire que tout cela. Ce qu'il y a de sûr, c'est que j'arrivai enfin ici avec une fièvre 
déclarée, qui me tient jusqu'à présent et qui fait de moi une allumette pour l'apparence et un brin d'amadou pour la valeur. Ce n'est que d'hier et d'avant-hier que j'ai repris quelques forces et quelques lueurs de raisonnement libre. C'était une fièvre lente qui me prenait tous les jours : nul appétit, ennui et dégoût continuels, et une faiblesse si grande que j'avais des éblouissements quand je me levais de mon fauteuil. Enfin, je commence à me remettre à force de quinquina; la fièvre a levé le pied. Le reste suivra. »

“...Je n'étais pas à Paris lorsqu'y arriva ton excellente lettre, écrit-il à vingt ans à son ami Soulier. Ii fallut me la renvoyer à La Forêt. Tu es surpris à ton tour de voir une date si retardée. A la suite d'une marche longue par la chaleur, je me refroidis par imprudence et me donne la fièvre. Elle m'a quitté il y a une dizaine de jours et me permet d'écrire à mon aise.

" J'étais travaillé par une fièvre lente et 
quotidienne.... C'est une chose triste pour un homme qui ne cherche à cent vingt lieues de son trou dont il a grand'peine à se tirer autre chose que l'amusement, de ne trouver que la pâle maladie. Ma fièvre revenait tous les jours. Elle n'était ni violente ni dangereuse, mais elle avait bien des désagréments : le premier, c'est que c'était la fièvre, et celui-là, ainsi qu'il est loisible de le penser, renferme assez généralement tous ceux qui en sont la conséquence... Je me traînais de là dans une bergère au coin du feu, et j'y restais enterré jusque vers cinq ou six heures du soir, où les avant-coureurs de la fièvre, se glissant dans mes nerfs, commençaient à balancer tout mon sang dans mes veines, de la glace à une ardeur dévorante.

"...Ce Souillac que tu vois en tête de ma lettre est le pays de mon beau-frère, où j’ai été passer un mois, à peine guéri de ma fièvre, languissant encore et faible comme une pauvre herbe sans soutien.... Je me croyais débarrassé de cette terrible fièvre. Hélas ! je ne tardai pas à la reprendre. Elle fut violente dans la seconde 
apparition. Je serai, je crois, encore abandonné à moi-même cet hiver. L'idée de ce tableau que j'ai à faire me poursuit comme un spectre. J'aurais bien désiré pouvoir retourner promptement à l'atelier. Oh! que je suis ganache! J'ai plus d'une fois essayé de dessiner pendant mes fièrres, et, ce qui m'a le plus affligé, c'est que tout ce que j'ai voulu chercher pour mon tableau n'a été que misérable. Je me suis occupé davantage de toutes les folies qui me passaient par la tête... un homme qui se lève à huit ou neuf heures fatigué de sa nuit et qui va là tout d'un trait s'accoussiner dans une bergère au coin du feu, tandis que les autres vont à la chasse; qui avale ses deux prises de quinquina pendant qu'ils déjeunent, et qui voit s'écouler assez lentement, mais bien dans ses mains et sous ses yeux, sa journée qui est tout à son esprit pendant que tout son corps ne marche, ne digère ni ne mange; qui enfin se possède bien jusqu'à ce que la fièvre se glisse par des avant-coureurs glaçant jusqu'à la source de ses nerfs pour l'envoyer dans son lit faire de la philosophie; cet homme-là est dans un monde nouveau, 
assurément. Alors, que de plans, que d'entreprises qui ne font reculer ni son esprit, ni les forces de son corps! Il se plonge dans le travail avec ténacité. L'œil distrait de son foyer, il retourne avec acharnement sa matière, et jusque clans la nuit, quand il souffre, il est escorté de ses idées qui trompent l'ennui. Voilà ce que j'ai été dans ma fièvre. Les aliments me répugnaient, me soulevaient. La nuit ne m'apportait que de la fatigue, je ne faisais pas deux pas sans éblouissements, je ne pouvais écrire sans avoir la tête fendue; mais quand je m'arrêtais à mes rêveries, ma tête travaillait beaucoup sans fatigue; je faisais des plans de toute espèce, j'entreprenais de tout. Le malheur est qu'il ne mo reste presque rien cle tout cela, parce que je ne m'y stuis mis que quand je commençais à m'habituer à la fièvre, laquelle alors commençait à aller en dérive à cause des médecines et du quinquina.

"Avec la fièvre que j'ai tant maudite s'est donc envolé tout mon génie pour la composition.... Après bien des traverses, j'arrive enfin à Paris, aussi fiévreux qu'auparavant. 11 est vrai 
que maintenant elle me laisse quelques jours de bon. Mais, quand elle revient, adieu, peinture! adieu tout! Il faut tout quitter. Tu vois ma misc̀re. "

Cette fièvre fut le eauchemar permanent de Delacroix. Conséquence presque fatale de toute fatigue cxagéréc, elle revient toujours dans les conditions les plus critiques, l'entrave et le mine. Delacroix, dès l'âge de trente ans, se déclarait affaibli et usé. "Il s'entourait physiquement, dit encore M. Firon, de mille précautions hygiéniques, et, moralement, il affectait quelques formules sceptiques qui semblaient indiquer un certain dédain, un certain dégroût de la vie. Sa vie, disait-il, c'étaient ses nerfs, son foie, sa rate, c'était sa fièvre. Cettc fièvre enfantait pour lui des chimères; or, quand un homme est malheureux par cles chimères, à quel degré de malheur ne peut-il pas bientôt descendre? »)

Les plus petits excès se traduisaient chez lui par des fatiguos exagérées; le repos et le silence étaient indispensables à la santé de Delacroix: le moindre excès lui était fatal. L'air du soir, 
une veillée prolongée ou une conversation trop animée l'abattaient : il perdait la voix et se trouvait réduit à s'enfermer pour huit jours. Depuis les premières fièvres qu'il avait prises à Angoulême, à l'âge de vingt ans, jusqu'à sa mort, sa vie n'a été qu'une suite d'indispositions continuelles. Il ne pouvait pas travailler longr temps de suite, rapporte M. Lassalle-Borde, qui fut pendant dix ans son collaborateur et son aide, à cause de sa mauvaise santé.

“ Lorsque ses nerfs ne le servaient pas, il tombait dans une prostration pénible à voir. Ce n'était pas le même homme. "Ah! mon cher "Lassalle, me disait-il, que vous êtes heureux " d'avoir une nature robuste! Combien je rous " envie votre vigueur; cela vous donne une " humeur égale. Vous auriez fait un bon mari; “ moi, j’y ai renoncé, sentant que je n'aurais " fait qu'une malheureuse, ce qui m’aurait tué. "Et puis la peinture absorbe trop. »

“ A certains moments; il avait une énergie extraordinaire. Le duc d'Orléans vint le voir un jour et l'invita à un bal costumé qu'il donnait aux Tuileries. C'était l'hiver qui précéda la mort 
de ce prince. Le malheur voulut qu'il eût ce jour une fièvre des plus fortes. Je fus le voir dans la soirée. Il était au lit et me dit combien il était désolé de ce fâcheux contre-temps qui ne lui permettait pas de répondre à cette flatteuse invitation.

" Tout d'un coup il se galvanise, saute à bas de son lit, sonne sa fidèle gouvernante Jenny et lui dit de tirer d'un coffre un costume qu'il avait rapporté de son voyage au Maroc. " Lassalle, mon ami, vous allez me servir de " valet de chambre. "

“ La servante et moi nous l'affublâmes de ce costume; pendant qu'elle courait chercher une voiture, j'achevais de placer à sa ceinture les armes complètement indispensables à ce costume. Tout ce poids le fatiguant, il se trouva mal ; j'étais très embarrassé pour le faire revenir. Quand Jenny arriva, il était livide : " Il " faut vaincre ou mourir, me dit-il, partons! " S'étant regardé à la glace, il s'arrêta : “Mettez" moi un peu de fard. " Lui ayant maquillé le tour des yeux, il avait réellement l'air d'un prince d'Orient. Je l'aidai à descendre l'escalier; 
comme je sentais qu'à chaque marche il fléchissait, je le pris clans mes bras et le portai juscu'à la voiture. Jenny l'accompagna munie de sels. Il ne voulait faire qu'un acte d'apparition aux Tuileries. Il eut la chance de rencontrer au bas du grand escalier son ami Alexandre Dumas, (qui l'aida à monter. Tous les deux se présentèrent en même temps devant le prince, qui fut surtout très gracieux pour lui et le complimenta sur son costume. Après cela, il se hâta de regagner sa voiture où l'attendait sa gouvernante. Il paya cette équipée par huit jours d'une fièvre et d'un malaise inexplicable. »

Si nous insistons tant sur ces détails pathologriques de la vie de Delacroix, c'est que son génie fut à coup sûr l'enfant de ses malaises, et que c'est à ses émotions maladives qu'on cloit l'artiste étrange, tourmenté, complexe dont la peinture carillonnante et tumultueuse ne peut être comparée à celle de nul autre de ses devanciers. Supprimez le feu interne, supprimez la fièvre qui brûlait incessamment ses nerfs, engendrait les désirs immodérés de travail conçus dans des périodes longues de repos 
forcé ; supprimez les chutes et les rechutes, les brusques passages d'un état languissant à d'éphémères vigueurs et les alternances désespérantes de ces deux états excessifs, évidemment vous n'aurez pas Delacroix. Imagine-t-on le peintre du Massacre du Scio, de la Liberté, de Sardanapale, de l'Héliodore, de l'Entrée des Croisés; le décorateur de la Chambre des députés, du Sénat, de l'Hôtel de Ville et du Lourre, l'auteur de ces innombrables compositions étranges, tourmentées, rageuses; l'interprète admirable de Shakespeare, de Byron, de Goethe; l'imagine-t-on frais, dispos, gaillard, fleuri, jovial et dodu? Non, toutes ces œuvres violentes sont le résultat d'un sang consumé, d'une âme inquiète, secouée, cahotée, asservie par sa souffrance même à un amour de l'art immodéré et triomphant, qui se traduit par des séries successives d'excès meurtriers accompagnés de mornes lassitudes, par des défaillances, par des marasmes répétés suivis de renaissances admirables et fécondes au cours desquelles les baisers se multiplient, les étapes se doublent, la substance cérébrale coule à flots et le génie s'épanouit en 
des floraisons superbes mais étranges, dont la robustesse et les rutilances ne se peuvent puiser que dans les humus vierges féconds en miasmes qui tuent par excès de vie. 


\section{Sacrifices à l'art. - Amitié.}

- Delacroix sacrifia tout à son art. Il n'eut d'autre préoccupation que lui. Son existence même lui fut offerte sans marchandage. "Pour avoir la tête plus lucidle, dit M. Riesener, pour être plus propre au travail, il avait fini par supprimer le déjeuner et ne mangeait qu'une fois par jour. Les médecins l'avaient prévenu qu'il se tuerait. Il prétendait sentir mieux qu'eux ce qui lui convenait; s'il déjeunait il ne pouvait travailler et il ne pouvait se résoudre à cesser le travail. »

M. Piron constate la même habitude : " Delacroix ne déjeunait pas : son estomac était paresseux, la digestion de son dîner de la veille n'était finie que le lendemain vers midi ou deux heures. Il ne prenait donc rien le matin. "

L'amitié paraît avoir été pendant toute la durée de la vie de Delacroix le sentiment prédominant de sa nature. Ses lettres fourmillent d'expressions délicates, de formules affectueuses. Il s'y révèle un besoin d'être aimé des compa- 
gुnons de son enfance, de conserver intacts et de resserrer toujours davantage les liens de jeunesse qui l'unissaient aux amis de la première heure. "Les vrais, les fidèles, les constants amis de Delacroix ont été les amis de sa grande jeunesse. Les relations du monde même les plus intimes qu'il ait entretenues depuis ont emprunté quelque chose de la gêne et des ménagements que les circonstances ou malheureuses ou militantes de sa vie leur ont forcément communiqués. Son véritable abandon et sa confiance la plus entière se sont portés sur les hommes qu'il avait connus et aimés dans sa jeunesse et qui se trouvaient placés un peu en dehors de ses travaux et de ses combats habituels. " Le bonheur si vrai, si franc que manifeste Delacroix à chaque renouvellement d'année qui va être l'occasion d'une réunion des vieux amis, prouve quelle était la profondeur de son affection.

" Il y avait dans l'année, dit M. Moreau, un jour consacré à un repos complet : plusieurs mois à l'avance Delacroix y pensait; il l'attendait avec une de ces impatiences enfantines qu'on se 
fût étonné de rencontrer chez un homme aussi grave. Ce jour, c'était celui de la Saint-Sylvestre. Une habitude de l'extrême jeunesse réunissait à cette date les amis de la vingtième année : MM. Pierret, Henri Hugues; Guillemardet, Leblond, Champmartin, Piron, Villot, Soulier, Riesener, Commairas, Lelièvre. Autour d'un festin sans apprèts, à la flamme d'un punch joyeux, on portait tantôt chez l'un, tantôt chez l'autre, les santés réciproques, et l'on, enterrait joyeusement l'année écoulée en tournant des regards pleins d'espoir vers celle qui déjà commençait. »)

Comme on s'aimait alors et comme on aimait ces réunions modestes dont le principal attrait était celui de se trouver ensemble! Qu'il est loin de nous ce temps, le bon vieux temps de nos pères où les liens d'amitié, formés dès la jeunesse ou l'enfance, résistaient à toutes les épreuves; où la camaraderie, prête à tous les sacrifices, était bien une réalité pour ceux qu'elle rápprochait! Verrait-on, aujourd'hui comme alors, un membre du cénacle amical traverser la France d'une frontière à l'autre, 
pour être présent au jour fixé, à une simple soirée dont l'unique but était de réunir, une fois par an, des cœurs que faisait battre à l'unisson le culte de l'art et de l'intelligence?

Qu'on juge de l'intimité de ces sentiments par les quelques morceaux qui suivent, détachés de ces lettres précieuses, monument impérissable où tous les sentiments du peintre se trouvent exprimés dans leur chaude naïveté :

“ ..... Au moment où je t'écris ceci (il s'agit de M. Pierret), je ne puis m'empêcher d'éprouver un contre-coup qui me ramène et d'autres idées qui me reviennent souvent dans le cceur. Il me ramène aussi à te parler un peu, non pas de tout ce que je fais ici, qui est peu fait pour t'intéresser, mais de toi, mais de notre amitié à tous deux, mais des sentiments de l'un et de l'autre, étrangers à notre amitié mais que la confiance mutuelle a rendus communs à tous deux. Quelque plaisir que l'on trouve dans la vie nouvelle et agissante, elle ne peut éteindre la mémoire des doux nœuds que l'âme a formés dlans d'autres lieux, dans d'autres temps. On ne conserve dans la vie que la mémoire des senti- 
ments touchants; tout le reste est moins même que ce qui s'est passé, parce que rien ne lui prête plus de couleurs dans l'imagination. Avec quel bonheur je me rappelle nos douces. conversations, nos chers épanchements! Avec quel plaisir je t'embrasserai à mon retour, toi, mon bon ami qui as écouté toutes mes folies! que tu vas trouver froid le commencement de cette lettre! Au milieu de mes occupations dissipantes, quand je me rappelle quelques beaux vers, quand je me rappelle quelquə sublime peinture, mun esprit s'indigne et foule aux pieds la vaine pâture du commun des hommes. De même, quand je pense à mes affections, mon âme embrasse avec ardeur la trace fugitive de si chères idées. Oui, j'en suis sûr, la grande amitié est comme le grand génie, le souvenir d'une grande et forte amitié est comme celui des grands ouvrages des génies... quelle vie ce doit être que celle de deux poètes qui s'aimeraient comme nous nous aimons! Ce serait trop) grand pour l'humanité. Te souviens-tu de certaines conversations que nous eûmes quelques jours avant mon départ? Je t’ai dit. que e'était 
à chaque ami à sentir la part d'affection qu'il a le droit d'attendre dans les affections de son ami. Je te le répète et je désire que tu sentes juste.

“.... Viennent donc les soirées d'hiver qui chassent les soucis au coin d'un bon feu, et cette soirée de la Saint-Sylvestre où nous renouons chaque année un pacte fraternel. »

Delacroix écrivait cette lettre de la Charente où il était en villégiature chez son beau-frère. 11 n'avait pas vingt ans et déjà sa nature chaleureuse et tourmentée se faisait jour au travers de ces lignes tombées couramment de sa plume. Ailleurs, c'est un cri du cœur, vibrant et mélancolique. C'est encore à Pierret qu'il s'adresse.

«.... Je me recueille : j'oublie tout ce qui m'entoure; je pense à ce qui m'est encore cher sur la terre. Je ne suis heureux, tout à fait heuroux, que lorsque je suis avec un ami.... »

Et plus loin encore, à Pierret qui vient de perdre son père: «Je te fais des reproches, je te parle de ta négligence pour moi, pauvre orphelin! de ce que j'ai souffert de ne pas avoir reçu 
de tes lettres, de toi, cher ami, qui as souffert la plus extrême douleur de l'humanité! Tu mettais ton père au cercueil, tandis cqu'au milieu de mes amusements je m'étonnais parfois d'éprouver un retard.....

“.... Sainte amitié, amitié divine, excellent coeur! Non, je ne suis pas digne de toi. Tu m'enveloppes de ton amitié; je suis ton vaincu, ton captif. Je n'ai jamais aimé un homme comme toi, mais ton cœur, j'en suis sûr, sera inépuisable.....

" .... Oui, c'est bien à toi à donner la SaintSylvestre. Si ce n'eût été à toi, j'eusse voulu que c'eût été à moi; que les pots, les ripailles sont douces choses dans la.vie! Là, à la lumière de la chandelle, tous unis, on s'établit sur une table, où l'on s'appuie les coudes, et on boit et mange beaucoup pour avoir beaucoup de ce bon esprit d'homme échauffé. C'est là la gaieté, et que la nôtre est vraie! Ah! que les potentats et les grands politiques sont à plaindre de n'avoir point de Saint-Sylvestre, et je crois qu'à tous les âges de la vie nous pourrons retrouver avec la même candeur cette soirée si heureuse. Nous 
ne sommes pas des marchands. Notre cœur de jeunes gens n'ira pas à vingt-cinq ou trente ans se cacher au fond d'un coffre-fort. Les cocurs passionnés et surtout ceux qui sont occupés de l'amour d'un de ces arts qui sont la nourriture de l'âme, ces âmes elles-mêmes ne deviennent pas vieilles et sèches. Pour toi, quand tu serais marchand de bonnets, quand tu serais Auvergnat, marchand de cuivre et tant d'autres dont la cervelle, les entrailles et toutes les facultés sont : argent, tu ne serais pas encore comme tous ces gens-là. Tu seras peintre, ami, nous marcherons ensemble. O délicieux peintre, que tu nous donneras d'heureux moments! N'as-tu pas senti de la vergogne et une bien forte, quand on t'a demandé si tu étais peintre? Cela a dû te percer bien avant, j'en suis sûr....

“ .... Je comptais avoir le temps d'écrire à Guillemardet. J'ai vu que je n'avais plus le temps. Cette fois que je paye un port de lettre, je l'attends énorme, ce sera un véritable in-folio et de la vitesse n'y gâtera rien. Et ce bon, ce cher petit Soulier; figure-toi recevoir une lettre de Florence! mon bon ami, j’ai pleuré 
en l'ouvrant et ce qu'elle contenait ne m'en a pas fait repentir. Nous la lirons ensemble. C'est un bon garçon que Soulier et que j'aime tendrement. Mais c'est inutile à dire et à répéter cent fois. Ainsi, bonsoir, mari, oui mari et heureux mari! ma prochaine sera, j'espère, plus copieuse, mon moral sera quelque peu remonté. » A Guillemardet : “... Il y a une chose qu'on regrette toujours quelque part qu'on la laisse : c'est l'amitié. Je crois ne pas t'avoir vu depuis un an. Combien nous est-il arrivé de rester ainsi sans nous voir? Toi-même il y a peut-être des semaines que tu n'as vu P...; mais quand on respire le même air, c'est presque comme si tu le royais. On se sent prochè les uns des autres, parce qu'on sait qu'en faisant quelques pas on se retrouve. Maintenant, au contraire, je cherche à me rappeler vos traits. Hier, en trottant sur la grande route, je me disais tout en rêvant : "Où sont-ils, à cette heure? Peut-être à " table, peut-être à la queue du spectacle à s'en" tretenir de l'absent." 11 y eut pendant quelques instants un ciel magnificue que j'admirais avec bonheur, et je pensais que, peut-être, vous en 
faisiez autant. Je ne puis en vérité penser sans un serrement de cœur aux longues années que je passerai en Italie, loin de vous et loin de tous ceux qui peuvent s'intéresser à moi.....

«..... Heureux qui possède un coin de terre; mais si ce coin de terre a dix mille arpents, je n'en veux pas sans souvenirs qui m'y rattachent et m'y rappellent à chacue pas ceux que j'ai aimés. Je préférerais à une villa magnifique le plus petit enclos où se serait passée ma jeunesse. »

Nous pourrions multiplier nos citations à l'infini. Il n'y a pas une lettre de la jeunesse de Delacroix qui ne contienne une page, une phrase, un mot où l'amitié, le sentiment vainqueur de son âme, ne se fasse jour sous des formes très différentes, mais toujours empreintes d'une chaleureuse sincérité. Les extraits que nous donnons sont suffisants pour permettre d'en jug'er et nos commentaires n'y ajouteraient rien.

Nous ne pouvons cependant passer sous silence des liaisons intimes qui, pour ne pas avoir donné lieù à des démonstrations d'amitié aussi 
vives que celles de la première jeunesse, n'en furent pas moins empreintes d'une cordialité charmante et exercèrent sur la vie du grand artiste la plus heureuse influence. En tête des hommes qui furent pour Delacroix des amis de second ordre, non moins précieux que les premiers, il faut placer M. Berryer. " .... Il profitait presque tous les ans, dit M. Piron, de l'hospitalité qu'il lui offrait. Des liens de famille l'unissaient à l'illustre orateur. Il nous a dit souvent que le père de M. Berryer avait débuté sous les auspices du sien, et que c'était sur les conseils de M. Charles Delacroix que M. Berryer, le père du nôtre, avait embrassé la carrière du barreau. ")

Delacroix trouvait à Augerville autre chose encore qu'une belle campagne et une brillante hospitalité : il trouvait un causeur supérieur, ami des arts, avec lequel il était en parfaite communion d'idées. Ce goût, cet amour sacré de l'art l'avait aussi rapproché de $\mathbf{M}^{\text {me }}$ Sand : Maurice Sand était son élève. Eugène passait à Nohant d'excellents moments. “..... Le lieu est très agréable, écrit-il à Pierret, le 7 juin 1842 , 
et les hôtes on ne peut plus aimables pour me plaire. " $\mathrm{Au}$ nombre de ces hôtes était Chopin, dont " par instants il arrive par la fenêtre ouverte sur le jardin des bouffées de musique qui se mêlent au chant du rossignol ». Il avait pour lui une grande affection : “J'ai, écrit-il encore de Nohant, des tête-à-tête à perte de vue avec Chopin que j'aime beaucoup et qui est un homme d'une distinction rare; c'est le plus - vrai artiste que j'aie rencontré. Il est de ceux, en petit nombre, qu'on peut admirer et estimer. " Ailleurs il dit : "Chopin m'a joué du Beethoven divinement bien : cela vaut bien de l'esthétique. » 


\section{Affection de Delacroix pour sa bonne. Ses conséquences.}

Parmi les amis de Delacroix il en est un qui mérite une mention toute particulière parce qu'il joua dans la vie de l'artiste un rôle pour ainsi clire prépondérant. Cet ami ou plutôt cette amie, c'est Jenny Leguillon. 'Tous les gens qui ont fréquenté Delacroix ont connu cette femme dévouée et ont eu plus ou moins à souffrir de son humeur un peu fantasque, fortement encouragée par l'autorité absolue dont elle jouissait dans l'intérieur du maître. Laissons M. Piron, qui la connut mieux que personne, nous clire ce qu'elle fut :

"Molière avait sa servante, Piron avait $\mathrm{M}^{\text {Ile }}$ de Bar, Delacroix avait Jenny. Delacroix la consultait sur toutes choses : sur la tenue de sa maison qu'elle gouvernait d'ailleurs arbitrairement, sur ses dépenses, sur le caractère et la valeur des relations qu'il entretenait dans le monde, sur les soins à donner à sa santé; il la consultait, enfin, même sur sa pein-, 
ture, car Jenny donnait son avis en cela comme en tout; elle témoignait de son amour pour l'art et Delacroix y croyait, puisçu'il lui a laissé des œuvres de lui par attribution spéciale.

“ Jenny n'était pas une servante comme celle cle Molière; elle ne vivait pas dans le genre d'intimité qui liait Piron à $M^{1 l e}$ de Bar : c'était une Égérie gouvernante d'un ordre intermédiaire. Son origine et son passé avaient été très modestes; mais, comme elle s'était successivement et profondément placée dans la confiance de son maître, la société intime et continue d'un homme de formes si gracieuses avait poli sa manière et éclairé son esprit.

“ On n'entrait qu'arec son agrément, et le plus grand nombre des visiteurs, au moins dans les dernières années, était sévèrement éconduit; tout homme qui parlait trop ou surtout qui faisait trop parler, qui contrariait enfin, qui empêchait de travailler, était mis au ban de Jenny par Jenny elle-même, et il lui était impossible de pénétrer.

" Il était assez difficile de déterminer si, dans cette exclusion, presque générale, pro- 
noncée par Jenny, son désir d'assurer son influence intérieure l'emportait sur le tendre intérêt qu'elle portait à la santé de son maitre; au moins c'était une opinion bien arrêtée chez elle, et qui n'a été que trop justifiée par l'événement, que le repos et le silence étaient indispensables à la santé de Delacroix; le monde et ses exigences devaient être mortels pour lui.

" L'attachement éclairé de Jenny, en même temps que l'exercice d'une autorité toujours croissante, devait lui assurer un gouvernement sans contrôle. Celui-là conduit clans un intérieur, a-t-on dit, qui a le plus souvent raison, et Jenny n'avait pas tort quand elle disait que l'amour du monde aurait tué Delacroix plusieurs années plus tọt sans son active surveillance, sans ses anxieuses recommandations. Bientôt donc personne ne put balancer son crédit, il n'y avait pas d'autre volonté que la sienne, et tout pliait dans la maison devant cette volonté.

"..... Quand un visiteur entrait, Jenny écoutait la conversation derrière la porte, et elle ètait à cela bien et clument autorisée. Le but de cette précaution était d'éviter à Delacroix la 
peine de lui rapporter ce qui s'était dit, et on n'avait plus qu'à le commenter.

“ On a reproché à Jenny d'avoir employé d'autres moyens pour obtenir un isolement plus durable et plus complet : on a dit qu'elle saisissait toutes les circonstances favorables pour éloigner les gens amis ou ennemis; car tous à ses yeux paraissaient dangereux pour la santé et la tranquillité du maître. Il est certain qu'il y a eu des chagrins et des séparations provenant de circonstances qu'un esprit plus favorablement clisposé que le sien aurait peut-être facilement évités; mais Jenny était maladive et nerveuse; sous l'empire de douleurs névralgiques, elle se montrait peut-être plus sévère et plus rancuneuse qu'elle ne l'était réellement. Elle a beaucoup aimé, il lui faut beaucoup pardonner. Il est un fait cependant qu'on a remarqué et que je dois constater, à mon tour, avec regret, c'est que, par suite de cette habitude d'isolement, peut-être aussi à cause de la saison qui tenait beaucoup de personnes éloignées de Paris, notre ami est mort seul, entre les mains de sa gouvernante, privé des consolations que lui aurait 
sans doute procurées la présence de quelquesuns de ses parents et de ses amis. ”

Rien ne peut donner une idée plus exacte que les lignes qui précèdent de l'influence exagérée de Jenny sur Delacroix. En haine des détails d'intérieur et par ce sentiment naturel qui pousse les gens subjugués par une passion dominante à tout abandonner de ce qui, autour d'eux, ne se rattache pas à cette passion, Delacroix en était venu à ce point de n'être plus entre les mains de sa gouvernante qu'une sorte d'enfant obéissant et craintif. Ses amitiés, ses préférences, ses goûts, tout fut sacrifié aux caprices de Jenny, et ses amis, les plus intimes eux-mêmes, furent souvent impuissants à franchir le cordon sanitaire si jalousement formé par elle autour de la personne de son maître. Singulière conséquence d'un excessif amour d'indépendance. Cet homme qui “ aimait tant ses amis qu'il ne voulait pas les voir se marier », qui " ne pouvait pas souffrir qu'une femme vînt se placer entre lui et eux », qui poussait les choses au point de refuser obstinément de diner chez ses amis mariés, qui écrivait à $\mathrm{S}$. à pro- 
pos d'un mariage qu'on tentait de réaliser pour lui : " Tu as trop d'amis qui te veulent beaucoup trop de bien. Ils t'ont rendu beaucoup de services qui se sont trouvés leur être plus utiles qu'à toi. Décroche-toi, mon ami, vis libre de reconnaissance. Le zèle, bien ou mal entendu, de ceux qui te veulent tant de bien, ne vaudra pas une indépendance, si minime fût-elle »; cet homme a renoncé à toutes les joies de la famille, à toutes les douceurs d'un intérieur régulier, pour aboutir à quoi ? à l'isolement le plus insolite et le plus douloureux eu égard aux besoins d'une nature expansive comme la sienne, et finalement à la mort dans la plus lamentable des solitudes et le plus cruel des abandons, résultat fatal de l'implacable servage et de la complète confiscation de sa personne à laquelle il s'était progressivement soumis pour conserver quoi? sa liberté. Il paraît, du reste, s'être rendu un compte amer de cet état de choses, car nous trouvons dans une note écrite sur un album et datée d'Augerville, le 9 septembre 1861, cette réflexion mélancolique : “On se fait un rempart contre beaucoup de misères de chaque jour, 
dans le goût passionné qu'on a pour un art et une science, ou une recherche quelconque qui intéresse l'esprit; mais pour que ce goût vous préserve de l'ennui, il faut qu'il soit dominant, et alors vous négligez des devoirs ou des nécessités essentielles, et vous vous trouvez isolé et bientôt abandonné. » 


\section{Amour.}

Chez des artistes du tempérament et de la valeur de Delacroix, l'amour et l'art ne peuvent guère habiter sous le même toit. Aussi envahissants l'un que l'autre, il faut que la place reste à l'un d'eux sans partage. Pour les hommes de génie la peinture est une maîtresse exigeante, inflexible, tyrannique et rude, qui ne souffre pas de rivale. Qui s'est donné à elle lui appartient tout entier. Il faut choisir. Delacroix n'hésita pas : il renonça dès le début délibérément mais non sans peine aux liaisons attachantes et plus tard au mariage. Il ne faudrait pas se figurer pourtant qu'il fût insensible aux choses de l'amour et que son âme pleine de toutes les arcleurs soit restée froide aux sollicitations du sentiment le plus aigu de la jeunesse. On en jugera par les extraits suivants de ses lettres: ".... Je ne sais comment ça se fait, je suis toujours sur l'escalier et toute la journée je descends dans la cour pour remonter et pour redescendre. Certain bruit de porte que tu con- 
nais retentit à tout moment à mon oreille et souvent j'entends quand rien ne retentit. J'ouvre la porte, je m'avance d'un air indifférent, et une face à culotte sort de cette porte maudite qui fait tant de train à mon tympan. J'entends encore le bruit, j'accours comme un fou, et je m'arrête la main sur le loquet : je balance, j'écoute au travers des fentes et j'ourre; je mets le nez dehors, j'entends un frou-frou de sylphide. La porte d'en haut se referme et je n'ai rien vu. Je ne veux pas me rendre intéressant et te dire que je n'ai qu'une seule idée. J'en ai d'autres, mais elles me ramènent toujours à une qui les colore toutes et qui me tient dans une douce moiteur d'âme, tantôt chaleur, tantôt frisson....

“ .... Les jolis yeux! limpides comme de belles perles et fins et doux comme un velours. Le nez est assez original; la narine est retroussée fièrement et s'enfle de temps en temps à l'unisson des prunelles qui se dilatent et se remuent. La bouche est d'une élégance charmante. Mais le triomphe de cette tête c'est dans son contour. La joue, le petit double menton, 
la manière dont tout cela se porte sur le col vaut des autels. Oh! la singulière petite femme! “ .... A neuf heures je fus averti, et en quatre sauts je fus en haut. J'y trouve qui tu sais, fidèle à sa douce coutume. J'avais aujourd'hui le sang plus fouetté qu'à l'ordinaire et je la trouvais dix fois plus aimable. Un instant après mon ange en tablier gras s'avise de sortir pour aller chercher quelque godiveau et quelque chair à saucisse pour sa daube qu'elle- est en train de farcir. Grande affaire pour elle, bonne affaire pour nous! Pan! je mets les verrous et nous voilà seuls, assis sur une chaise et bientôt genoux contre genoux. O Dieu, jamais je ne sentis mon cœur battre avec cette force! Yorick penche sa tête sur le sein d'Éliza. Yorick saisit Éliza par sa taille légère et l'attire à son tour près de ses lèvres... »

Delacroix n'est plus à Paris ; il est à la maison des Gardes.

“ ... J'y pense toujours. Il y a un an que je l'ai connue. J'y pense presque toutes les nuits. Il y a tant de douceur dans cette amertume même que je fais mon bonheur de me ronger 
et de me persécuter on roulant de mille manières cette image dans mon esprit. Que deviendrais-je saus les longues soirées d'hiver où j'affrontais le froid avec tant de plaisir pendant des heures pour une ou deux minutes de bonheur! Que peut-on comparer à cette douce attente dans l'obscurité des nuits, à cette entrevue furtive yui s'évanouit dans l'instant et vous laisse muet, et, le cou tendu, suivre des yeux ce que vous ne royez plus ?... Tu as raison, la douleur de perdre ces biens-là est trop vive. Quand je pense à la dernière lettre, aux adieux qu'on m'y signifie, et, en même temps, à la dernière entrevue si longuement scellée, aux jours qui suivirent la séparation, je ne sais sur quel côté dormir et je me remue comme un homme qui a la fièvre... " ... Je crois aussi que ce sentiment (l'amour;) est si fort que le plus éloquent homme de la terre n'a jamais dit tout ce qu'il sentait; que ce sentiment-là a, pour celui qui l'éprouve, des trésors de jouissances intimes qu'il ne pourra jamais réfléchir dans l'âme des autres...

“...Je suis malheureux, je n'ai point d'amour. Ce tourment délicieux manque à mon bonheur. 
Je n'ai que de vains rêves qui m'agitent et ne satisfont rien du tout. J'étais si heureux de souffrir en aimant! Il y avait je ne sais quoi de piquant jusque dans ma jalousie, et mon indifférence actuelle n'est qu'une vie de cadavre. Je suis obligé, pour vivre réellement à ma manière, c'est-à-dire par les sentiments et par le cœur, de chercher ces jouissances dans la peinture et de les lui arracher. Mais la nature n'entend pas tout cela, et quand je retombe sur mon cœur vide de tout le poids de mon ennui trompé et distrait artificiellement, je sens trop qu'il faut à la flamme de l'aliment et que je ferais d'autre peinture si j'étais toujours tenu en haleine par la douce chaleur de l'amour... »

Le peintre devait bientôt se dégager, vaincre et neutraliser dans son cœur les effets de cette flamme éphémère. Le moment n'est pas loin où Delacroix ne considérera plus l'amour comme l'aliment de ses ardeurs de poète, mais bien comme le plus dangereux ennemi d'un artiste qu'il trouble et auquel il fait perdre un temps précieux. Il est intéressant de voir comment il traite cette passion d'art, ce métier d'artiste, et 
comment ils le traitent. Nous sommes en 1828. Delacroix est définitivement lancé. La période de lutte a commencé. Le peintre est dans la fournaise. 11 écrit à Soulier : “...Tu me crois donc un homme bien répandu? Les quelques soirées où je vais par hasard m'ennuyer et me désennuyer finissent au total par me fatiguer physiquement à l'excès. Le plus souvent, je suis accaparé par quelque jobard qui me parle peinture à tort et à travers, pensant que j'emporte de sa conversation et de sa capacité une haute idée. De femmes, ça ne m'en procure pas, je suis trop pâle et trop maigre. La grande préoccupation de mon existence, celle qui tient en suspens et en échec les hautes et puissantes facultés que la nature m'a accordées, au dire de quelques bonnes grens, c'est d'arriver à payer mon terme tous les trois mois et de vivoter mesquinement. Je suis tenté de m'appliquer la parabole de Jésus-Christ qui dit que son royaume n'est pas de ce monde. J'ai un rare génie qui ne va pas jusqu'à me faire vivre paisiblement comme un commis. L'esprit est le dernier des éléments qui conduisent à faire fortune; cela sans figure, sans 
exagération. L'imagination, quand pour comble de malheur ce don fatal accompagne le reste. consomme la ruine, achève de flétrir, de briser dans tous les sens l'âme infortunée. L'amour de la gloire, passion menteuse, feu follet ridicule (qui conduit toujours droit au gouffre de tristesse et de vanité! Je ne parle pas de l'amour qui a les peines les plus cuisantes, mais qui a réellement quelques instants rafraîchissants. Si j'ai des enfants, je demanderai au ciel qu'ils soient bêtes et qu'ils aient du bon sens. "

Ces instants rafraîchissants de l'amour, il ne paraît pas les arnir goûtés. Il ne paraît pas avoir été jamais épris dans le vrai sens du mot. Les cris amoureux que nous avons rapportés ne sortent pas des profondeurs de la poitrine; ces sensations de jeunesse dont M. Pierret fut le confident ne chatouillent qu'à fleur de peau. Ce sont des vibrations de la chair bien plus que des tressaillements de l'âme, vibrations courtes, ne laissant pas de traces profondes, incapables de détourner l'homme de sa voie ni de le dériver sérieusement, sauf pour quelques heures et à la passade. Toute l'épopée amoureuse de Delacroix 
s'est réduite à quelques aventures galantes provoquées par le voisinage, la cohabitation sous le même toit; témoin la petite Anglaise femme de chambre de sa mère et autres fillettes du même acabit, dont il aimait à parler cquelquefois, mais qui n'avaient laissé dans son souvenir qu'une impression fugitive dépourvue de douceur autant que d'amertume. En somme, comme le dit M. Piron, autant il était passionné en amitiés, passionné de parti pris, autant, en amour, il était froid, raisonneur et partisan des plaisirs faciles. Ce qu'il ne pouvait tolérer surtout, c'est qu'une femme vînt se placer entre lui et ses amis. 
Gritique et esthétique. - Idéal et réalisme.

La critique de Delacroix n'est pas à la hauteur de son génie. Cependant on trouve dans les morceaux littéraires réunis par M. Piron des aperçus intéressants et ingénieux. L'art de Delacroix est un art réfléchi : il avait sur les choses des idées précises, arrêtées et motivées; son esprit était celui d'un raisonneur; il ne redoutait pas la discussion et s'en tirait à merveille; l'esthétique qui sc dégage de son œuvre est absolument personnelle, il y a donc lieu de s'étonner de la tiédeur relative de ses aperçus, et du peu de pittoresque de ses expressions; son style est froid, presque pauvre, même lorsqu'il semble dominé par un sentiment enthousiaste. Il met complètement en défaut la définition de Buffon. Rien n'est moins Delacroix que son style. Il y a pourtant à distinguer entre les pensées fugitives écrites au hasard du crayon ou de la plume sur un chiffon de papier, un album, un agenda, 
tombées de son esprit sans préméditation, et les rares études faites sur commande qu'il a écrites pour des revues. Tandis que les morceaux volants du maitre vont droit au but, les autres tergiversent, hésitent et révèlent toutes les inexpériences d'une plume timide qui, faisant un métier d'occasion, se préoccupe trop du lecteur et verse, à cause de cela, en des formules reçues, lesquelles ne se dégagent que péniblement, restent incolores et pèchent enfin par les seuls défauts qu'on fût en droit de ne pas attendre d'un homme essentiellement fin, ardent et original comme l'était Delacroix. Ces études, qui ne se trouvent pas en librairie, ont été publiées dans la Revue des Deux Mondes, la Revue de Paris et le Moniteur. En voici les titres : Des Critiques en matière d'art, Portrait de Pie VII, de Sir Thomas Lawrence, Raphael, Michel-Ange, Prudhon, Gros, De lEnscignement du dessin, Le Poussin, Questions sur le Beau, Des Variations du beau, Charlet, Puget. Nous croyons utile d'en donner quelcques extraits choisis parmi les passages les plus remarquables qui s'y trouvent disséminés. 
Mais nous nous réservons d'insister davantage sur les improvisations, où l’idée, librement jaillissante, n'a point été altérée et gelée par la crainte d'un public qui, pour leur auteur, ne devait jamais être appelé à les connaître. Delacroix s'y retrouve avec ses qualités bien personnelles, et c'est à ce titre surtout que ces fragments sont précieux.

Qu'est-ce que l'idéal dans l'art? qu'est-ce que le réalisme? Delacroix nous a dit ce qu'il pense de ces dleux générateurs, à l'association desquels toute belle œuvre cloit le jour. Il l'a écrit en une note sur une page de ce précieux cahier que nous voudrions voir imprimer tel qu'il est, sans aucun changement, ni classement, ni ordre.

“ Serait-il trop hasardé de dire que l'idéal est ce qui va à l'idée, imitée ou non, et le réalisme l'expression plus réelle des objets dans l'imitation qu'en fait la peinture? C'est là, je crois, le sens de ce mot.

“ Il est impossible de ne pas avouer que la nécessité où se trouve le peintre de déployer des moyens artificiels pour rendre le vrai, même 
dans son sens littéral, doit produire des différences entre l'objet et la représentation qu'il en fait. Il met toujours dans son imitation quelque chose 'de son tour d'esprit, le degré de dextérité physique qui lui est propre; il fait sentir, par la grâce ou la disgrâce avec laquelle il traduit ce qu'il voit. Le même modèle, rendu aussi exactement que possible par vingt artistes, présentera, dans leurs tableaux, vingt images différentes. Je vais plus loin : le même artiste sera souvent impressionné d'une manière différente devant le même objet. En quoi consistera donc le réalisme? Qui en décidera?

“Si l'on ne prend le mot dans le sens rigoureux, on peut approuver le réalisme tel que l'ont pratiqué certaines écoles. Je veux parler de celles où, tout en se livrant à son imagination pour la composition ou l'ordonnance de son sujet, le peintre cherche dans l'exécution une reproduction plus précise de la nature.

“ Dans de telles écoles, il peut y avoir autant d'idéal que dans les ouvrages où on a cru y atteindre en s'éloignant des types de la nature pour les embellir. Les Espagnols, Murillo, Zur- 
baran, etc.; en Italie, Caravage, le Guerchin, sont des modèles de cette espèce de réalisme, le seul qui soit permis dans les arts, parce qu'il n'exclut pas l'idée, la pensée, l'âme enfin de l'artiste. Il faut une apparente réalité; c'est le réalisme littéral qui est stupide. Holbein, dans ses portraits, semble la réalité même et il est sublime; la main de l'Homme à la toque, de Raphael, de même. Mais c'est le sentiment particulier du peintre qui imprime ce cachet. On en trouvera la preuve dans la comparaison de ces peintures naïves, et pourtant pleines d'idéal, avec la plupart des figures de David, lequel imite tant qu'il peut, tout en embellissant, et qui n'arrive que rarement à l'idéal. Il est impossible de pousser l'imitation plus loin que dans le tableau des Horaces, par exemple : la jambe, le pied d'Horace, etc., sont presque serviles d'imitation; l'intention d'embellir se remarque pourtant dans le choix des formes.

“ J'ai dit ailleurs, sur le Beau, que David avait moins d'idéal que Rembrandt, malgré sa correction et son affectation des formes antiques; chose singulière, dans plusieurs de ses portraits, 
il est aussi idéal que Raphael avec plus de fidélité dans l'imitation. Son portrait du pape est d'une idéalité frappante : toute l'âme clu personnage, toute sa résignation respirent dans ses traits. Le portrait de $M^{\text {me }}$ de V..., qui est peutêtre le chef-d'œuvre de David, est la plus noble figure qu'on puisse imaginer, et il n'a fait que traduire exactement le naturel.

“ Les systèmes absolus sont toujours absurdes dans les choses de sentiment. Qui cacherait dans les Thermopyles la figure du jeune homme qui attache ses sandales ne trouverait, dans tout ce tableau, que le travail d'un homme d'école et non celui d'un homme de génie. Cette seule figure, au contraire, une des plus parfaites que la peinture ait produites, est dans le véritable esprit de l'antique et non dans le système d'imitation étroite des statues qui dépare tous ses ouvrages.

“ La vieille femme, dans les Sabines, les enfants, la femme qui élève en l'air un enfant au maillot, etc., etc., sont des lueurs du même genre qui placent David très haut. Il n'y a rien de plus idéalement conçu chez aucun autre, 
ancien ou moderne, que la figure du Socrate dans la Mort de Socrate, elle est vraiment divine; que. l'académie se retrouve çà et là dans les autres figures, que la peinture soit froide, la couleur sèche et crue, ce sont de grands inconvénients, sans doute; peut-être les agréments qui manquent là, tels que la grâce de l'effet, le fondu du contour, etc., sont-ils comme le miel dont il faut absolument couvrir les bords du vase. L'idée la plus forte ne perdra rien du moins à être ornée et habillée avec toutes les splendeurs de l'art. Do là l'infériorité de David relativement aux grands maîtres qui réunissent aux charmes de l'exécution la force de la conception; de là aussi le tort inexcusable de certaines écoles, qui se font de l'absence de toutes les qualités charmantes de la peinture une sorte de titre à l'admiration. David, du moins, était naïf dans sa manière de rendre les objets. Il n'affecte nullement de les faire autrement qu'ils ne sont, sous prétexte de l'autorité des vieilles fresques, comme font ces écoles dans leurs ciels couleurs d'ardoise, leurs figures de brique, leurs fonds d'or, etc. 
"Les formes de l'Antiope, les figures de Michel-Ange et tant d'autres sublimes morceaux, qui manquent d'imitation littérale, font rêver. Chez les maîtres primitif; dont nous avons parlé, l'imitation, au contraire, loin de nuire à l'effet sur l'imagination, l'aug'mente sans doute. Qu'est-ce donc qui va à l'âme, sans quoi il n'y a ni peintres ni spectateurs? Le je ne sais quoi, l'inspiration mystérieuse, le je ne sais quoi qui donne l'âme à tout.

“ De là la nécessité dle ne prendre du modèle que ce qui sert à expliquer, à corroborer l'idée. L es formes du modèle, que ce soit un arbre ou un homme, ne sont que le dictionnaire où l'artiste va retremper ses impressions fugitives; ou plutôt leur donner une sorte de confirmation, car il doit avoir de la mémoire. Imaginer une composition, c'est combiner les éléments d'objets que l'on connait, qu'on a vus, avec d'autres éléments qui tiennent à l'âme de l'artiste. Beaucoup au contraire composent avec le modèle sous les yeux, ils ôtent ou ils ajoutent, mais ils partent toujours de cet objet étranger à eux-mêmes, le modèle extérieur. Ils sont donc 
toujours dominés par l'ascendant de cette nature vivante, qui n'a qu'à se montrer, même sans choix et sans lien avec autre chose, pour paraitre séduisante. Cette manière de procéder explique l'étonnante sécheresse de certaines con. ceptions. Dans les ouvrages où l'artiste a commencé par un détail sans rapport avec une idée préconçue, le malheureux ne peut plus, juscqu'à la fin, se sauver que par l'imitation exacte de ces détails, qui ont été l'occasion de sa mince inspiration. Sans doute, le modèle est nécessaire et presque indispensable, mais ce n'est qu'un ésclave qui doit obéir à la partie de l’invention; on lui emprunte quelques détails caractéristiques que l'imagination la plus privilégiée ou la mémoire la plus fidèle ne pourraient reproduire, et qui donnent une sorte de consécration à la partie imaginée. Il va sans dire que cette manière de travailler exige la science la plus consommée, et pour être savant il faut la vie entière.

"Quand je dis qu'il faut emprunter seulement quelques détails au modèle, on ne doit pas prendre cela d'une manière trop étroite et trop absolue. Chaque organisation donne la règle 
du degré d’imitation. Les Holbein, les Memling, sont sublimes, non pas malgré leur étonnante et exacte imitation, mais à cause d'elle. Tout dépend de l'esprit dans lequel on imite... "

Voilà certes un morceau sans prétention littéraire, mais où l'idée du peintre est clairement exprimée et cela vaut mieux. Qui s'attendait à rencontrer de la naïveté chez David et surtout du réalisme? Pourtant on ne peut se refuser à reconnaître que les exemples choisis par Delacroix démontrent la vérité de cette affirmation.

Nous aurions voulu pouvoir transcrire ici tout ce que nous avons lu d'observations sagaces, d'aphorismes ingénieux, de réflexions justes formulées par cette intelligence vaste et compréhensive. Cela faisant, nous eussions accompli le vœu que M. Chesneau a tant de fois émis, nous aurions fait une édition complète des ouvres littéraires de Delacroix. On eût vu alors, comme le dit l'auteur des Peintres et Statuaires romantiques, se dessiner dans toute sa finesse éléggante, sobre, un peu hautaine, cette physionomie du plus lettré de nos peintres. 
Le penseur y apparaitrait à côté de l'artiste. C'eût été enfin un dernier et durable hommage rendu à la mémoire du maître. Dans l'impossibilité où nous sommes d'accomplir cette tâche, nous avons tenté d'y suppléer en prenant, un peu partout, des exemples, véritables lambeaux tirés de la dépouille du maître, nous tenant pour satisfait si les échantillons de la tunique peuvent donner l'idée de l'ampleur de ses plis et un faible aperçu de l'éclat de sa couleur. Sans parler des peintres qu'il a étudiés spécialement, Delacroix a laissé partout une trace de la préoccupation que lui ont causée tous les grands de toutes les écoles, les modernes aussi bien que les anciens, et pour les définir il a souvent trouvé le mot caractéristique et topique. 


\section{Appréciation de certains maîtres.}

Sur Michel-Ange. - "Donner une idée du style de Michel-Ange et surtout de l'élévation où il l'a porté dans les peintures de cette voûte (la chapelle de Sixte IV) est une chose prescue impossible... Les ouvrages de Michel-Ange donnent incontestablement la sensation la plus épurée et la plus élevée qu'il soit possible d'éprouver pour un art. Il semble qu'il n'ait jamais pensé qu’à se plaire; du spectateur et de son goût particulier il ne s'en inquiète point. Il agrandit, il invente, non pas pour éblouir ou pour charmer, mais pour dominer l'imagination... Il ne faut pas être étonné du mépris des artistes médiocres pour ce sauvage génie.

Ils ne peuvent s'empêcher de haïr ce style terrible qui les subjugue malgré eux; ils s'en prennent à eux du sentiment profond de leur impuissance et se rejettent alors sur les incorrections et les bizarreries, fruits de son caprice...

"Pense au grand Michel-Ange; nourris-toi de ses grandes et sévères beautés... » 
Sur Raphael. - " Le nom de Raphael rappelle à l'esprit tout ce qu'il y a de plus élevé dans la peinture, et cette impression qui commence par être un préjugé est confirmée par l'examen chez tous ceux qui ont le sentiment des arts...

“ Raphael n'a pas plus qu'un autre atteint la perfection. Il n'a pas même, comme c'est l'opinion commune, réuni à lui seul le plus grand nombre de perfections possible; mais lui seul a porté à un aussi haut degré les qualités les plus entraînantes et qui exercent le plus d'empire sur les hommes, un charme irrésistible dans son style, une grâce vraiment divine, qui respire partout dans ses ouvrages, qui voile les défauts et fait excuser toutes les hardiesses...

“ On peut dire que son originalité ne paraît jamais plus vive que dans les idées qu'il emprunte. Tout ce qu'il touche il le relève et le fait vivre d'une vie nouvelle. C'est bien lui qui semble alors reprendre ce qui lui appartient et féconder des germes stériles qui n'attendaient que sa main pour donner leurs vrais fruits. 
“Le Jugement de Pâris, de Raphael, dans une épreuve affreusement usée, m'apparaît sous un jour nouveau, depuis que j'ai admiré son admirable entente des lignes... Cet intérêt mis à tout est aussi une qualité qui efface complètement tout ce qu'on voit après. Il n'y faut pas même trop penser de peur de jeter tout par les fenêtres. ")

Sur Masaccio. - “ La fortune qu'on dit si juste, apparemment pour ne pas consoler ceux qui n'ont pas la faveur de leur siècle, a mal traité bien des hommes dignes d'un meilleur sort; ou plutôt, l'ingrate qu'elle est, elle a souvent immolé une gloire ancienne à une nouvelle. Elle a caché la figure de Masaccio derrière le rayón dont elle a entouré Raphael, et peut-être qu'un demi-siècle plus tard un si beau génie eût eu une destinée toute contraire. »

Sur Léonard de Vinci, Titien. - “ Il est des talents délicats qui ne peuvent facilement se satisfaire; attentifs à captiver l'esprit, ils s'adressent à lui par tous les moyens dont l'art 
dispose : ils refont cent fois un morceau, ils sacrifient la touche, l'exécution savante qui fait ressortir plus ou moins les clétails, à l'unité et à la profondeur de l'impression. Tel est Léonard de Vinci, tel est Titien. Il est d'autres talents comme Tintoret, mieux encore comme Rubens, et je préfère ce dernier parce qu'il va plus avant dans l'expression, qui sont entraînés par une sorte de verve qui est dans le sang et dans la main. »)

Sur Murillo. — «Il faut voir le beau où l'artiste a voulu le mettre. Ne demandez pas aux Vierges de Murillo l'onction chaste, la timide pudeur des Vierges de Raphael; louez dans les traits de leur visage et dans leur attitude l'extase divine, le trouble vainqueur d'une créature mortelle élevée vers des splendeurs inconnues. Si l'un et l'autre de ces peintres introduisent dans ces tableaux, où ils nous montrent la Vierge dans sa gloire, quelques-unes de ces figures de pieux donataires ou de saints personnages de la légende, nous sommes charmés, chez Raphael, de leur noble simplicité et de la grâce de leur 
mouvement; chez Murillo, nous admirons avant tout l'expression dont ils sont pénétrés.

Sur Rembrandt. - “On a demandé comment ont fait les anciens qui n'avaient pas d'antiques. Rembrandt, qui était presque dans le même cas, puisqu'il n'était jamais sorti des marais de la Hollande, montrait ses broyeurs de couleur's et disait: "Voilà mes antiques. "... Rembrandt, en faisant le portrait d'un mendiant en haillons, obéissait aux mêmes lois du goût que Phidias sculptant son Jupiter ou sa Pallas.

( Un Holbein, un Rembrandt.... ces Allemands.... ces Italiens des écoles primitives.... étincellent de beautés et de cet idéal que les écoles vont chercher la toise à la main.

"Guidés par une naïve inspiration, puisant dans la nature qui les entoure et dans un sentiment profond l'inspiration que l'érudition ne saurait contrefaire, ils passionnent autour d'eux le peuple et les hommes cultivés; ils expriment des sentiments qui étaient dans toutes les âmes : ils ont trouvé naturellement ce joyau sans prix 
qu'une inutile science demande en vain à l'expérience et à des préceptes. »

Rubens est le peintre qui préoccupa le plus Delacroix. Son nom revenait à chaque instant dans sa conversation et c'est certainement le maître qui eut sur lui la plus grande influence. Il est curieux de noter quelle fut l'impression qu'il éprouva au premier contact qu'il eut avec lui. Le peintre écrit de La Haye à M. Pierret: “ ..... Je t'ai bien désiré devant les belles peintures que j'ai vues.

" Emporté par l'instinct de son génie, Rubens dédaigne l'histoire toute nue ou ne lui accorde qu'une place secondaire. Dans les magnifiques tableaux où il nous peint la vie d'Henri IV et de Marie de Médicis, si l'on en excepte la sublime figure de la reine, dans la Naissance de Louis XIII, les personnages contemporains ne sont, le plus souvent, que de froids témoins d'une action dont les véritables acteurs sont des êtres surnaturels. Les passions personnifiées dans les tableaux de Rubens sont devenues les personnages principaux..... 
"Rubens a vu l'Italie et les anciens, mais, dominé par un instinct supérieur à tous les exemples, il revient des contrées où s'engendre la beauté et demeure Flamand. Il trouve la beauté du peuple et des apôtres, hommes simples, dans cette Pèche miraculeuse où il nous peint le Christ disant à Simon : "Laisse là tes filets et suis-moi : je te ferai pêcheur d'hommes. » Je défie que l'homme-Dieu eût dit cela à ces disciples si bien peignés auxquels il donne l'institution chez Raphael. Sans l'admirable composition, sans cette disposition savante qui place le Christ tout seul d'un côté, les apôtres rangés ensemble en face de lui, saint Pierre à genoux recevant les clefs, nous serions peut-être choqués d'un certain apprêt dans les poses et dans les ajustements. Rubens par contre présente des lignes brisées et décousues, des draperies sans élégance et jetées comme au hasard, qui déparent ses sublimes et simples caractères : il n'est plus beau par ce côté.

“ Jè n'ai pas éprouvé l'effet que j'en redoutais. Je craignais d'être tout à fait abattu. Au contraire, et pour ne parler que de Rubens, qui 
est le dieu de tout ce monde-là, j'ai vu ici ce que je n'avais pu comparer ailleurs, c'est combien il a été inégal comme tout le monde. Auparavant, je ne lui croyais qu'une manière; il est facile de voir dans les ouvrages de ce pays-ci qu'il a fait tous les essais et connu toutes les incertitudes : il est tantôt l'imitateur de Michel-Ange, qui, du reste, - lui revient souvent; tantôt de Véronèse et du Titien, et presque toujours, dans ces phases diverses, -il est emprunté et gêné. Quand il veut s'appliquer, il est froid et sec; quand il s'affranchit de ses modèles, il est le grand Rubens. ”

Les rejetons de forte race ne sont pas troublés par les vertus de leurs ancêtres. Ils les prennent pour exemple, tâchent de les imiter, sans jamais choir dans le pastiche. Par certains côtés Delacroix est un fils de Rubens; il est fils impressionné, sentimental et vibrant, de cette famille d'artistes grands, féconds, indépendants, qui ne relèvent que d'eux-mêmes, et dont la nature se réfléchit dans le miroir d'un art franc, expression directe de leur tempérament et de leur génie. Pour des hommes de la 
valeur de Delacroix, l'œuvre de Rubens n'est qu'un bain salutaire, un stimulant aigu, qui ne saurait dans aucun cas déprimer le talent, mais au contraire double les forces, rend les muscles souples et le cerveau lucide. Ces hommes-là peuvent abuser, contempler, commenter, copier sans crainte de subir l'effet nuisible des enivrements. Ils sont assez forts pour conserver leur raison intacte, en dépit des boissons les plus capiteuses qui ne produisent jamais chez eux que de fécondes hyperesthésies.

Sur Véronèse. - “Dans le festin de Paul Vẹ́ronèse je vois des hommes comme je les rencontre autour de moi, de figures et de tempéraments variés, qui conversent et échangent des idées, le sanguin près du bilieux, la coquette près de la femme indifférente ou distraite, enfin la vie et le mouvement. Je ne parle pas de l'air et de la lumière, ni des effets de la couleur, qui sont incomparables. ")

Sur Puget. - " Le nom de Puget est un des plus grands noms que présente l'histoire des 
arts. Il est l'homme de son pays, et, par une bizarrerie remarquable, l'allure de son génie semble l’opposé du génie français. De tout temps, sauf de rares exceptions, parmi lesquelles Puget est la plus brillante, la sagesse dans la conception et l'ordonnance, et une sorte de coquetterie dans l'exécution ont caractérisé le goût de notre nation dans les arts du dessin; au rebours de ces qualités, Puget présente, dans ses ouvrages, une fougue d'invention et une vigueur de main qui approchent de la rudesse et qui durent étonner dans son tempss plus qu'elles ne feraient au nôtre. Aussi l'espèce de disgrâce qu'il subit pendant sa longue carrière doit-elle être attribuée en grande partic à cette opposition qu'il offrait avec la manière des artistes ses contemporains, manière qui flattait le goût général. C'est précisément ce contraste qui le fait si grand aujourd'hui : aux yeux de la postérité, il efface tout ce que son époque a produit et admiré. »

Sur le Poussin. - Delacroix a fait une étude magistrale. Il faudrait la citer tout entière. Elle est pleine d'aperçus ing'énieux, d'anecdotes inté- 
ressantes, de comparaisons, de jugements précieux sur la " génération des peintres qu'on a nommés naturalistes, et qui sortaient directement des Carrache, des Caravage, des Ribeira » et clu Guerchin, " le plus pathétique peut-être do de tous les contempteurs de l'idéal ». De même sur l'Albane, sur le Guide, "grénies plus souples et plus épris de la grâce ", qui " mêlèrent à l'imitation je ne sais quel attrait particulier, clû autant à la suavité du pinceau qu'au choix plus attentif de natures gracieuses... " Coryphées de ce genre attrayant qui a duré presquo jusqu'à nos jours, et dont on retrouve les dernières traces dans toutes les peintures du dernier siècle, goût devenu tellement dominant, tellement enraciné, que, pendant plus de cent cinquante ans après la mort de ces maitres, on n'envoyait les jeunes gens en Italie que pour étudier cette manière, et particulièrement cello du Guidle. » Sur le Dominiquin, “ le Boeuf, dlont ses maitres avaient dit que ce bouf fertiliserait lo champ de 'la peinture s, et que le fanatisme pour l'école du Guide, fanatisme furieux, aváit forcé de se cacher au fond de Rome, pour échapper 
à la persécution et préserver sa vie, lorsque le Poussin lui fit rendre justice; sur Michel-Ange, " ce Goliath de la peinture»; sur Raphael, sur Rubens, sur le Titien, sur Le Sueur, sur Le Brun, enfin sur le Poussin lui-même dont il dit : “On a tant répété qu’il est le plus classique des peintres qu'on sera peut-être surpris de le voir traiter dans cet essai comme l'un des novateurs les plus hardis que présente l'histoire de la peinture. Il est arrivé au milieu d'écoles maniérées, chez lesquelles le métier était préféré à la partie intellectuelle de l'art. Il a rompu avec toute cette fausseté, s'y trouvant porté par sa pente naturelle et sans parti pris; mais il ne faudrait pas conclure de cette qualité de réformateur, qu'il ait eu une très grande influence sur ses contemporains.... Il est probablement le seul des grands artistes qui n'ait pas sacrifié à la tentation de s'approprier quelques-uns des mérites de ces hommes imposants, que nous sommes habitués à considérer comme les lumières de l'art.... Poussin n'a pas imité les bas-reliefs et les statues par le còté matériel.... Il n'a pas affecté une prétendue pureté, en cherchant à prendre, 
pour ainsi dire sur le fait, la forme d'un pli, d'un meuble, d'une coiffure. Ceci est l'art de l'antiquaire, mais non de l'artiste, qui doit remonter à l'esprit, au sens de ce qu'il s'approprie en l'imitant; c'est l'homme qu'il étudie à travers l'antique, et au lieu de s'applaudir de retrouver le peplum ou la chlamyde, il fait ressusciter en quelque sorte le mâle génie des anciens dans la représentation des formes des passions humaines. Telle est l'imitation du Poussin...

"..... On peut adresser au Poussin un reproche plus sérieux que celui d'avoir donné les costumes de la colonne Trajane à des Grecs, ou d'avoir introduit des temples romains en Égypte, au temps des Pharaons: c'est d'avoir fait un abandon systématique de la couleur, si effectivement cet abandon a été aussi prémédité qu'on le $\operatorname{dit.....}$

«..... Le Poussin a trouvé incontestablement la beauté; mais cela n'a pas dans ses tableaux cet attrait irrésistible qui nous charme dans ceux de Raphael. Les figures de divinités qu'il emprunte à la fable, celles de ses saintes et de 
ses madones ont beaucoup de noblesse, mais elles la doivent surtout à une certaine correction un peu monotone et un peu froide. Il ne peint ni la modeste rougeur des vierges, ni la pâleur extatique des saints et des martyrs; il n'a pas cette onction pénétrante des Vierges de Murillo, non plus que la douce langueur et la tendre complexion de celles du Corrège. Il ne sait pas, comme ces deux maîtres, les noyer dans des auréoles resplendissantes, les montrer tout éperdues, au milieu de ces gloires et de ces légions d'archanges, à travers lesquelles leurs yeux semblent s'élever jusqu'à Dieu.

"Mais, en revanche, quelle supériorité dans les sujets qu'il emprunte à l'histoire! Quelle hauteur, quelle vigueur dans ces mâles Romains, qui sont vraiment des hommes! Qu'on est loin de ces héros de théâtre, qui semblent n'avoir que l'habit! Quels Grecs que ces Phocion, ces Eudamidas, ces Achille! Quel Romain que ce Coriolan vaincu par les prières de sa mère, au milieu de son camp.....»

Sur Gros._- «...Il semble qu'on peut affirmer 
que le caractère le plus général du génie est la hardiesse et la confiance dans la force de ses conceptions. Si l'on examine avec attention tout ce qui fait véritablement beauté dans les ouvrages des grands maîtres, on verra qu'un esprit juste, mais timide, enchaîné par l'usage et les précédents, n'aurait jamais risqué certaines images, certaines expressions, certaines tournures, qui saisissent, par un rapport frappant de l'idée avec la forme qui leur est donnée.

“Qu'on examine, dans les ouvrages célèbres, toutes les beautés consacrées et dont l'habitude a rendu l'effet moins piquant, on verra qu'elles étaient, presque toutes, à leur apparition, de nature à choquer les puristes. Pour parler de la littérature, par exemple, chaque langue a son arsenal de tournures, d'accouplements de mots, d'expressions usitées, que l'usage applique à l'expression de certaines idées. Ces tournures ont été employées une première fois avec hardiesse, par un esprit aventureux. L e goût consacre les unes et repousse les autres: là est le secret du talent, là est la force qui lui fait apprécier, clans une combinaison toute nouvelle, ce 
qui est le vrai, ce qui n'a qu'un semblant de vrai, ou ce qui est faux, et tout à fait à rejeter. Cela explique comment ces esprits faux et boursouflés sont enclins, par cela même, à se croire extraordinaires. Cette extrême confiance en ses idées est le seul rapport, peut-être, que la sottise ait avec le génie, et c'est malheureusement le privilège dont elle abuse le plus. »

Si l'on applique ces réflexions aux belles peintures de Gros, et surtout à la Bataille d'Aboukir, on sera surpris de la franchise et de la nouveauté des pensées. Les écoles de peinture ont, comme la littérature, leurs moyens d'effet, qui sont, en quelque sorte, la propriété de tout le monde; ce sont des poses de convention, des façons de mourir, de tomber, de maudire, que l'on apprend à l'académie et qui deviennent, pendant tout le temps qu'un maître exerce son influence, le langage, les hiéroglyphes parlants de l'art pour les artistes et pour le public.

"Gros a osé faire de vrais morts, de vrais fiévreux, je parle toujours des belles parties de ses ouvrages, et dans ees parties, on ne lui a 
jamais assez su gré de la naïveté singulière et, en 'même temps, de l'audace de certaines inventions, qui semblent interdites à la peinture, mais dont l'effet est immense, quand la tentative est heureuse. Il sait peindre la sueur qui inonde la croupe de ses chevaux, au milieu de la bataille, et presque l'haleine enflammée qui sort de leurs naseaux; il vous fait voir l'éclair du sabre, au moment où il s'enfonce dans la gorge de l'ennemi. On a vu quel parti il sait tirer d'un détail qui peut sembler trivial et inutile, au profit du terrible et du pathétique, par l'accent particulier qu'il sait lui imprimer. Dans le champ de bataille d'Eylau, le cheval de Napoléon a les jambes visiblement mouillées et trempées de neige juscu'au-dessus du grenou. Le peintre inventa dans le même tableau, auprès d'un tas de morts, dont on entrevoit vaguement les formes, au milieu de la fange, un fusil abandonné, dont la baïonnette est tordue et couverte de petits glaçons ensanglantés. J'insiste sur cette poésie des détails qui est propre à Gros : je crois cette partie de l'art plus interdite que toutes les autres, s'il est possible, à la médiocrité, non pas 
que ces idées ne puissent s'offrir à tout le monde dans la composition. »

Sur Charlet. - "Charlet est à la tête de ces hommes rares de notre temps qui ne me paraissent pas avoir été mis à la place que la postérité leur réserve sans doute... On remarquera que c'est surtout par un certain côté littéraire que Charlet a rencontré chez nous la popularité. Son talent de peintre n'était estimé que des connaisseurs et on ne lui donnait guère que le rang d'un habile caricaturiste... Peut-être est-ce un don malheureux de notre race que cette manie de l'esprit qu'on veut mettre dans tout et qui gâte tant d'ouvrages de littérature, où du moins cette recherche pourrait à la rigueur sembler plus à sa place; elle est mortelle dans la peinture, qui tire ses moyens d'effets d'une source toute différente. L'attention que vous sollicitez pour des idées ingénieuses distrait la pensée de la signification morale de l'image présentée aux yeux, de son sens mystérieux et profond, qui ne veut point être analysé, et qui excite la rêverie au moyen d'un langage parti- 
culier qui n'est point celui de la langue écrite ou parlée. C'est donc un phénomène des plus rares que l'apparition de ces étonnantes productions douées au plus haut degré de tous les mérites de la peinture et auxquelles une sorte d'explication amusante pour l'esprit n'enlève aucun des mérites inhérents à l'art.

“ C'est le contraire de ce qu'on a récemment appelé, dans un jargon emprunté aux Anglais, des Illustrations où le peintre s'empare de l'iclée du poète pour la commenter à sa façon; chez Charlet c'est la création de peintre qu'il semble résumer pour l'esprit de tout le monde par un mot piquant ou philosophique.

"Que de dessins admirables et que de charmantes idées, que de sentiment et que de verve, que de scènes comiques ou attendrissantes dans cette vaste comédie humaine, dans ces images doublement parlantes qui s'adressent au cour et à l'esprit! Les personnages de Charlet sont à lui ; ils ont la tournure et l'accent qu'il a voulus.

“ Les types de Charlet sont de ceux qu'on n'oublie point, et la variété en est infinie. Il n'a 
jamais répété ni la même tête ni le même ajustement...

" Charlet est de la lignée de ces immortels railleurs qui s'attaquent au ridicule et au vice plus sûrement que les prédicateurs de vertu... »

Sur Sir Th. Lawrence. - «... Par le grand nombre de ses productions capitales; Lawrence rappelle tout à fait ces anciens peintres dont la fécondité nous étonne, et que nous sommes convenus de nous figurer retirés dans leur atelier, soigneux de leur réputation seulement par de beaux ouvrages, peu hommes d'intrigue et de salons. Sir 'Thomas qui, par son immense talent, peut se passer de l'intrigue, n'est pas moins courtisan poli que grand peintre. Ses personnages en prennent sans doute cet air noble et cette tournure distinguée qu'il sait donner à presque tous. Son talent se sent d'habitudes élevées et du commerce de l'aristocratie. Ce qu'on se demande avec le plus de surprise, c'est comment il suffit à tant de choses ; car, malgré l'apparente facilité de sa manière, rien n'est plus consciencieux que son travail... 
"Arec un rare bonheur, Lawrence évite la roideur de certains maitres, sans tomber dans les grâces minaudières d'une époque plus récente. Ses personnages vivent réellement : ils pourraient marcher, se mouvoir. Il saisit sur les traits la nuance la plus délicate de mélancolie ou de gaieté; et ce n'est encore qu'une partie de son talent. L'effet le plus pittoresque ajoute un admirable relief à ces têtes déjà si pleines de vie. On. peut le blâmer de pousser quelquefois jusqu'à l'affectation quelques recherches de contrastes piquants et inattendus; mais, au milieu de ses caprices les plus bizarres, il vous captive encore; l'cil est forcé de le chercher, de venir à lui. Son tableau est une espèce de diamant qui brille tout seul là où il se trouve, et qui éteint tout autour de lui... »

Sur Bonnington. - " J'ai eu quelque temps Bonnington dáns mon atelier, écrit-il à Soulier. J'ai bien regretté que tu n'y sois pas. Il y a terriblement à gagner dans la société de ce luron-là, et je te jure que je m'en suis bien trouvé... 
“ .... On peut trouver dans d'autres artistes modernes des qualités de force ou d'exactitude dans le rendu supérieures à celles des tableaux de Bonnington, mais personne dans cette école moderne, et peut-être avant lui, n’a possédé cette légèreté dans l'exécution qui, particulièrement dans l'aquarelle, fait de ses ouvrages des espèces de diamants dont l'œil est flatté et ravi indépendamment de tout sujet et de toute imitation...

“ Je ne pouvais me lasser d'admirer sa merveilleuse entente de l'effet et la facilité de son exécution; non qu'il se contentât promptement. Au contraire, il refaisait fréquemment des morceaux entièrement achevés et qui nous paraissaient merveilleux ; mais son habileté était telle qu'il retrouvait à l'instant sous sa brosse de nouveaux effets aussi charmants que les premiers. Il tirait parti de toutes sortes de détails qu'il avait trouvés chez des maîtres et les ajustait avec une grande adresse dans sa composition. On y voil des figures presque entièrement prises dans les tableaux que tout le monde avait sous les yeux, et il ne s'en inquiétait 
nullement. Cette habitude n'ôte rien au mérite de ses ouvrages ; ces détails pris sur le vif, pour ainsi dire et qu'il s'appropriait (il s'agit surtout de costumes), augmentaient l'air de vérité de ses personnages et ne sentaient jamais le pastiche. »

Quoique le morceau qui suit ne contienne que peu ou point d'aperçus critiques sur Géricault, nous croyons intéressant de le donner en entier, parce qu'il indique d'une façon nette et précise la nature des sentiments qui animaient Delacroix pour le grand peintre, son contempo. rain, et renferme d'intéressants détails historiques intimes.

" Il faut placer au nombre des plus grands malheurs que les arts ont pu éprouver de notre temps la mort de l'admirable Géricault. Il a g’aspillé sa jeunesse; il était extrême en tout; il n'aimait à monter que cles chevaux entiers et choisissait les plus fougueux. Je l'ai vu plusieurs fois au moment où il montait à cheval : il ne pouvait presque le faire que par surprise ; à peine en selle, il était emporté par sa monture. Un 
jour que je dinais avec lui et son père, il nous quitte avant le clessert pour aller au bois de Boulogne. Il part comme un éclair, n'ayant pas le temps de se retourner pour nous dire bonsoir, et moi de me remettre à table avec le bon vieillard. Au bout de six minutes, nous entendons un grand bruit : il revenait au galop; il lui manquait une des basques de son habit; son cheval l'avait serré je ne sais où, et il lui avait fait perdre cet accompagnement nécessaire. Un accident de ce genre fut la cause déterminante de sa mort. Depuis plusieurs années cléjà les accidents, suite de la fougue qu'il portait en amour comme dans tout, avaient horriblement compromis sa santé; il ne se privait pas pour cela tout à fait du plaisir de monter à cheval. Un jour, clans une promenade à Montmartre, son cheval l'emporte et le jette par terre. Le malheur voulut qu'il portât par terre, ou contre une pierre, à l'endroit de la boucle absente de son pantalon, où se trourait un bourrelet qu'il avait formé pour y suppléer. Cet accident lui causa une déviation dans l'une des vertèbres, laquelle n'occasionna, pendant un temps assez long, que 
des douleurs qui ne furent pas un avertissement suffisant du danger. Biot et Dupuytren s'en aperçurent quand le mal était déjà presque sans remède; il fut condamné à rester couché, et, moins d'un an après, il mourut, le 28 janvier 1824 .

" La vente qui eut lieu après sa mort fut loin d'être fructueuse, comme celles que nous avons vues dernièrement se succéder sous nos yeux. La totalité du prix ne s'éleva pas, à beaucoup près, à celui d'un seul des tableaux que l'on s'est disputé dans la vente de la duchesse d'Orléans. Elle n’a pas été à 40,000 francs. Il a fallu plusieurs années de négociations pour décider le gouvernement à donner 6,000 francs de la Méduse, laquelle avait été adjugée à ce prix, lors de la vente à ce pauvre Dorcy, que nous avons tous connu, et qui l'avait prise par dévouement. C'est à la persistance de Forbin que l'on doit de voir au Louvre ce bel ouvrage dont personne ne voulait.

" Géricault avait de la fortune, assez, malheureusement, pour lui donner trop d'occasions de distractions, qui ont nui à la suite de ses travaux et surtout à sa santé. Il en perdit la plus 
grande partie au moment où il se trouvait déjà couché sur son lit de douleur. Son ami l'agent de change, dont la déroute a été célèbre, fut cause de son désastre; il lui avait persuadé de laisser placer son argent à gros intérêts. Je l'ai vu dans les derniers temps, et presque poussé par la nécessité, heureux de vendre à des prix médiocres d'admirables esquisses ou tableaux. "

Ces lignes sont extraites du cahier manuscrit et relatées par M. Piron. Delacroix dit encore plus loin : “Quoiqu’il me reçût avec familiarité, la différence d'âge et mon admiration pour lui me placèrent à sun égard dans la situation d'un élève respectueux. Il avait été chez le même maître que moi, et, au moment où je commençais, je l'avais vu, déjà lancé et célèbre, faire à l'atelier quelques études. Il me permit d'aller voir sa Méduse pendant qu'il l'exécutait dans un atelier bizarre qu'il avait près des Ternes. L'impression que j'en reçus fut si vive qu'en sortant je revins toujours courant, et comme fou, jusqu'à la rue de la Planche, que j’habitais alors. » Et pour terminer nos citations par un 
cri de douloureuse indignation : “ ... Les hommes sont ainsi faits : ils voient sans s'émouvoir des efforts merveilleux et demandent encore des merveilles. Avec quelle froideur n'a-t-on pas accueilli de nos jours les ouvrages étonnants qui ont marqué la carrière si courte de l'illustre et à jamais regrettable Géricault! Tant de verve, tant de nouveauté n'avaient concilié à la $M e ́-$ duse, au Hussard, au Cuirassier que l'admiration enthousiaste de quelques jeunes gens. ")

Il est curieux de constater aujourd'hui, où le système du concours paraît avoir définitivement prévalu, ce qu'en pensait Delacroix et pour quelles raisons il était amené à le repousser. Cette lettre, écrite au directeur de l'Artiste, parut dans ce journal en avril 1831. Elle mériterait assurément d'être transcrite en entier; mais il en est de même de chaque morceau critique de Delacroix, et la limite de ce volume ne nous permet pas de céder à notre entraînement. Nous nous bornerons donc à en extraire les passages les plus intéressants.

“... Au premier aperçu, il m’a paru commode comme à vous d'avoir un moyen d'éprou- 
ver les talents comme on éprouve les métaux, et de les tirer de la foule à l'instant par le contrôle qui se produit de soi-même entre le bon et le mauvais. Si ce moyen-là est trouvé en effet, monsieur, quel problème nous aurons résolu!

" Mais en y réfléchissant plus mûrement, vous serez conduit à découvrir que ce moyen, simple et applicable en théorie, offre à la pratique mille difficultés...

“ On s'est aperçu qu'après la difficulté d'amener à concourir beaucoup de gens, pour qui ce système est nouveau, il se présentait la difficulté plus grande de trouver des juges, des juges sans passion et sans préjugés, point susceptibles de préférer leurs amis à tous les autres et ne cherchant que la justice et le bien de l'art...

“On a été aussi très embarrassé pour savoir si ce moyen avait pour objet d'employer le talent avant tout, ou seulement d'obtenir des ouvrages réunissant assez de qualités passables pour ne pas choquer dans la place qu'ils devront occuper...

“Vous ne voyez peut-être pas co qui empêche l'inspiration de naitre d'un concours. Le. 
sujet peut avoir de l'intérêt, être tel enfin qu'on se le fût imposé à soi-même.

"Remarquez que ce n'est pas à la nécessité de rendre tel ou tel sujet que je m'en prends, mais à la nécessité de passer par le crible impitoyable du concours, d'être aligné sous les yeux du public, comme un troupeau de gladiateurs qui se disputent d'impertinents sourires et qui prennent plaisir à s'immoler entre eux dans une arène. Sainte pudeur de l'artiste, quelle épreuve pour vous!

" La verve n'est pas une effrontée qui s'accommode des mépris comme des applaudissements tumultueux d'un théâtre, qui se roule sous les yeux du public pour lui arracher ses faveurs hautaines. Plus elle est brûlante et sincère, plus elle a de modestie. Un rien l'effarouche et la comprime. L’artiste, enfermé dans un atelier, inspiré d'abord sur son ouvrage et plein de cette foi sincère qui seule produit des chefs-d'œuvre, vient-il par hasard à porter les yeux au dehors, sur les tréteaux où il va figurer et sur ses juges qui l'attendent, aussitôt son élan s'arrête. Il jette un cil attristé sur son ouvrage. Trop de 
dédains attendent le chaste enfant de son enthousiasme; il manque de courage pour le suivre dans la carrière qu'il voit s'ouvrir. Il devient alors son propre juge et son bourreau. Il change, il gâte, il s'épuise; il veut se civiliser et se polir pour ne pas déplaire.

"Une idée ridicule s'offre à moi. Je me figure Rubens étendu sur le lit de fer d'un concours. Je me le figure se rapetissant dans le cadre étroit d'un programme qui l'étouffe, retranchant ses formes gigantesques, ses belles exagérations, tout le luxe de sa manière... »

Et la conclusion de Delacroix, qui serait également la nôtre si nous étions appelé à donner notre avis, c'est que le concours ne peut aboutir qu'à “ dégoûter le talent et à encourag’er la médiocrité ».

Voici une remarque qui semble écrite d'hier et tout exprès pour la génération actuelle. Le mal qui mine l'art si profondément à notre époque avait déjà, il y a vingt-cinq ans, atteint des proportions assez inquiétantes pour alarmer Delacroix : “ ... Les jeunes gens ne sont entichés que de l'adresse de la main. Il n'y a peut- 
être pas de plus grand empêchement à toute espèce de véritable progrè̀s que cette manie unirerselle à laquelle nous avons tout sacrifié. C'est elle qui empêche de sacrifier tout ce qui n'est pas absolument nécessaire au tableau, qui fait préférer le morceau à l'ensemble et qui empêche de travailler jusqu'à ce qu'on soit véritablement satisfait. ”

En voici une autre non moins digne d'être reproduite :

“... Les écoles modernes ont pu enseigner le beau comme on enseigne l'algèbre, et non seulement l'enseigner, mais en donner de faciles exemples. Quoi de plus simple, en effet, à ce qu'il semble? Rapprocher tous les caractères d'un modèle unique, atténuer, efíacer les différences profoncles qui séparent dans la nature les tempéraments et les âges divers de l'homme, éviter les expressions compliquées ou les mouvements violents capables de cléranger l'harmonie des traits ou des membres, tels sont, en abrégé, les principes à l'aide desquels on tient le beau comme dans sa main! Il est facile alors de le faire pratiquer à des élèves et de le trans- 
mettre de génération en génération comme un dépôt. »

Les Fragments sur le beau, l'idéal et le réalisme qui ont été réunis par M. Piron abondent en pensées, en jugements, en préceptes, en réflexions remplies de finesse, de pénétration et de clairvoyance. Il est extrêmement dommage qu'on ne se soit pas décidé à les faire connaître au public. C'est avec un véritable chagrin que nous nous condamnons à n'en transcrire que des extraits détachés nécessairement réduits, et qui, par conséquent, ne peuvent donner qu'une faible idée de l'intérêt et des leçons qui se dégagent de leur enscmble.

“ Ils croient qu'ils ont fait le beau quand ils ont répété à satiété les nez droits, les draperies en tuyaux de l'antique. Quelle inspiration peuvent-ils mettre dans ces éternelles contrefaçons? Comment n'y aurait-il qu'une manière d'être beau? L'imagination de tous les temps et de toutes les latitudes sera-t-elle enchaînée à . l'admiration unique de ces types? Ils sont sublimes d'ailleurs; ce que je réprouve, c'est l'imitation aveugle. 
“ ...Là où l'artiste est tendu et cherché, il perd son cachet, son originalité, en un mot, son style; là où il s'abandonne à sa nature telle qu'elle est, il est maître et sûr de ses moyens d'effet. Chaque homme de talent a en lui des types particuliers de vrai et de beau.

" ...Quand Ingres disait en voyant le Prisonnier de Chillon sans en connaître l'auteur : Voilà qui est beau, est-ce parce qu'il y retrouvait ses principes sur la beauté?

"Quand David témoignait l'admiration la plus vive pour le Christ en croix de Rubens et généralement pour toutes les peintures les plus fougueuses de ce maître, ce n'était pas à cause de la ressemblance de ces tableaux avec les statues antiques ou avec ses propres tableaux.

“ ...Il n'y a pas de degrés dans le beau; la manière d'être beau seule diffère.

“ ...Albert Dürer, Holbein, les maîtres allemands en général, les Lucas de Leyde, Memling, parmi les Flamands primitifs, avec leurs figures souvent piteuses, maigres, contournées, fourmillent de beautés. Les élèves modernes •t prétendus imitateurs du beau antique, si sûrs de 
leurs principes sur le beau et qui le mesurent une toise à la main, ne contiennent pas une parcelle de la vraie beauté, de celle qui s'adresse à l'âme en passant par les yeux... »

“ .....Les systèmes absolus sont toujours absurdes dans les choses de sentiment. »

" ...David était naïf dans la manière de rendre les objets : il n'affecte nullement de faire autrement qu'ils ne sont, sous prétexte de l'autorité des vieilles fresques, comme font les ingristes dans leurs ciels couleur d'ardoise, leurs figures de brique, leurs fonds d'or, etc.

“ ...C'est le réalisme littéral qui est stupide. Holbein, dans ses portraits, semble la réalité même, et il est sublime. La main de l'Homme à la toque de Raphael est de même. Mais c'est le sentiment du peintre qui imprime ce cachet. “ ...Eh! réaliste maudit, voudrais-tu par hasard me produire une illusion telle que je me figure que j'assiste en réalité au spectacle que tu prétends m'offrir? C'est la cruelle réalité des objets que je fuis, quand je me réfugie dans la sphère des créations de l'art. Que m’importent tes person- . nages vrais que je retrouve dans la rue sans me 
donner la peine de feuilleter ton livre? Je suis du moins le maître d'en détourner la vue, quand je la trouve sous mes pas, tandis que toi, tu m'en fais voir toute la crasse et toute la misère. " ...Le but de l'artiste n'est pas de reproduire exactement les objets; il serait arrêté aussitôt par l'impossibilité de le faire. Il y a des effets très communs qui échappent entièrement à la peinture et qui ne peuvent se traduire que par des équivalents : c'est à l'esprit qu'il faut arriver, et les équivalents suffisent pour cela. Il faut intéresser avant tout. Devant le morceau de nature le plus intéressant, qui peut assurer que c'est uniquement par ce que voient nos yeux que nous recevons du plaisir? L'aspect d'un paysage nous plaît non seulement par son agrément propre, mais par mille traits particuliers qui portent l'imagination au delà de cette vue même.

" ...Devant la nature elle-même, c'est notre imagination qui fait le tableau.

“...On ne peut assez répéter que les règles du beau sont éternelles, immuables et que les formes en sont variables. Qui décide de ces 
règles et de ces formes diverses qui sont tenues de se plier à ces règles, toutefois arec une physionomie différente? Le goût sẹl, aussi rare peut-être que le beau; le goût, qui fait deviner le beau là où il est et qui le fait trouver aux grands artistes, qui ont le don d'inventer. “ ..Qui dit un art dit une poésie. Il n’y a pas d'art sans un but poétique.

“ ...Ce qui caractérise vraiment le grand poète, le grand peintre, tout grand artiste enfin, ce n'est pas seulement l'invention d'un type frappant d'une pensée, c'est sa réalisation, sa personnification par le côté le plus énergique. C'est cette puissance d'imagination qui concentre en une conception tous les caractères, qui la fait exister réellement et prendre rang comme une créature complète.

“...La grandeur des maitres de l'art ne consiste pas dans l'absence des fautes.... Que d'heureuses données se sont perdues dans les mains de faiseurs dont l'inhabile nature ne saisit qu'un coin de sa propre invention!

“ ...En tout objet, la première chose à saisir pour le rendre avec le dessin, c'est le contraste 
des lignes principales : avant de poser le crayon sur le papier, en être bien frappé.

“...Toute production d'un homme qui n'est pas abondant porte nécessairement un cachet de fatigue.

" ...Le sacrifice impose des sacrifices contre le naturel ou l'expression, de même qu'en poésic on sacrifie à l'harmonie.

“...Bien qu'il travaille de la main, le peintre n'est pas un chirurgien : ce n'est pas dans sa dextérité que consiste son mérite.

“ ...La naïveté s'ignore. L’homme de talent croit souvent imiter pendant qu'il est original. Prudhon croyait peut-être imiter le Corrège, et il faisait d'excellent Prudhon.

“...Tous les sujets deviennent bons par le mérite de l'auteur.

" ...Dans la peinture comme dans le reste, les pédants, les gens qui affectent de certaines qualités sont pris pour ceux qui les ont.

"...Les lois de la raison et du bon goût sont éternelles, et les gens de génie n’ont pas besoin qu'on les leur apprenne. Mais rien ne leur est plus mortel que les prétendues règles, manières, 
conventions qu'ils trouvent établies dans les écoles, la séduction même que peuvent exercer sur eux des méthodes d'exécution qui ne sont pas conformes à leur manière de sentir et de rendre la nature. » 


\section{Pensées philosophiques et critiques.}

Delacroix n'a pas seulement écrit sur les choses de l'art et sur les artistes. Il était lettré et préoccupé de littérature. Aussi retrouve-t-on sur ses albums, auxquels il confiait les réflexions dont nous avons détaché quelques bribes, des considérations sur la littérature et les littérateurs, ainsi que des pensées philosophiques et même métaphysiques. On nous saura gré de ne pas les laisser dans l'ombre, d'en reproduire les lignes qui nous ont paru le plus intéressantes, en tous cas, de les signaler et d'appeler l'attention du public sur ces feuilles volantes qui, pour n'avoir pas l'intérêt des précédentes, sont pourtant remplies de pensées toujours pittoresquement exprimées.

“ ... J'ai toujours éprouvé que, contrairement à l'opinion reçue et accréditée surtout par les gens de lettres, il entrait véritablement plus de mécanisme dans la composition et l'exécution littéraire, que dans la composition et l'exécution en peinture. 
“ ... Les gens de lettres se figurent qu'ils ne sont point des ouvriers parce qu'ils ne travaillent pas avec les mains.

“ ... Quoi qu'en puissent dire les littérateurs, leur art ne présente pas les difficultés du nôtre. Tout homme qui a de l'imagination et qui sait sa langue se formera dans peu à écrire; tout homme qui a quelque chose à dire le dira bien, peut-être mieux que le littérateur de profession, parce qu'il sera moins occupé de la forme et de la rhétorique de son discours que $\mathrm{du}$ fond et de la substance.

" ... Ce qui fait aussi les bons ouvrages littéraires par des hommes qui ne sont pas littérateurs, c'est que, faisant une excursion dans cet art étranger, ils ne parlent que de ce qu'ils savent bien, tandis que le littérateur juré est très souvent entraîné à parler de toute espèce de choses, à cause de cette fluidité de langage ; cette facilité de parler élégamment sur tout leur fait aisément croire qu'ils puisent sur tout à volonté. “... Kant, en séparant le beau de l'utile, prouve clairement qu'il n'est point du tout dans la nature des arts de donner des leçons. 
“ ... Les bouffonneries rebutent à la vérité dans Shakespeare, mais tout autant que son sublime outré. Il est beau par ses traits de vérité bien enchâssés, bien choisis pour l'endroit, ce qui est peut-être presque tout l'idéal.

“ ... Le silence impose toujours; dans les affaires, dans les relations de toute espèce, les hommes assez sages pour se taire à propos conservent un ascendant remarquable. "Nous avons vu qu'il était de ceux-là.

“ ... Il faut être écrivain de profession pour écrire sur ce que l'on ne sait qu’à moitié, ou sur ce que l'on ne sait pas du tout.

" ... Le fait est comme rien, puisqu'il passe. Il n'en reste que l'idée; réellement même, il n'existe pas dans l'idée, puisqu'elle lui donne une couleur, qu'elle se le représente en le teignant à sa manière et suivant la disposition du moment.

“ ... L'homme domine la nature et en est dominé. Il est le seul être de la création qui, non seulement lui résiste, mais la dompte ou en élude les lois, et qui étende son empire par sa volonté et son activité. 
“ ... La nature ne se soucie ni de l'homme ni de ses travaux; ni en aucune manière de son passage sur la terre. Qu'il invente ou construise des merveilles, ou qu'il vive comme une brute, pour la nature c'est tout un. Le vrai homme c'est le sauvage; il s'accorde avec la nature comme elle est.

“... Tout change, tout est roman. Nous sommes frappés de l'anéantissement qu'amène la mort, de l'oubli profond de ceux qui ne sont plus; nous-mêmes ne nous oublions-nous pas?

"Les portraits des morts faits après la mort paraissent bientôt ressemblants, parce que l'imation qui n'a que des souvenirs vagues se prend à cette réalité.

“... J'ai beau chercher la vérité dans les masses, je ne la rencontre, quand je la rencontre, que dans les individus. Pour que la lumière jaillisse des ténèbres, il faut que Dieu y allume un soleil; pour que la vérité entre chez un peuple, il faut que Dieu y jette un législateur. La vérité n’est révélée qu'au génie, et le génie est toujours seul. Que voyez-vous dans l'histoire? D'un côté, Moïse, Socrate, Jésus-Christ; 
de l'autre les Hébreux, les Grees et l'univers. D’un côté, les peuples qui persécutent et qui tuent; de l'autre, la victime isolée qui les éclaire.

" ... On veut jouir de tout et on ne sait pas jouir de soi-même. Médite ce mot : Quand tu ne jouis pas de toi, tu es comme si tu étais un autre.

“ ... L'amour de la gloire est un instinct sublime, qui n’est donné qu'à ceux qui sont dignes d'obtenir la gloire. L'amour d'une vaine réputation qui ne flatte que la vanité, c'est tout autre chose. L'enthousiasme se nourrit de luimême.

“... La dispersion des facultés dans des essais qui ne mènent pas directement à un grand but est presque aussi funeste que la paresse qui les endort ou le découragement qui ôte la force d'y donner essor; faut-il s'alıandonner à un lâche découragement parce que le siècle est gangrené? »

Nous ne résistons pas au désir de transcrire ici en entier une boutade amusante qui caractérise un des côtés de l'esprit de Delacroix et 
cache sous une forme ironique un très grand fonds de vérité :

“Quand l'égalité aura fondé tout à fait son empire, ce sera une des charges du public de pourvoir de maîtresses les hommes laids et rachitiques; pour ôter à la part des beaux, il faudra trouver des femmes disposées à se dévouer à cette fraternité évangélique; peut-être les mal favorisés de la nature ne se trouverontils pas sulffisamment dédommagés par un simple dévouement; ils présenteront requête pour être aimés. Les hommes d'esprit scront invités à s'observer un peu pour ne pas trop humilier ceux qui en seront dépourvus; n'y ayant pas de moyen de donner de l'esprit et du sens commun, comme de la soupe à ceux qui en manquent, et ne pouvant l'ôter à ceux qui en ont, il faudra les contraindre à ne pas s'en servir. - L'Évangile a déjà prescrit de tendre l'autre joue à celui qui a déjà frappé la première; on ne pourra être aussi bon citoyen que son voisin qu'en étant aussi bête que lui. L'avocat qui, dans un procès, aura mieux parlé que son adversaire sera mis à l'amende pour compenser 
sa supériorité. Les femmes laides auront seules le droit d'avoir de la toilette. On ne jouera que les pièces des mauvais auteurs, pour les consoler un peu. On invitera même les gens de talent à les aider de leur savoir-faire. Quelle injustice de la nature de se montrer mère tendre pour les uns et impitoyable marâtre pour les autres! Rien ne scra plus juste que de renverser un ordre impie au moyen de toutes ces petites concessions mutuelles. Qu'il scra touchant de voir régner sur la terre, au moyen de la politique, ce que lir vieille religion de Jésus n'a pu réaliser; cet accord des âmes qu'on ne pensera plus à demander qu'à la pure raison, puisque le sentiment et les prédications religieuses n'ont pu l'effectuer !

"Remarquez qu'il ne sera pas nécessaire de s'aimer les uns les autres pour s'empresser de se porter secours, il suffira de bons projets de lois, de bonnes tables des droits et devoirs, gravées sur le marbre à cléfaut de l'être dans les cœurs. Le mot de conscience n'aura plus de sens. Le mot balance sera mis à sa place. Toute l'éducation consistera à perfectionner la notion 
de cette balance morale qui consistera à se rendre compte de ce que manque la raison, afin (le faire valoir ses droits à propos, afin de ne pas être mis à la queue de l'estomac de vos frères. Ai-je autant dîné que mon ami? tel sera le fondement de la morale. Le premier devoir d'un citoyen ne sera plus de se sacrifier, mais de se conserver pour la République. Si chacun s'applique à se satisfaire, cette foule de bonheurs particuliers ne constituerait-elle pas la félicité générale, c'est-à-dire la prospérité de la patrie, qui doit être le premier des vœux d'un citoyen? ») 
Mélancolie, amertume et doute.

Delacroix était d'une nature triste, saturnienne comme aurait dit feu Desbarolles. Les déboires de son extrême jeunesse, les revers de fortune, la mort prématurée de ses parents, sa santé, avaient mis son âme en deuil. Il était enclin aux humeurs noires, il avait des sericments de cour, il était spleenetique enfin. Non pas qu'il boudât la vie, tout au contraire; sa mélancolie, ses découragements venaient surtout de ce qu'il se trouvait entravé dans son désir immense de lui dérober tout ce qu'elle comporte de grand. Comme tous les gens qui ont besoin d'être consolés, il savait consoler les autres. Il trouvait en lui des accents émus et sincères pour pallier chez un ami les effets délétères des désespérances dont lui-même souffrait cruellement. La lettre suivante à M. Villot en fait foi. C'est en même temps une douce caresse philosophique et un réconfortant aussi mâle qu'amical. " Mon cher ami, je ne puis m'empêcher de répondre à votre si aimable lettre, d'abord par 
le plaisir de causer avec vous et par l'espérance que vous me récrirez encore, tout en vous donnant carrière et ne ménageant pas mes yeux ; j'en trouverai toujours pour cela; et ensuite pour vous gronder de la tristesse dont elle est pleine et à lacuelle vous semblez céder tout à fait. Cela m'a fait une peine véritable, et je voudrais, dans ma réponse, non pas vous dire seulement que je suis affligé de ce qui vous afflige, ce qui ne serait que pour l'acquit de ma conscience et ne vous serait pas très utile, mais pour trouver des raisons de vous consoler efficacement. Non, vous n'êtes pas cet homme profondément malheureux que vous dites, on ne peut pas l'être sans remède et avec cet abandon complet quand on a votre intelligence et votre cœur. Si on souffre beaucoup par ces deux côtés, on s'en élève aussi d'autant mieux au-dessus de la vulgarité et de mille nécessités humaineș. La vie de l'esprit est un si grand talisman contre le découragement absolu! On s'accoutume trop facilement à mille avantages que nous n'invoquons pas assez quand l'ennui s'empare de nous... Pensez à ce que serait pour vous main- 
tenant la nécessité de vivre au fond d'une province sans toutes les ressources contre les peines réelles. Celles-ci, je n’essaie pas sottement de vous armer contre elles ou plutôt je veux vous armer contre elles, puisqu'on ne peut s'y soustraire et cesser de vivre en leur présence. C'est sans doute le plus qu'on peut de ces instants où l'imagination est ravie par de nobles chimères. Je conçois aussi qu'un de vos chagrins les plus vifs, surtout en considération dı moyen que je vous offre, soit l'interruption que votre santé vous force de mettre à vos travaux. Il rous faut donc vous priver de cet instrument si puissant d'encouragement, le succès. Mais vraiment n'est-ce pas une illusion complète dont les jouissances trompeuses sont à cent lieues du plaisir que l'on éprouve au moment du travail? Là est la véritable jouissance et elle est dans vos mains sous mille. formes que la variété de vos études et de vos connaissances met à votre portée. Qu'est-ce que le théâtre sur lequel se produit et est débattue votre réputation d'un jour? Voyez l'ignorance profonde du monde entier, sauf un très petit 
nombre de connaisseurs, même des hommes les plus marquants. Voyez, dans ce petit nombre de gens qui jugent et qui apprécient, les controrerses sans fin sur les hommes les moins contestables, et jugez ce qui reste pour le beau rêve de la gloire.

“ Plus j'arance dans la vie et plus je me persuade de la nécessité de ce principe de la sagesse que comporte notre nature : Jouis de ce qui est dans tes mains. Toutes les folies des utopistes à perfectionnement viennent de ce qu'ils ont voulu agir avec des instruments qu'ils rêvent et qui n'existent pas. Ç'a été aussi la règle souveraine des grands hommes de tous les temps : c'est que la base de toute grandeur est la raison. Que vous produisiez, mon cher ami, ou que vous vouliez le simple emploi de la vie en vue du bonheur, c'est-à-dire de l'oubli des peines qu'elle engendre nécessairement et inévitablement, ne cherchez rien qu'en vousmême pour trouver les éléments qui vous seront nécessaires. On m’a dit que les savants définissaient la vie : la résistance aux affinités chimiques. Cela me plaît assez quoique cela soit 
savant; il me semble voir la machine humaine entourée d'agents ennemis qui entravent la vie, tandis qu'un principe intérieur travaille sans cesse à sa conservation en repoussant les injures de la nature extérieure. Il en doit être de même de la recherche du bonheur. Il y en a qui éloignent le sentiment de leur tristesse par les jouissances du corps; il en est d'autres qui doivent les combattre avec la recherche du beau, la contemplation, les passions du grand. Vous n'êtes pas plus incomplet que les plus grands des hommes. I es plus beaux ouvrages, les plus grands cours portent cette tache originelle que vous me dites. En changeant d'organisation vous changeriez de misères. Peut-être une organisation moins cléfectueuse sous certains rapports ne vous offrirait-elle aucun des dédommagements qui sont dans vos mains. Voudriez-vous être un de ces butors qui s'enivrent tout le jour ou qui chassent du matin au soir? Passeriez-vous vos jours dans un comptoir, à la Bourse, au milieu de l'agiotage? Sacrifieriezvous une seule noble jouissance à tous ces ignobles bonheurs de ces animaux sans plumes? 
Aimez-vous et estimez-rous comme vous le méritez et comme vous voyez que le font vos amis. Je serais désolé en particulier de vous voir céder autant de place au stérile chagrin, à l'ennui que nous portons tous au dedans de nous... "

Ces conseils si sages, empreints d'une si amicale philosophie, si pratiques, si simples, si dénués de tout pédantisme, en les donnant à Fr. Villot c'est à lui-même que Delacroix les. donne. Car il n'était point de ceux qui voient la vie en rose, qui regardent l'avenir avec confiance, “ qui, ne s'émouvant point, de rien n'ont l'âme atteinte ». Tout atteignait la sienne. Sa sensibilité maladive le rendait impressionnable aux moindres contrariétés et le plongeait parfois. dans des accès de marasme dont le contact de ses amis et l'amour de son art avaient peine à le dégagoer.

“ .... J'irai à Rome vivre avec les morts, écrit-il à Soulier, et oublier tout ce qui ne sera pas peinture ou amitié. Je réaliserai peut-être tous mes rêves brillants. Hélas! je suis bien triste en ce moment. Ce temps est gris et l'air si glacé ! ’) 
Et à Félix G. : " ... Nous vivons, mon bon ami, dans un temps de découragrement. Il faut de la vertu pour y faire un dieu du beau uniquement. Eh bien! plus on le cléserte, plus je l'adore. Je finirai par croire qu'il n'y a au monde de vrai que nos illusions. ”

Cette lettre est datée de 1828. A cette époque, Delacroix avait déjà exposé, outre Dante et Virgile, qui lui valut un grand succès, douze toiles, au nombre desquelles se trouvaient: le Massacre de Scio, la Mort de Sardanapale, le Doge Marino Faliero décapité, le Christ au jardin des Oliviers, et voila où il en était avec le public et les amateurs; il ne pouvait payer que péniblement son terme... On s'explique. l'amertume de sa lettre.

“ ... Cher ami, écrit-il encore à Soulier trois: ans plus tard, l'âge amène du changement dans les. caractères: dans les uns, c'est de la misanthropie et de la tristesse qui teint pour eux tout en sombre; chez les autres, c'est de l'orgueil et de l'insensibilité. Je ne crois pas être un de ces: derniers, car mon cour s'élance souvent vers le. temps des doux épanchements et des larmes 
d'amitié. Dans des accès de souffrance morale, on voudrait presque être mauvais pour rompre sans réserve avec tout ce qui est doux et consolant. On voudrait ne pas croire à la vertu; mais elle existe, j'en suis sûr, et les exemples, pour être rares, n'en sont pas moins encourageants. "

Et à la même époque, toujours à Soulier, qui va se marier : “... Tu ne pouvais me donner de nouvelle qui me fit plus de plaisir. Au moins, un de nous trouve un abri contre la mauvaise fortune. Cela m'a fait palpiter, moi qui fuis les émotions et qu'elles fuient. Liidée de ton bonheur prochain fait une diversion à la monotonie de mon existence. Tu prends le bon parti, celui de la paix, et il n'y a que celui-là au monde. Il n'y a pas de pire situation que de ne pas savoir comment on dînera dans huit jours, et c'est la mienne. Donne-moi un désert et fais-moi l'amputation d'un vieux et irascible reste d'amourpropre, je serai encore heureux dans le monde. Mais la réputation, la réussite, ce succès qu'on n'atteint jamais, tout cela vaut-il qu'on se casse la tête toute la vie pour l'atteindre... Un des caractères du découragement est de vous faire 
considérer votre profession comme inutile à vous et aux autres. La paresse, d'accord en cela avec l'humeur noire qui teint tout à vos yeux, dépouille de son charme le plus grand la possibibilité de travailler, lequel charme est cette possibilité elle-même. Rien au contraire ne donne plus d'âme, plus d'entrain, que de voir que d'autres font cas de cet art dont vous êtes fatigué, et, de là le bien qui peut résulter des dissertations sur les arts, toutes creuses qu'elles puissent paraitre au vulgaire...

“... Je suis sous l'empire d'un sentiment nerveux qui me rend comme une personne hystérique. Ma solitude et mon esprit toujours en l'air, et peut-être, je crois, une crise particulière de mon tempérament, me font vouloir et ne pas vouloị et me faire des monstres des choses les plus simples...

“... C"est l'instable qui est le fixe. C'est sur l'incertain qu'il faut baser. Il en résulte qu'à cause de la brièveté des moments où nous pourons jouir du repos ou d'un certain état de plaisir, nous sommes dans l'appréhension continuelle de l'état prochain qui nous menace et du 
fardeau cu'il nous faudra reprendre. Voilà la grande supériorité dés animaux sur nous, et qui égalise un peu la balance en leur faveur. Dans la répartition des biens et des maux attachés à leur condition et à la nôtre, la nature leur a accordé le don de jouir plus pleinement de l'instant favorable et leur cache mieux en même temps les côtés menaçants de la vie mortelle. Cela explique parfaitement le côté philosophique de l'ivrognerie, sans parler du plaisir que vous cause, en passant dans la gargamelle, le liquicle bienfaisant qui doit un peu plus tard endormir les soucis et ôter les épines dont se rembourre l'oreiller de la vertu comme celui du remords... " ... Il faut prendre au vol le bonheur passager que comporte encore la vie à notre âge. Je me regarde comme le mouton enfermé dans une bergerie qu'on laisse brouter çà et là quelque maigre provende jusqu'à ce qu'une grande main vienne l'emporter et le faire disparaître. Je jouis donc de ces petits revenants-bons en attendant le moment de tout quitter. Quelquefois, je me demande s'il est réellement possible de jouir de ce dont on entrevoit la fin prochaine. Enfin 
c'est la vie... La vie ne va que par soubresauts, et prescque toujours ce sont des chagrins...

“... Vous me demandez où est le bonheur dans ce monde. Après de nombrcuses expériences; je me suis convaincu qu'il n'est que dans le contentement de soi-même. Les passions ne peuvent donner ce contentement; nous désirons toujours l'impossible, ce que nous obtenons ne nous satisfait pas. Je suppose que les gens qui ont une solide vertu doivent posséder une grande partie de ce contentement dont je fais la condition du bonheur. ")

Pour en finir avec cette éclosion de papillons noirs, voici les tristes réflexions que suggère à Delacroix le sort si envié et si peu connu des artistes, même de ceux dont les succès furent éclatants. Que penser de celui des autres? C'est une note extraite du cahier manuscrit :

“ ... L'histoire de notre temps présente de tristes exemples de la vie malheureuse des artistes. Voyez Gros, qui avait acquis tout ce qu'il voulait et qui est allé mourir dans une mare; Léopold Robert, qu'on adorait et qui s'est coupé la gorge. Ceux qui ne s'abandonnent point eux- 
mêmes, comme Gros et Robert, sont abandonnés du public, qui ne veut pas absolument les voir longtemps sur la scène. L'oubli ou l'indifférence commence pour nous dès ce monde. Prudhon, qui a plu difficilement à une partie du public qui ne lui pardonnait peut-être que grâce à une certaine afféterie qui est le côté faible de son talent, Prudhon, qui n'a jamais été accepté par les artistes de son temps, est mort définitivement assez misérable et peu regretté. Le fameux Greuze, cet homme dont la vogue avait été immense, et avec juste raison, est mort littéralement dans la misère et a été mis dans la fosse commune. Nous voyons, au milieu de nous, Vernet, qui a lassé la fortune et la réputation à force de succès pendant plus de trente ans, promener sa mauvaise humeur de l'Algérie à la Russie et vivre sombre et chagrin, lui qui était l'homme heureux par excellence. On ne pense plus à lui; ses meilleurs amis ne voient plus que les défauts de ses ouvrages. On ne lui tient aucun compte de ses admirables facultés...

“Que notre raie, bien faite au milieu du front, trace un sillon bien blanc dans une che- 
velure bien noire; que nos mains, soignées, soient recouvertes de gants frais; que l'atelier, garni de bibelots, suffise à distraire le regard d'une femme du monde; surtout que le veston soit de velours; et tout ira bien. Avec ça, pas de mauvaise peinture, pas de critique agaçante et désagréable, la vie est un enchantement, et, au bout, pas de fosse commune. ")

Les exemples sont bien choisis, mais cela n'est pas encourageant. "Ceux qui ne s'abandonnent point eux-mêmes sont abandonnés du public. » Lamentable vérité dont se sont malheureusement pénétrés les artistes nés à notre époque scientifique, positive et sceptique. Rester inébranlable dans ses convictions, c'est aujourd'hui faire œuvre de stupide entêtement, en peinture comme en toute autre chose. Sacrifier sa vie à une idée, c'est risquer le cabanon de Sainte-Anne. Aussi, avec quelle grâce se font les évolutions, avec quelle délicatesse d'olfactif on flaire le vent, et quelle merveilleuse faculté intuitive on développe dès l'enfance pour deviner le goût du public, le suivre dans ses transformations incessantes, se plier à toutes ses fantaisies et abdiquer 
entre ses mains, sans honte et le sourire aux lèvres, toute personnalité! On ne voit plus d'artistes se noyer dans des mares. Foin de ces désespoirs ridicules et de ce vieux jeu des Romains de la grande époque! Ces suicidés gênants sont des gens cu'il faut oublier au plus vite.

Voilà, ce nous semble, un nombre de citations variées suffisant pour permettré d'affirmer le caractère inquiet, tourmenté, souffrant de Delacroix. Ses irritations, ses lassitudes, ses im- . patiences, ses soucis, on en rencontre la trace à chaque pas dans sa correspondance et dans les récits que nous ont laissés ses amis. Le grand homme, comme on voit, est ligoté dans la terrible robe de Nessus. Le sang empoisonné du centaure s'est g'lissé dans ses veines. Il lui faut renoncer au calme, à la sérénité. Toutes ses joies seront viciées par la crainte et le doute. Ses plaisirs sont troublés; il n'a jamais de satisfaction pure. Son cocur, sans envie, déborde de mélancolie. Il ne s'assoit jamais bien aise et sans souci dans le confortable de la vie et dans la placide quiétude d'une âme satisfaite. 
Son objectif est si haut qu’il désespère toujours de l'atteindre. Il se sent une vaste envergure pourtant et donne parfois d'orgueilleux coups d'ailes vers l'empyrée; mais les cimes semblent s'élever toujours au fur et à mesure que son vol grandit, et plus il monte, plus le doute s'accentue, plus le repos fuit. Qu'on songe à ce que devait avoir d'écœurant et de découragreant cette critique amère et ignorante, cette critique " choquante, même dans la louange », (qui ne cesise de harceler l'artiste du commencement jusqu'à la fin de sa magnifique carrière. Qu'on juge de quelle influence irritante elle dut agir sur ses nerfs malades, et combien ce grand génie, àbsolument exempt de sotte vanité, souffrit des incertitudes, des perplexités, des appréhensions que jetaient dans son esprit sincère, fougueux parfois jusqu'au désordre, ces réticences, ces méprises voulues, ces railleries impitoyables, ces dénis de justice accablants, odieux, qui, dans la solitude d'une vie concentrée, deviennent des rongeurs misérables, néfastes et morbifiques, qui déchiquètent l'âme et perforent le cour. La conscience du vrai, 
l'intuition du génie sont heureusement des rocs contre lesquels se brisent les vilenies, les bassesses, les sottises et les molestations; mais il est malgré cela des heures de défaillance, où le flot noir du dégoût monte jusqu’à la lèvre, où les ressorts se détendent, où la prostration vient, où toute énergie disparait, où la confiance en soi s'évanouit; heures terribles, pendant lesquelles une brume opaque voile le phare et où les plus vaillants, se sentant hors de combat, se disent : A quoi bon? Plus qu'aucun autre artiste, Delacroix subit les tortures de ces durs et lugubres moments d'abandon. On peut dire qu'ils remplirent les trois quarts de son existence.

A ces malaises, à ces impatiences, à ces lassitudes, à ces vexations, à ces chagrins, pain quotidien de l'artiste, il y eut pourtant quelques répits; ce furent les deux voyages qu'il fit, fort courts tous les deux, mais, qui, l'un et l'autre, lui laissèrent de vives et salutaires impressions. 


\section{Voyage en Angleterre.}

" L’idée d'un voyage en Angleterre, qu'il accomplit en 1825, dit M. Piron, paraît avoir pris naissance au commencement de la même année. Bonnington était à Paris, et Delacroix disait que c'était " un fameux garçon ". Thalès Fielding partait et formait le projet de l'aller voir à Londres. Les portraits de Lawrence et les paysages de Constable étaient bien faits pour agir sur l'imagination du jeune peintre que la nouveauté n'effrayait pas. Il y avait en Angleterre un art nouveau à étudier. Bonnington, Isabey, Colin et Delacroix réunirent chacun les ressources dont il pouvait disposer, et ils partirent pour Londres presque en même temps. C'était au mois de juin 1825. Ce voyage fut très intéressant. La vue de Constable, et de Lawrence surtout, impressionna vivement Delacroix, modifia sa manière, et le Massacre de Scio, qui parut à la fin de 1825, fut la première manifestation de ses nouveaux procédés de peinture. En 
ce qui touche à ses impressions générales, elles sont contenues dans ses lettres.

“ Mes premiers pas en Angleterre ne m'ont point charmé..... J'étais d'une impatience extrême d'entrer dans ce port; à peine ai-je été débarqué, que je ne me suis pas senti beaucoup de goût pour tout ce que je voyais, et cette impression dure encore. Surtout en arrivant à Londres, mon idée constante était que je me trouverais bien malheureux d'ètre obligé d'y rester éternellement. Je suis pourtant d'un naturel assez cosmopolite. Mais je ne doute pas que ce que j'ai trouvé de choquant ne vienne de mon manque d'habitude des usages....

“ ... L'immensité de cette ville ne se conçoit pas: les ponts sur la rivière sont à perte de vue les uns des autres. Ce qui m'a le plus choqué, c'est l'absence de tout ce que nous appelons architecture, préjugé ou non, cela me déplaît. Et puis, ils ont une rue de Waterloo qui est un tas de palais d'opéra, à la suite l'un de l'autre..... Mais les belles boutiques! Le luxe extrême! Le soleil est encore d'une nature particulière. (V'est continuellement un jour d'éclipse..... Le 
6 juin, Delacroix écrit de Londres, à Soulier : "Je suis enfin dans ce pays qui est presque tien, et où je regrette beaucoup de ne pas t'avoir auprès de moi. Il est impossible d'être mieux accueilli et avec une politesse plus noble que par les personnes auxquelles je me suis recommandé. Cette ville est superbe et fort différente de la nôtre en beaucoup de points. Mais en définitive, cela revient toujours au même, et je crois, à présent, n’avoir pas changé de place. Je me suis cruellement ennuyé pendant les premiers jours; j'ai été sur le point de repartir sans cérémonie. Cela vient de ce que je ne faisais que voir de côté et d'autre, sans autre fruit que me fatiguer. Je suis très flâneur, à la vérité, mais pas badaud, de la manière que je vais dire; je me soucie peu de voir à Londres une foule de choses fort curieuses, sans doute, mais qui ne sont pas de ma compétence; et il y en a tant de cette espèce que je n'ai jamais clésiré voir à Paris, que je ne veux pas commencer ici. Je te dirai même que toutes ces galeries éternelles de tableaux se ressemblent furieusement, et qui en connait une, sait les autres. 
“ L'aspect premier de leur peinture ne m’a pas fait plaisir. Je m’y fais à présent. Je ne m’étonne pas de l'impression défavorable qu'en rapportent ceux qui n’ont pas là-dessus les idées que nous avons. L'imitation des vieux maîtres a ses inconvénients comme toutes choses.

"Il se forme une société de grands personnages qui, sous la protection du gouvernement, encourage les grands tableaux. Je crains, dans cette mesure, la perte de l'école anglaise. Ils ont des peintres admirables dans les proportions moyennes. L'envie de briller davantage les ôtera de la route qu'ils suivent. Ils feront de grands tableaux, qui ne seront plus à la portée des particuliers.

“Cette société a acheté une grande croûte de M. Hilton, moyennant 2う,000 francs. C'est une réminiscence maladroite de tout ce que les maîtres ont fait. En revanche, il y a des peintures de genre très belles. J'ai été chez M. Wilkie, et je ne l'apprécie que depuis ce moment. Ses tableaux achevés m'avaient déplu, et, dans le fait, ses ébauches et ses esquisses sont au-dessus de tous les éloges. 
"Comme tous les peintres de tous les âges et de tous les pays, il gâte régulièrement ce qu'il fait de beau. Mais il y a à se contenter dans cette contre-épreuve de ses belles choses.

“Les chevaux, les voitures, les trottoirs, les parcs, la Tamise, les batcaux de la Tamise, les bords de la Tamise, Richmond et Greenwich, tout cela demanderait des volumes de lettres...

“.... J'aime mieux notre pays, et, loin de chercher à affecter de la conformité avec les façons anglaises, je me plais à me faire voir tout en Français. Les Anglais ne sont pas chez eux ce qu'ils sont chez les autres, et tous les hommes sont les mêmes. Ils sont bien plus prévenants, bien plus empressés à savoir votre opinion sur leur pays, et par revanche, je me sens un peu cc qu'ils sont chez nous: fort disposé à relever la France et à leurs dépens, ce que nous ne faisons jamais vis-à-vis d'eux, quand nous sommes dans nos foyers. "

Delacroix s'est sans doute laissé prendre à quelque banalité hospitalière, car ce jugement est en désaccord complet avec la vérité des faits. Il n'y a pas de peuple au monde, qui, vis-à-vis 
des étrangers, fasse meilleur marché que nous des. qualités spéciales de la France, et ne soit plus disposé à exalter celles des autres pays. Delacroix, du reste, ne paraît pas avoir eu affaire uniquement à des gens remplis d'une si extraordinaire bienveillance pour ceux de sa nation, car dans une lettre suivante, il dit:

“Je romps des lances pour la France, contre tous les Anglais possibles. »

Voici, à quelques jours de date, deux attitudes bien différentes et bien contradictoires.

" ..... J'ai vu chez Wilkie une esquisse de Knox le puritain, prêchant devant Marie Stuart. Je ne peux t'exprimer combien c'est beau, mais je crains qu'il ne la gâte. C'est une manie fatale. »)

Il fit quelques excursions dans le Cornwal et en Essex avec l'un de ses hôtes. Mais c'est à Londres surtout qu'il étudia les Anglais, leurs artistes, leur peinture et leur théâtre. Ses impressions sont très variables; il passe facilement, sur les hommes et sur les choses, d'un extrême à l'autre, sauf cependant sur la peinture et les artistes. “Fielding est le meilleur enfant 
possible. Cowpley (son frère) est un homme qu'on ne voit pas et peu dans ma nature. Le soleil n'est pas la partie la plus brillante de l'Angleterre.... J'ai été chez Lawrence avec quelqu'un qui était assez recommandé auprès de lui, pour qu'il fût pour nous d'une grande complaisance. C'est la fleur de la politesse et un véritable peintre de grands seigneurs. J'ai vu chez lui de très beaux dessins de grands maîtres et des peintures de lui, ébauches, dessins même, admirables. On n'a jamais fait les yeux, des femmes surtout, comme Lawrence, et ces bouches entr'ouvertes d'un charme parfait. Il est inimitable.....

" J'ai vu ici une pièce de Faust, qui est la plus diabolique qu'on puisse imaginer. Le Méphistophélès est un chef-d'œuvre de caricature et d'intelligence. C'est le Faust de Grothe, mais arrangé... J'ai vu le Freischutz sur deux théâtres différents, avec de la musique qu'on a supprimée à Paris. Il y a des choses fort singulières dans la scène de la fonte des balles. Ils entendent mieux que nous l'effet dans le théâtre, et leurs décorations, qui ne sont pas exécutées avec 
autant de soin, font mieur ressortir les personnages.....

“ J'ai vu Richard III, joué par Kean, qui est un très grand acteur, quoi qu'en dise l'ami Duponchel..... J'ai vu aussi Othello par lui....

“Les expressions d'admiration manquent pour le génie de Shakespeare, qui a inventé Othello et Yago..... A l'exception des pièces de Shakespeare, je n'ai rien vu sur leurs théâtres, qui ne fût des imitations plus ou moins maladroites de ce qu'on a en France. »

$\mathrm{Au} 27$ juin, Delacroix, qui est à Londres, écrit :

“ Plus j'y reste, et plus je voudrais y rester. " $\mathrm{Au} 1^{\text {er }}$ août, ce n'est plus la même chose. Il attend avec impatience le moment de rejoindre ses amis et il écrit à Pierret:

" Il y a décidément quelque chose de triste et de roide dans tout ici, qui ne cadre pas avec tout ce qui est en France. La propreté des maisons et de quelques rues est compensée par la saleté cles autres. Les femmes sont toutes mal tenues, avec des bas sales et des souliers mal faits. Ce qui me frappe le plus, c'est une mes- 
quinerie générale, qui fait qu'on se croit dans un pays de gens plus petits et plus rétrécis que chez nous. Je commence à croire qu'on y est, s'il est possible, plus commère et plus ganache... Je ne sais par quel caprice la nature a fait naître Shakespeare dans ce pays-ci. C'est lui, assurément, qui est le père de leurs arts, et on est tout surpris du désordre méthodique qu'ils y apportent. "

Plus loin il dit : "Il y a dans le sang de ce peuple quelque chose de sauvage et de féroce qui perce horriblement dans la canaille, qui est hideuse. " Et voici la conclusion, l'impression dernière et résumée dans une lettre à Pierret, datée du 12 août : “... Du reste, l’Angleterre me semble peu amusante. Il n'y aurait qu'un motif bien puissant, comme, par exemple, d'y faire des affaires, qui pût m'y retenir. J'ai vu seulement, dans mon séjour, la possibilité de travailler fructueusement un jour dans ce pays regorgeant d'or. - Je serai à Paris vers la fin du mois. J'ai trouvé ta lettre, hier, en rentrant rongé de mélancolie... »

Ce voyage en Angleterre eut une grande 
influence sur Delacroix et sur son talent. J'imagine que c'est Kean qui lui fit comprendre Shakespeare et que le souvenir de ses impressions anglaises le porta à interpréter l'œurre de Gœthe d'abord et celle du grand tragique anglais par la suite. En effet, les clix-sept planches du Faust dans lesquelles, dit Gothe, " il surpassa les tableaux que je m'étais faits des scènes écrites par moi-même ", ont été exécutées au cours des années 1826 et 1827, c'est-àdire immédiatement après le retour de Londres, et je crois trouver dans l'Hamlet, qui ne vit le jour qu'en 1843, une allure spéciale, une sorte d'élégance un peu guindée qui doit être le reflet lointain du remarquable acteur dont le talent avait si vivement impressionné Delacroix. 


\section{Voyage au Maroc.}

A la fin de 1831, Delacroix écrivait à II. Villot . “... Je suis en train de courir pour un assez grand projet. Je serai probablement parti pour le Maroc la semaine prochaine. Ne riez pas trop, c'est très vrai. Je suis donc très ahuri... m

Que s'était-il passé ? Rien que de très naturel. M. le comte de Mornay, pour lequel Delacroix avait une grande sympathie, renait d'être nommé ambassadeur de France auprès de l'empereur du Maroc, et il avait décidé Delacroix à l'accompagner. L 11 janvier 1832, les voyageurs partaient de Toulon sur un navire à voile et, le 24, Delacroix écrivait à Pierret : “ ... Enfin, nous voici devant Tanger! Après treize jours fort longss et d'une traversée tantôt amusante, tantôt fatigante, et après avoir éprouvé quelques jours de mal de mer, ce à quoi je ne m'attendais pas, nous avons essuyé des calmes désespérants et puis des bourrasques assez effrayantes, à en juger par la figure du com- 
mandant de la Perle. En revariche, des côtes charmantes à voir, Minorque, Majorque, Malaga, les côtes du royaume de Grenade, Gibraltar et Algésiras. Nous avons relâché dans ce dernier endroit. J'espérais clébarquer à Gibraltar, qui est à deux pas, et à Algésiras par la même occasion; mais l'inflexible quarantaine s'y est opposée. J'ai pourtant touché le sol andalou avec les gens qu'on avait envoyés à la provision. J'ai vu les graves Espagnols en costume à la Figaro nous entourer à portée de pistolet de peur de la contagion (le choléra sévissait cruellement en France à ce moment), et nous jeter des navets, des salades, des poules et prendre, du reste, sans le passer dans le vinaigre, l'argent que nous déposions sur le sable de la rive. Ç’a été une des sensations de plaisir les plus vives que celle de me trouver, sortant de France, transporté, sans avoir touché terre ailleurs, dans ce pays pittoresque; de voir leurs maisons, ces manteaux que portent les plus grands gueux et jusqu'aux enfants des mendiants, etc.; tout Goya palpitait autour de moi. Ç'a été pour peu de temps. Repartant de là hier matin, nous 
comptions être à Tanger hier soir, mais le vent, qui était d'abord insuffisant, s'est élevé si fort sur le soir que nous avons été obligés de franchir entièrement le détroit et d'entrer malgré nous dans l'Océan. Nous avons passé une très mauvaise nuit; mais la chance ayant tourné sur le matin, nous avons pu revenir sur nos pas, et ce matin, à neuf heures, nous avons jeté l'ancre devant Tanger. J'ai joui avec bien du plaisir de l'aspect de cette ville africaine. Ç'a été bien autre chose quand, après les signaux d'usage, le consul est arrivé à bord dans un canot qui était monté par une vingtaine de marabouts noirs, jaunes, verts, qui se sont mis à grimper comme des chats dans tout le bâtiment et ont osé se mêler à nous. Je ne pouvais détacher mes yeux de ces singuliers visiteurs. 'Tu juges, cher et bon, de mon plaisir de voir pour la première fois chez eux ces gens que je viens chercher de si loin ; car c'est bien loin, cher ami, et j'ai plus d'une fois, dans les planches de ma prison flottante et durant des nuits assommantes de roulis et de mauvaise mer, songé à mon nid paisible et aux figures que j'aime depuis que j'aime. Si 
c'était à refaire je referais ce voyage, mais l'absence a bien des chagrins.

“ Nous devons faire demain notre entrée magnifique. Nous serons reçus par les consuls des autres puissances, par le pacha, etc... »

Ce voyage dura six mois. On peut juger du nombre, de la variété et de l'intensité des impressions qu'un pareil pays devait produire sur un tel esprit. Delacroix avait projeté d'écrire une relation complète de ce voyage, il ne l'a pas fait et s'est borné à transmettre à ses amis un trop court résumé de ses notes : c'est grand dommage.

«.... Je suis tout étourdi de tout ce que j’ai vu.... Il faudrait avoir vingt bras et quarante-huit heures pour donner une idée de tout cela. Les Juives sont admirables. Je crains bien qu'il ne soit difficile d'en faire autre chose que de les peindre : ce sont des perles d'Eden... Je suis en ce moment comme un homme qui rêve et qui voit des choses qu'il craint pouvoir lui échapper... Au milieu de cette nature vigoureuse j'éprouve des sensations pareilles à celles que j'avais dans l'enfance; peut-être que le 
souvenir confus du soleil du midi, que j'ai vu clans ma première jeunesse, se réveille en moi. Tout ce que je pourrai faire ne sera que bien peu de chose en comparaison de ce qu'il y a à faire ici; quelquefois les bras me tombent et je suis certain de n'en rapporter qu'une ombre. ')

Voici le récit d'une scène qui émut si fortement Delacroix qu'on en trouve des traces dans la plupart de ses compositions où figurent des chevaux : " ... Deux de ces chevaux ont pris dispute, et j'ai vu la bataille la plus acharnée qu'on puisse imaginer; tout ce que Gros et Rubens ont inventé de furies n'est que peu de chose auprès. Après s'être mordus de toutes les manières en se grimpant l'un sur l'autre et en marchant sur les pieds de derrière comme des hommes, après s'être, bien entendu, débarrassés de leurs cavaliers, ils ont été se jeter dans une petite rivière dans laquelle le combat a continué avec une fureur inouïe. Il a fallu des peines de diable pour les tirer de là... »

Le fragment de lettre qui suit prouve combien Delacroix augurait mal du bénéfice qu'il pourrait ultérieurement tirer de son voyage en 
Afrique et à quel point il comptait peu profiter des documents qu'il récoltait.

“..... J'emploie avec plaisir une part de mon temps au travail, une autre considérable à me laisser vivre..... Je suis sûr que la quantité assez notable de renseignements que je rapporterai d'ici ne me servira que médiocrement. Loin du pays où je les trouve, ce sera comme des arbres arrachés de leur sol natal; mon esprit oubliera ces impressions et je dédaignerai de rendre imparfaitement et froidement le sublime vivant et frappant qui court ici dans les rues et qui vous assassine de la réalité. Imaginez, mon ami, ce que c'est que de voir couchés au soleil, se promenant dans les rues, raccommodant ses savates, des personnages consulaires, des Catons, des Brutus, auxquels il ne manque même pas l'air dédaigneux que devaient avoir les maîtres du monde; ces gens-ci ne possèdent qu'une couverture dans laquelle ils marchent, dorment et sont enterrés, et ils ont l'air aussi satisfait que Cicéron devait l'être de sa chaise curule. Je te le dis, vous ne pourrez jamais croire à ce que je rapporterai, parce que ce sera bien loin de la 
vérité et de la noblesse de ces natures. L’antique n'a rien de plus beau. »

A M. Villot : “..... C'est un lieu tout pour les peintres. Les économistes et les saint-simoniens auraient fort à critiquer sous le rapport des droits de l'homme et de l'égalité devant la loi, mais le beau y abonde, non pas le beau si vanté des tableaux à la mode. Les héros de David et compagnie feraient une triste figure avec leurs membres couleur de rose auprès de ces fils du soleil; mais en revanche le costume antique y est micux porté, je m'en flatte. Si vous avez quclques mois à perdre, quelques jours, venez en Barbarie, vous y verrez le naturel qui est toujours déguisé dans nos contrées, vous y sentirez de plus la précicuse et rare influence du soleil qui donne à toute chose une vie pénétrante. Je rapporterai sans doute des dessins, mais cela ne donnera pas la meilleure partie de l'impression que tout ceci procure. "

Il en rapporta des montagnes de dessins et de croquis. Malgré les difficultés de travail qu'il rencontra " à cause qu'il était impossible de dessiner ostensiblement d'après nature même 
une masure », malgré le temps perdu dans l'excursion à Mequinez ou Meknez où l'empereur du Maroc recevait M. de Mornay, il bonda ses cartons de petits chefs-d'œuvre. Les Femmes mauresques, la Noce juive, les Convulsionnaires de Tanger, ces admirables et impérissables tableaux, brillants comme des escarboucles, remplis de soleil et de couleur locale, empreints d'un sentiment si délicat, si vrai, du milieu, des mœurs, des attitudes orientales, furent le résultat de cette excursion qui ne devait rien produire! et que le peintre considérait comme une simple promenade d'amateur. Avec cette étonnante faculté d'assimilation qui est le propre du génie, Delacroix s'était en quelques mois imbu du caractère et des effets de l'Orient. Les œuvres qui plus tard naquirent de ces impressions semblent avoir été faites sur place.

Ce voyage marque le véritable point de départ de la réputation de Delacroix. Le Salon de 1833, où il exposa ses trois toiles, lui valut un vrai succès. C'est à partir de ce moment qu'il compte des admirateurs passionnés, qu'il devient 
chef d'école et que la fortune commence à lui sourire un peu. En 1833 il est hors d'affaire, sa vie matérielle est assurée : il peut enfin rêver, travailler et produire en suivant l'impulsion pleine de son talent, sans se sentir troublé par l'approche du terme. 
Voyage en Belgique. - Il ne voit pas l'Italie.

En 1838, Delacroix sortit de France pour la troisième et dernière fois. Il visita la Belgique et la Hollande. Le voyage fut court et cette brièveté nous prive de ses impressions directes. Il n'eut pas le temps d'écrire. M. Burty n'a recueilli qu'une lettre insignifiante adresséc de La Haye à Pierret, laquelle n'est qu'un simple souvenir d'ami, gros de promesses, mais vide de récits. Nous avons déjà vu quelle fut la nature de l'émotion qu'il ressentit au contact des maîtres, et en particulier de Rembrandt, de Rubens et d'Holbein, nous n'y reviendrons pas.

Chose étrange, Delacroix ne vit pas l'Italie!

Il n'avait pas vingt ans que déjà il projetait d'y faire un long séjour et ce projet était tellement arrêté dans son esprit, son exécution paraissait à tel point prochaine que l'amitié, ce sentiment si vif chez lui, souffrait déjà et par avance d'une séparation imminente. Il écrit en effet à Guillemardet, en 1818 : “... Je ne puis, en -vérité, penser sans un serrement de cœur 
aux longues années que je passerai en Italie, loin de vous et loin de tous ceux qui peuvent s'intéresser à moi..... »

Trois ans après, fin janvier 1821, il écrit à Soulier : “Vous n'avez pas froid, vous, vous pouvez écrire à vos amis sans la goutte au bout du nez, et sans vous morfondre les doigts. On est chaudement à Florence. On y voit un beau soleil, un ciel d'azur, une nature vigoureuse, de belles femmes. Oh! Dieu! de ces têtes qui n'ont jamais paru dans nos climats... Ah! j'irai quelque jour savourer la paresse sous un ciel encore plus pur que le vôtre. J'irai le soir respirer le frais de la mer de Naples et m'en donner le jour à l'ombre des orangers. J'irai à Rome vivre avec les morts et oublier tout ce qui ne sera pas peinture et amitié. Je réaliserai peut-être tous mes rêves brillants. Hélas! je suis bien triste en ce moment, le temps est si gris et l'air si glacé? Jouissez bien de votre Italie. »)

Huit jours plus tard, toujours à. Soulier : “.... Cher ami, tu regrettes Paris; moi, je regrette toi et la Toscane que je ne connais pas. " 
Et à M. Rivet : «... En attendant les mois se passent et je ne vous vois point et je ne vois point Venise que nous aimons tant, ni Rome, ni tant d'autres bonnes choses. J'avais bien pour cette année le projet de vous surprendre en y allant dans cette Italie qui semble chaque année reculer devant moi par cette suite des entraves perpétuelles qui nous enchaînent, nous autres gens indépendants..... »

Deux mois plus tard, il remercie Soulier d'un dessin envoyé d'Italie; et dans cette lettre se trahit, en même temps qu'un vif désir de voir la patrie de Michel-Ange, une hésitation de très mauvais augure pour l'accomplissement d'un projet formé pourtant depuis longtemps : “... Je ne sais par quel instinct tu m'as destiné le dessin qui me plait le plus dans tout l'envoi. Pourquoi, traître, ne l'as-tu pas achevé? C'est ce que tu as fait de mieux. Je ne peux pas te rendre le plaisir qu'il me fait tous les jours. Lui seul serait capable de me faire aller en Italie. Dieu, quel pays! Comment, vous avez des ciels comme cela? Je ne plaisante pas, ce diable de dessin m'avait tourné la tête, 
et j'avais déjà fait une foule de plans superbes pour aller manger mon petit revenu dans la Toscane, auprès, de toi, mon cher ami. Mais ne parlons pas de tout cela. Je n'aurai jamais la force de prendre une résolution, et je pourrirai toute ma vie où le ciel m'a jeté en commençant..... )

Puis, à quelques jours de là : “ ... Oui, bon ami, j'entrevois enfin sûrement une chose certaine, mon voyage très prochain en Italie. Cette idée me travaille continuellement. Je ne demande au ciel qu'une chose, c'est d'avoir le bonheur de t'y posséder longtemps à mon tour... » Que s'était-il donc passé? Je l’ignore, mais il est probable que Delacroix comptait sur un succès de Salon pour se procurer des ressources suffisantes à l'accomplissement de son projet qu'il désirait en réalité ardemment pouvoir réaliser, ainsi qu'en témoigne ce fragment d'une autre lettre de la même époque: " ... Je suis pris trois ou quatre fois par mois d'une envie d'émigrer en Italie. J'ai renoncé à courir la chance du prix de l'Académie. Comme je ne désire pas aller à Rome pour 
y manger et y loger dans un palais, je saurais aussi m'y contenter de peu comme je fais ici. »

Enfin en mai 1828 : “ ... Heureux ami, écrit-il à M. Rivet, qui voyez tous les jours, peut-être avec indifférence, toutes les belles choses auxquelles je rêve depuis quinze ans, que vous êtes cruel de ne pas plus souvent écrire quelque chose de tout cela! Que votre lettre s'est fait attendre... Si cela ne vous touche pas médiocrement, qu'importe ? Suive'z toujours ce que vous sentez. Si vous ne peignez pas, écrivez. J'ai assez des impressions de toute la bande voyageuse et écrivante qui me gâte l'Italie depuis que je m'occupe d'elle... »

Ainsi donc il rêve depuis dix ans de voir l'Italie, ses aspirations dans ce sens sont incessantes, ses amis l'ont vue et il ne la verra pas! C'est que, dit M. Piron, sa vie a été un combat et qu'il n'a jamais trouvé le loisir de se reposer. Faut-il le regretter? Nous ne le croyons pas pour notre part. Delacroix ne pouvait guère s'élever plus haut qu'il ne l'a fait. Et qui sait si le commerce des maitres italiens n'eût pas eu sur lui assez d'influence pour mo- 
difier sa manière et lui enlever en partie la qualité capitale de son talent, l'originalité à outrance; qui sait si Michel-Ange et Raphael, qu'il aimait tant, n'eussent pas mangé Delacroix comme ils en ont mangé tant d'autres, devenus timides et incertains en présence des maitres inimitables qu'on est sans cesse tenté d'imiter quand une fois on s'est mis avec eux en intime communion? Cette lacune dans sa vie ne nous inspire aucun regret. 


\section{Son opinion sur lui-même.}

Nous avons montré Delacroix, ou plutôt Delacroix s'est montré lui-même, sous ses différents aspects individuels. Nous connaissons les divers incidents de sa vie, du reste peu accidentée. Il nous a montré ses tendances, ses qualités, ses défauts mêmes. Sa critique de certains maîtres, ses considérations générales sur l'art, ses réflexions esthétiques ou philosophiques suffisent pour donner une idée assez complète de l'homme en ce qui touche toutes choses étrangères à ses propres œuvres plastiques. Voyons maintenant comment il se juge lui-même, après avoir jugé les autres.

Dans une lettre datée du 15 avril 1821 , Delacroix a déjà écrit à Soulier : “Je sors d'un travail de chien, qui me prend tous mes instants depuis deux mois et demi. J'ai fait dans cet espace de temps un tableau assez considérable qui va figurer au Salon. Je tenais beaucoup à m'y voir cette année et c'est un coup de fortune que je tente. Si on y fait quelque peu d'atten- 
tion, ce sera un motif de plus pour spronar mi à t'aller joindre le plus tôt possible. " Il s'agit ici de Dante et Virgile, qui valut à Delacroix un éclatant succès. Il avait donc bien fait de tenter un coup de fortune. Ses espérances ne furent pas trompées. En 1828, les choses ne se passèrent pas aussi bien, ainsi que le prouve la lettre suivante, également écrite à Soulier : “... J'ai effectivement fini mon massacre $n^{0} 2$, mais j'ai eu à subir des tribulations assez nombreuses de MM. les très ânes membres du jury. J'en aurais long à te dire sur ce chapitre.

" Je continue ma lettre à deux jours d'intervalle. C'est ce matin qu'on a rouvert le Salon. Ma croûte est placée le mieux du monde. De sorte que, succès ou non succès, ce sera à moi qu'il faudra m'en prendre. J'ai éprouvé en arrivant là devant un effet abominable, et je ne souhaite pas que l'excellent public ait mes yeux pour juger mon chef-d'œuvre. C'est malheureux que je tombe à t'écrire un jour où je suis aussi vexé. Mais ce sera pour toi la peine de m'avoir écrit si peu de chose.

"Quel exécrable métier que faire consister 
son bonheur dans des choses de pur amourpropre! Voilà six mois de travail qui aboutissent à me faire passer la plus foutue des journées. Du reste, je suis habitué à ces choses-là et ne t'alarme pas trop pour l'amour de moi. C'est peut-être, c'est probablement comme toutes les autres fois, oủ le premier aspect de ma sacrée pcinture accrochée à côté de celles des autres me jugule entièrement. Cela me fait l'effet d'une première représentation où tout le monde sifflerait... " Et plus loin : “... Je suis ennuyé de tout ce Salon. Ils finiront par me persuader que j’ai fait un víritable fiasco. Cependant je n'en suis pas tout à fait convaincu. Les uns disent que c'est unc chute complète; que la Mort de Sardanapale est celle des romantiques, puisque romantiques il y a; les autres, comme ça, que je suis un inganno, mais qu'ils aimeraient mieux se tromper ainsi que d'avoir raison comme mille autres qui ont raison si on veut et qui sont damnables au nom de l'âme et de l'imagination. Donc je dis que ce sont tous des imbéciles, que ce tableau a des qualités et des défauts, et que, s'il y a des choses que j'admi- 
rerais mieux, il y en a pas mal d'autres que je m'estime heureux d'avoir faites et que je leur souhaite. Le Globe, c'est-à-dire M. Vitet, dit que quand un soldat imprudent tire sur ses amis comme sur ses ennemis, il faut le mettre hors les rangs. Il engage ce qu'il appelle la jeune école à renoncer à toute alliance avec une per.fide dépendance. Tant il y a que ceux qui me valent et vivent de ma substance crieraient haro plus fort que les autres. Tout cela fait pitié et ne mérite pas qu'on s'y arrête un moment, parce que cela va droit à compromettre les intérêts tout matériels, c'est-à-dire the eash (l'argent). ”

A M. Rivet : “...Que je voudrais m'admirer un peu moi-même; mais, le croiriez-vous? je doute plus que jamais de mon infaillibilité, et pourtant je ne suis pas découragé... »

“ Il n'était pas content de lui lorsqu'il s'examinait, dit M. Lassalle-Borde, mais lorsqu'il se comparait, c'était différent... »

Par l'ensemble de ce qu'a écrit Delacroix, il est assez difficile de déterminer exactement ce qu'il pensait de lui. A-t-il jamais joui de cette confiance particulière en soi qui est une 
qualité commune aux hommes de geénie et aux sots? Rien ne tend à le prouver, qu'un passage extrait du cahier manuscrit et qui, malgré l'affirmation qu'il contient, ne me paraît pas être l'expression de l'état ordinaire de son esprit. Parlant de certaines difficultés, il dit : “ ...Je me suis tiré de tout cela avec une très grande modération dans mes désirs et par une extrême confiance en moi-même : confiance qui est le talisman de la jeunesse et que l'âge tend à affaiblir. Je n'entends pas par cette confiance une aveugle présomption, qui est le ridicule de quelques talents, même estimables; je n'ai jamais eu une estime exagérée de ce que j'ai fait : j'en ai toujours vu les défauts au delà de ce que pouvaient faire les juges les plus sévères, mais j'étais persuadé que ces gens-là n'y voyaient pas le bien qui y était. » 
Mépris pour la critique.

On a dit que Delacroix méprisait la critique; nous n'en croyons rien.

Il faut un certain temps pour s'habituer aux conseils, pour les accepter avec calme, subir sans colère les procès de tendance et les jugements téméraires. Ce calme, un artiste ne le possède jamais, au début de sa carrière surtout. Ceux qui se maîtrisent et se taisent ne conçoivent pas moins des irritations sourdes contre ceux qui dévoilent publiquement leurs erreurs. Il est infiniment plus facile de croire à l'insuffisance d'un critique qu'à sa propre infériorité; quand on a consacré son temps, ses méditations, ses efforts à l'enfantement d'une œuvre, on la croit toujours bonne. Un artiste qui écouterait sans vain orgueil comme sans fausse humilité les gens qui s'occupent de lui ferait preuve d'une bien grande force et d'une rare sagesse. Delacroix a dû, comme tout autre peintre de race, regimber sous l'éperon; mais il était trop intelligent pour mépriser l'intelligence; 
je n'en veux pour preuve que ses rapports avec les critiques de son temps et le commerce amical qu'il ne cessa d'entretenir avec eux. Les traces qu'il nous en a laissées lui-même démontrent qu'il tenait leurs appréciations en grande estime, ëxtérieurement du moins, et rien ne nous autorise à croire que, dans l'intimité, il affectât pour eux le mépris qu’on veut dire. Si quelqu'un fut injuste pour Delacroix, du reste, c'est le public bien plus que la critique. Celle-ci, dès le début, le porta très haut, par l'organe de M. Thiers, "Aucun tableau, écrivait-il en 1822, ne révèle' mieux, à mon avis, l'avenir d'un grand peintre que celui de M. Delacroix représentant Dante et Virgile aux Enfers. C'est là surtout qu'on peut remarquer ce jet de talent, cet élan de la supériorité naissante qui ranime les espérances un peu découragées par le mérite trop modéré de tout le reste... L'auteur a, outre cette imagination poétique qui est commune au peintre comme à l'écrivain, cette imagination de l'art: qu'on pourrait appeler, en quelque sorte, l'imagination dù dessin, et qui est tout autre que la précédente.: Il jette ses figures, les 
groupe, les plie à volonté arec la hardiesse de Michel-Ange et la fécondité de Rubens : je ne sais quel souvenir des grands artistes me saisit à l'aspect de ce tableau; je retrouve cette puissance sauvage, ardente, mais naturelle qui cède sans efforts à son propre entraînement. ”

Voilà qui est bien dit; mais on conviendra qu'un pareil éloge initial n'était pas fait pour inspirer au maitre l'horreur de la critique. On la lui prête à notre sens très gratuitement. M. Thiers, qui avait si énergiquement lancé Delacroix et dont l'esprit sagace découvrait la trace du génie sous la première de ses toiles, écrivait deux ans après, à propos du Massacre de Scio :

" ... Son talent est ardent et audacieux. Il est dans le premier état de sensibilité où l'on touche le terrible et dans cette première irritation où la haine du calcul fait manquer ¿à la raison; il n'est pas mûr encore, mais son avenir est immense. ”

L'impression produite par cette toile que Delacroix appelle sa croûte et qui lui fit passer une de ses plus foutues journées, ainsi que nous l'avons vu, cette impression fut très grande; là hardiesse des mouvements, la liberté de la 
composition dégagée de toute règle d'école, la couleur surtout, étonnèrent et forcèrent l'éloge des vieux classiques eux-mêmes. Girodet fit à l'auteur ses compliments :

" Il avait remarqué, dit M. Rivet, la douleur poignante de la jeune mère, renversée, moribonde, dont les mains défaillantes ne pouvaient plus retenir son enfant. "Cela est touchant et bien senti, " lui dit-il, mais quand je m'approche, je ne “ retrouve plus le dessin de l'œil ; à peine si je " distingue les paupières. Pourquoi ne terminez" vous pas cet œil si expressif? - Parce que je " ne serais pas sûr de ne pas perdre cette expres" sion qui vous frappe, répondit Delacroix ; et si " pour apercevoir ces défauts vous êtes obligé de " vous approcher, permettez-moi de vous prier de “ rester à distance. " C'était la seule réponse que pouvait faire au peintre précis et guindé qu'était Girodet, le peintre des effets libres et hardis qu'était Delacroix. 'J Je pense, écrit-il, quc c'est à partir du Massacre de Scio que je commençai à devenir pour l'école un objet d'antipathie et une espèce d'épouvantail..... » Pourquoi pas? Il est certain que cette admirable 
toile est un formidable coup de pied donné dans le vieil arsenal vermoulu de l'école des pompiers et de son maitre David; mais si elle valut à son auteur les anathèmes de l'Académie, elle le fit d'emblée chef de l'école moderne, et c'est sur elle et sur sa sœur aînée que Delacroix bâtit sa fortune. En effet, la protection de M. Thiers suivit Delacroix pendant toute sa carrière et lui valut les grands travaux décoratifs qui permirent à son talent de battre son plein. "C'est le seul homme, dit-il, placé pour être utile qui m'ait tendu la main dans ma carrière... C'est lui qui me donna à faire, étant ministre de l'Intérieur, le salon du roi au Palais-Bourbon. Il le fit malgré les avis charitables de mes ennemis, ct même de mes amis, qui lui disaient comme à l'envi que c'était me rendre un mauvais service, attendu que je n'entendais rien à la peinture monumentale et que je déshonorerais les murs que je peindrais. »

Non, Delacroix ne méprisa pas la critique et ne se montra pas ingrat envers elle. Toutes les lettres adressées à MM. Silvestre, Astruc, Dumas, Thoré, Anclrieu, Pérignon, Charles Blanc, Gau- 
tier, Tourneux, Vacquerie, G. Sand, Chesneau, Burty, Rivet, Baudelaire, etc., le prouvent surabondamment. Elles prouvent d'autre part et d'une façon évidente que l'éloge le réconfortait et lui redonnait du cour au ventre. Il y a loin de ce qu'on y lit à ce dédain doublé de rancune amère qu'on a prêté au maître pour toutes choses écrites sur sa personne et qui ne se traduisaient pas par un éloge dithyrambique. M. Piron, du reste, dit en toutes lettres : “ Delacroix était très sensible aux critiques dont il était l'objet et très sensible aussi d'autre part aux louanges que ses amis et les hommes du métier lui donnaient souvent : il avait ses heures d'anxiété pendant lesquelles il éprouvait réellement le besoin de ces suffrages qui réveillaient sa confiance en lui-même. » 
Critique des autres. -Aspirations et préceptes. Manière de procéder.

Si Delacroix fut sensible à la critique pour lui-même, il n'exerça jạmais la sienne sur les autres. Les grands morts seuls le préoccupèrent et il ne formulait guère ses sentiments sur les vivants que d'une manière générale. Comme dans cette lettre à Alexandre Dumas où il dit : "Vous vous plaigniez avec raison de la tendance des arts. Nous visions haut autrefois. Heureux qui pouvait y atteindre! Je crains que la taille des lutteurs d'aujourd'hui ne leur permette pas même d'en avoir la pensée, Leur petite vérité étroite n'est pas celle des maîtres. Ils la cherchent terre à terre avec un microscope. Adieu la grande brosse, adieu les. grands effets des passions à la scène! "; ou dans cette autre à M. M..., qui vise l'Apothéose de Napoléon par M. Ingres : " Ce n'est qu'en arrivant de la campagne, il y a deux jours, que j'ai lu l'article bienveillant que vous avez bien voulu m'écrire à propos de mon travail de l'Hôtel de Ville. J'en 
ai été bien heureux et je m'empresse de vous en exprimer mes remerciements. Je ne sais si mon illustre confrère en plafond sera aussi satisfait de votre appréciation que je le suis pour ma part. Je suis entièrement de votre avis, à savoir que les camées ne sont pas faits pour être mis en peinture et qu'il faut que chaque chose soit à sa place, etc. "

Tout cela n'est pas bien méchant, comme on voit, et ne décèle guère un esprit grincheux qui trouve du charme à écorcher ses confrères. Cependant M. Lassalle-Borde, qui fut son collaborateur et son compagnon, dit : " Il n'était pas content lorsqu'il s'examinait; mais lorsqu'il se comparait, c'était différent. Alors il était impitoyable dans ses appréciations; il mordait à belles dents et aimait à frapper de grands coups. " M. Lassalle-Borde nous fournit encore sur ce sujet des renseignements précieux.

" Il faudrait que ce dont on a la vision, lui disait-il, pût être rendu sans peine; il faut que la main acquière également une grande prestesse... Paganini n'a dû son étonnante exécution 
sur le violon qu'en s'exerçant chaque jour pendant une heure à ne faire que des gammes. " Aussi, comme le relate M. Piron, Delacroix, en entrant dans son atelier le matin, dessinait-il, avant de semettre à peindre, pendant une demiheure au crayon; c'étaient là ses gammes à lui.

Le maitre, ainsi que nous l'avons vu déjà, réprouvait absolument l'asservissement à la nature vivante, à cette nature “ qui n'a qu’à se montrer même sans choix et sans lien avec autre chose pour être séduisante ». Il ne voulait pas que l'on composât avec le modèle. Imaginer une composition, disait-il, c'est combiner les éléments d'objets que l'on connait, qu'on a vus, avec d'autres éléments qui tiennent à l'âme de l'artiste. Or, cette combinaison ne peut se faire que si l'on n'est pas dès l'abord asservi par le détail à consulter, détail sans rapport avec l'idée préconçue. Il faut que l'idée puisse se faire jour sans le secours de la nature. C'est pourquoi il recommandait, pour acquérir cette indispensable virtuosité, de se livrer chaque jour à des études libres faites d'après les maîtres avec la seule préoccupation d'en reproduire le 
caractère. Il ne comprenait que les figures conçues d'un seul jet et trouvait le Titien pénible, autant que Rubens et Véronèse admirables : ". On. y sent, disait-il, trop de disparates dans l'étude d'après nature des diverses parties. Quelle différence avec Rubens! Quelle puissance de jet! comme tout se trait et sort de la même source, dans la forme et rlans la couleur! .... L'important n'est pas tant le fini d'un pied: ou d'une main que l'expression d'une figure par le mouvement. Et puis cela ne peut se faire qu'à l'aide d'un modèle qui ne vous donne presque jamais ce qui vous conviendrait. Une main, mais une main doit parler comme un visage. " Cette disposition d'esprit, cette indépendance, cette invincible tendance qui fit sa gloire, à se. substituer toujours aux choses qu'il voyait, à les interpréter, à les, estamper pour ainsi dire sur lui-même, lui rendait très pénible la:confection du portrait à cause de la nécessité où il était de respecter la littéralité des traits. Il ne se retrouvait dans la plénitude de ses moyens qu'en présence d'un personnage qui ne posait que dans son imagination. 
Delacroix ne pouvait pas se recopier sans se modifier suivant l'impression du moment. C'était là une des conséquences forcées de sa manic̀re de comprendre l'art qui, chez lui, n'était en réalité qu'un véritable jet cérébral, instantané et complet du premier coup, jet unique qui ne comportait pas de reflet.

Nous devons à M. Lassalle-Borde des indications très intéressants sur la manière de travailler de Delacroix et sur quelques procédés de détail. "Il était très minutieusement propret, dit-il; et dans sa personne et pour sa peinture. Il fallait que sa palette fût préparéc avec beaucoup de soin. Il avait dressé sa gouvernante à la faire et à la défaire : elle s'en tirait à merveille. Avant de peindre, il composait un grand nombre de tons sur sa palette, qu'il opposait avec un art infini et qui facilitaient la promptitude de l'exécution. Il m'en a donné la clef sans réserve aucune, cela étant nécessaire pour l'aider comme il le voulait dáns nos travaux. Il ne pouvait pas travailler longtemps de suite et sa mauvaise santé l'avait obligé d'adopter une manière de peindre qui lui permît d'interrompre 
et de reprendre facilement son travail. Lorsqu'un tableau était ébauché et à l'effet voulu, il le terminait à l'aide de hachures et de glacis. Il s'interrompait souvent et reposait ses nerfs en fredonnant quelque air avec une guitare, puis reprenait presque aussitôt la palette et peignait quelques instants encore avec une verve toute fébrile.

"Lorsque ses nerfs ne le servaient pas, il tombait dans une prostration pénible à voir : ce n'était pas le même homme. Mais à certains moments il avait une énergie extraordinaire.

“ Delacroix composait ses tableaux avec une extrême facilité; mais avant il feuilletait tous ses cartons qui renfermaient beaucoup de gravures de différentes écoles; cela fouettait son imagination. Et puis il prenait tout ce qui était à la convenance de son sujet, des figures et des groupes entiers, sans le moindre scrupule, qu'il transformait, à la vérité, au point de rendre ses larcins méconnaissables. "Raphael, du reste, " me disait-il, n'a pas fait autrement, avec tout “ ce que nous connaissons de l'antiquité qu'il “ s'est approprié, et tant d'autres ! ” 
Jean Gigoux nous donne dans ses Causeries sur les artistes de précieux renseignements sur les aspirations de Delacroix et sa manière de procéder.

" Il avait, dit-il, l'inquiétude de son art; il cherchait le quelque chose qu'on n'apprend d'aucun maitre et qui vous saisit. Il voulait la vie, la vie à tout prix, la vie partout, sur les terrains, dans les ciels, autour de ses figures. Le reste passait après.

“ Je me souviens qu'une fois, huit jours avant le Salon, nous terminions à la hâte nos tableaux dans une salle du Louvre, en bas, ou sont les statues. Nous étions l'un près de l'autre. Delacroix travaillait à son Saint Louis passant le pont de Taillebourg. Naturellement il allait à grands coups, avec l'ardeur que vous pouvez imaginer, levant à peine la tête par-ci par-là. Il jetait un clair sur le nez, sur une oreille, sur un casque, bref, partout où il en fallait; puis, se retournant vivement près de moi, il me disait :

"Vous verrez, cher ami, cela sera fait!"

“ Le soir, il était brisé; mais le lendemain 
il recommençait, s'appliquant à saisir le clapotement de l'eau, le mouvement des cheraux, et ainsi de même pendant les quelques jours qui nous restaient. L'impression, encore l'impression, toujours l'impression!

“ ..... Delacroix était extrêmement inégal dans son travail, nul ne le fut plus que lui. Il était le contraire d'Horace Vernet, auquel on eût pu appliquer le mot de Voltaire : “'Toujours " bien, jamais mieux. ”

“Ses petits tableaux étaient souvent fixés du premier jet; ses croquis, ses pochades le mettaient en verve. Tous les matins, avant de grimper sur son échafaudage, il crayonnait une ou deux figures d'après Raphael ou tout autre maitre ancien, ou même ant:yue: C'était sa manière de faire sa prière, à l'imitation des vieux maitres, qui, eux, se mettaient à genoux avant de commencer une cuvre.

"Quand son démon familier, son emportement le possédait, il casșait, il brisait les membres de ses personnages, les allongeant ou les raccourçissant, peu lui importait, pourvu que la peinture fût bonne et que la figure capitale tint 
bien sa place dans le tableau. Le fond avait, du reste, pour lui autant d'importance que la figure.

" Tout le monde peut voir à Versailles son Entrée des Croisés à Constantinople. Dans cette grande toile, toutes les figures sont à leur place, et il semble qu'elles y respirent l'air à pleins poumons. Vous diriez une fenêtre ouverte sur le passé. Vous voilà transporté comme par enchantement sur le Bosphore : vous voyez la ville avec ses rues étroites et blanches; au premier plan, un de ces rudes croisés maltraite un sénateur, peut-être le Paléologue lui-même; le vieillard se cramponne aux colonnes de porphyre; une femme à genoux implore la clémence de ce brutal; à droite, voici des guerriers à cheval; tout cela est superbe de vie. et de couleur; mais le croisé qui renverse le vieillard en robe violet et or montre-t-il son dos ou sa poitrine? Ne me fiant pas à mon seul jugement, j'ai consulté des artistes et des amateurs, nul ne put me répondre. Le maugrabin que je citais plus haut est dans ies mêmes conditions vaguues, si bien que Ricourt, grand partisan de Delacroix, 
répondit plaisamment à quelqu'un qui lui demandait : " Est-ce une poitrine ou un dos? ” Ricourt, dis-je, répondit : “ Ni l’un ni l'autre, " c'est de la peinture. »

“ Delacroix était le premier à convenir de ces choses, mais il n'en riait point. Un jour que mon ami Français faisait une lithographie d'après la Barque de don Juan, il pria Delacroix de venir voir son travail.

“ Celui-ci, affligé outre mesure en voyant froidement les défauts de son tableau, lui dit: “Que voulez-vous que je fasse à présent! “Voici une épaule de profil sur une poitrine de " face! Voici un homme qui meurt de faim au “ milieu de l'Océan et je l'ai fait gras et bien “ portant! C'est insensé! Comment ai-je pu " faire cela? "

“ Français lui dit :

“ Est-ce que vous ne pourriez pas y retou" cher un peu?

“ Y retoucher? Il y aurait trop à faire. “ J'avais la fièvre de la production dans cè " moment-là. Que voulez-vous? Faites comme " vous pourrez. Est-ce que Audran a copié 
“ Le Brun littéralement? Il l’a recalé. Eh bien, " recalez-moi aussi. "

" Mais, monsieur Delacroix ?...

"Non, non, recalez-moi tout cela; vous "faites des choses superbes tous les jours."

"Cette anecdote vous prouve que Delacroix eût écrit très bien sa propre critique. »

Delacroix eut peu d'élèves et cela se comprend. Il faut à tout enseignant une méthode. Le maître n'en avait aucune. Il peignait au courant de sa verve, de l'excitation de ses nerfs et de ses dispositions intellectuelles. Il pouvait bien de temps à autre laisser tomber quelque aphorisme précieux à ramasser, mais il n'avait pas cette suite dans la pratique d'idées arrêtées qui fait les professeurs utiles. Il était bien trop grand, trop chercheur et trop changeant pour enseigner au sens propre du mot. Il fallait se contenter de le regarder faire, s'inspirer des hautes qualités de sa peinture, so modeler sur lui, chose difficile, se hisser à la hauteur de son génie, chose impossible. Aussi fut-il peu suivi. De ceux qui écoutèrent ses conseils nul ne perça. Aucun ne tenta de 
l'imiter : nul n'y serait parvenu. L'expérience nous a prouvé que le sentiment ne fait pas école et tout l'œuvre de Delacroix est sentimental dans le plus vaste sens du mot. M. Burty a relevé comme ayant fréquenté l'atelier de la rue Neuve-Guillemin et plus tard celui de la rue Neuve-Bréda les noms de MM. Joly Grangedor, Desbordes-Valmore, Saint-Marcel, Maurice Sand, Andrieu, Eugène Lambert, Lassalle, Gautheron, E. Leygue, Th. Véron, Ferrussac, auxquels il faut joindre plusicurs amateurs inconnus. Il lui manquait aussi la qualité première du professeur : la patience. 


\section{Candidature à l'Institut.}

Dalacroix, si indépendant, si libre d'allures, si osé dans la manifestation de son talent, si entêté dans sa manière de voir et d'agir, si cassant, si indomptable en matière d'art, était, hors de son atelier, un régulier, un correct, un gentleman légèrement guindé. Sobre, rangé, il ne commettait jamais d'excès d'aucun genre et se contentait la plupart du temps d'obtenir auprès des femmes quelque succès d'esprit. Il aimait le monde en sceptique; on l'y recherchait. Il n'y apportait rien de ses troubles intimes, savait se modérer dans la discussion, ne sortait jamais d'une sorte de réserve diplomatique; il était du monde enfin par sa famille, par ses relations et par ses goûts. Il lui faisait, à ce monde, do nombreux sacrifices, y compris celui de sa santé, qui eut beaucoup à souffrir de l'abus des soirées. Rien de moins étonnant donc, rien de moins anormal, que ce désir très vif' qui le prit d'être de l'Institut. 
Cette compagnie sévère d'hommes arrivés qui constituait, surtout à ce moment, l'aréopage de l'art, ne pouvait manquer de le tenter. Y être admis, c'était être consacré. Delacroix se sentait las du doute des autres et du sien propre. Pour lui-même et pour le public, il désirait être officiellement reconnu. Beaucoup ont considéré cela comme une faiblesse. Mais ceux-là oublient que Delacroix ne s'est jamais posé lui-même en chef d'école; que ce ne fut pas un frondeur; qu'il repoussa toujours la qualification de romantique; qu'elle lui fut imposée malgré lui et qu'aucune des choses capables de satisfaire son amour-propre ne lui fut jamais indifférente. Celle-là étant du nombre, il la brigua, quoi de plus naturel!

Il se présenta le 4 février 1837, et voici la lettre qu'il écrivit au président de la classe des Beaux-Arts pour poser sa candidature :

“ Monsieur le Président, je vous prie de vouloir bien faire agréer par la classe des Beaux-Arts ma candidature à la place vacante dans son sein par la mort de M. Gérard. En mettant sous ses yeux les titres sur lesquels je 
pourrais fonder une prétention à l'honneur que je sollicite, je ne puis me dissimuler leur peu d'importance, surtout dans cette occasion où la perte d'un maitre aussi éminent que M. Gérard laisse dans l'école française un vide qui ne sera pas comblé de longtemps.

"Voici toutefois les noms de quelques-uns des ouvrages sur lesquels je prends la liberté d'appeler les souvenirs indulgents de l'Ácadémie :

"Le Dante et Virgile, le Massacre de Scio, le Christ au jardin des Oliviers, Marino Faliero, le Vingt-huit Juillet 1830, les Femmes d'Alger, Saint Sébastien, les Peintures de la Chambre des députés. "

Cette demande resta sans résultat. Delacroix se présenta de nouveau le 22 mars 1838, sans plus de succès, et il échoua encore le 28 décembre 1838. Le 7 décembre 1849, il écrivit encore au Président de l'Académie des BeauxArts : “... C'est pour la quatrième fois que j'ai l'honneur de me présenter aux suffrages de l'Académie; cette insistance et le désir, très naturel, de faire partie d'un corps illustre suffi- 
ront-ils pour faire excuser l'infériorité de quelques-unes des productions que j'ai mentionnées? J'éprouve une juste défiance en approchant d'une réunion qui représente les traditions et les principes éternels qui ont été ceux du grand goût chez tous les artistes célèbres; j'ose espérer pourtant que mon extrême insuffisance en présence des grands modèles ne passera pas aux yeux de l'Académie pour l'indice d'une tiède admiration ou d'un médiocre respect pour les objets du respect et de l'admiration de tous les siècles; le culte passionné que je leur ai voué est un titre que j'invoquerai avec plus de confiance que tous les autres, pour être admis à l'honneur de participer à de nobles travaux. ")

Cette lettre pleine de réticences, où on peut - lire entre les lignes à peu près ce que l'on veut; ne força pas encore pour cette fois les portes de l'Académie. Delacroix eut beau montrer patte blanche; la vieille eut de la méfiance et ne se laissa pas toucher. Le maître jugea prudent de se désister et de réserver ses efforts pour plus tard. 
En décembre 1856 il écrit à Soulier, et vers le milieu de cette lettre assez morose où perce une certaine impatience sous une feinte résignation, nous trouvons ce qui suit : " A la vérité je me suis porté pour être académicien, mais il y a si longtemps que j'ai eu cette envie-là que je commence à être blasé sur l'espoir et sur la crainte à cet endroit. Malgré une certaine rancune persévérante, on me dit que j'ai plus de chance cette fois. Dieu le veuille! »

Enfin, le 14 janvier 1859 , la persévérance de Delacroix finit par être couronnée d'un succès tardif, et il prit place sous la coupole, après s'être vu préférer Schnetz, Langlois, Couder, Cogniet. En vérité, il ne l'avait pas volé.

Voici ce qu'il écrivait à M. V. à cette occasion: “Je te remercie de ta lettre et j'y vois que tu avais à l'avance confiance dans le résultat. Je n'ai pas été aussi rassuré que toi pendant le cours des démarches qui l'ont amené; non que j'aie pu en faire de ma personne, car j'ai été retenu chez moi par un gros rhume pendant trois semaines; je n'ai donc pu faire de visites, j'ai écrit quelques lettres, et surtout j'ai eu dans 
l'illustre corps deux ou trois amis comme il n'en existe guère qu'au Monomotapa, qui ont pris ma cause en main avec une suite et une chaleur qui ont beaucoup contribué au succès; en somme, quoique tardive, cette élection est utile et me semble plus à propos, à présent qu'elle est faite, que je ne me le figurais auparavant. Aux félicitations que je reçois, je vois qu'elle était presque nécessaire pour qu'une certaine partie du public me mìt à une certaine place; cela a rassuré un bon nombre d'admirateurs, et quoiqu'il n'y eût rien de changé dans la valeur de l'homme et dans celle de ses ouvrages, il y fallait absolument l'étiquette. »

“. Cher monsieur et ami, écrit-il aussi à M. Dutilleux à la même occasion, il n'y a pas de félicitations qui puissent me flatter plus que les vôtres. La chose a été faite assez franchement et cela ajoute à la réussite aux yeux du public. Vous dites justement que ce succès il y a vingt ans m'aurait causé un tout autre plaisir; j'avais la chance dans ce cas de me voir plus utile que ne puis l'être maintenant dans une situation de ce genre. J'aurais eu le temps de devenir pro- 
fesseur à l'École; c'est là que j'eusse pu exercer quelque influence. Quoi qu'il en soit, je ne partage pas l'opinion de quelques personnes, amies ou autres, qui m'ont fait entendre plus d'une fois que je ferais mieux de m'abstenir. Il y a plus de fatuité que de véritable estime de soi-même à rester dans sa tente; au reste, je ne manque point ici à mes antécédents, puisque, une fois mon parti pris, je n'ai pas cessé de me présenter. ")

Delacroix sent bien où le bât le blesse. C'est le loup qui se passe au cou le collier du chien. Il n'a pas toujours parlé ainsi et nous pourrions sans peine le mettre en contradiction avec luimême. Mais quel est celui de ses confrères qui n'a pas fait de même? Jusqu'à trente ans on fronde, ensuite on s'humilie, on quémande et on est pardonné : au résumé, les excuses qu'il clonne sont valables. Ainsi que le dit M. Piron, à la recherche des circonstances atténuantes et s'elforçant de pallier une faiblesse :

“Pour le public ignorant, la consécration de la valeur d'un homme par une élection publicue a toujours paru nécessaire. Cette nomi- 
nation à l'Institut n'ajoutait rien au mérite réel de la peinture de Delacroix, mais, dans un certain monde on avait tellement pris l'habitude d'en dire du mal que son élection à l'Académie dut paraître étonnante à quelques-uns. Que d'injures! que de combats! que d'hommes engagés d'avance par les paroles qu'ils avaient prononcées, par les abominations auxquelles ils avaient voué le malheureux peintre! Comment espérer que ces hommes pussent jamais se rétracter et lui accorder leurs suffrages? C'est ce qui arriva cependant. » 
La fin. - Le testament - Le tombeau.

La vente.

Cette nomination à l'Institut, venue après vingt ans d'attente et de sollicitations aussi vaines que répétées, marque à peu près la fin de la carrière active et militante de Delacroix. L'ambition s'éteint, la santé fléchit de plus en plus. Il écrit à Soulier, de Champrosay, " ce village d'opéra-comique où on ne voit que des élégants et des paysans qui ont l'air d'avoir fait leur toilette dans la coulisse »: "Je sens que si je vivais à la campagne, je pourrais peut-être me refaire une santé. Quoique depuis longtemps je vive à Paris à peu près comme un campagnard quant aux distractions et à ce qu'on appelle les plaisirs de ce lieu-là, on n'y trouve pas la bénigne influence naturelle qui, à la campagne, agit sur l'imagination pour réagir sur le corps; là, on se sent au milieu d'objets amis et vraiment faits pour nous. Je ne puis me lasser de tout cela; ma petite promenade me ravit, et, 
sauf ce rhume, je me trouve beaucoup mieux. » A Paris, le maitre vivait plus retiré; il n'avait pas cependant complètement renoncé à ses habitudes mondaines, et la phtisie continuait sa marche sourde sans que son cortège de malaises pût le déterminer à rompre les liens qui l'attachaient à la société.

“ Un soir, dit M. Piron, le 19 mars 1863, en sortant d'un salon, l'affection du larynx dont il se plaignait depuis longtemps reparut tout à coup avec plus d'intensité. Il partit pour Champ. rosay le 26 mai, et en arrivant, il eut, au chemin de fer, un vomissement de sang assez abondant. Cet incident donna lieu à de graves inquiétudes, et il fut question de revenir immédiatement à Paris. Cependant, on attendit. Le 31 au soir, le sang revint en plus grande abondance : une cuvette en était remplie. Il n'y avait plus à balancer, le malade fut placé avec soin dans une bonne voiture et on revint à Paris. L'hémoptysie ne reparaît pas; le malade est plus calme, mais les crachements commencent" et la faiblesse devient de plus en plus grande. Après un mois passé à Paris, le médecin 
croit que l'air de la campagne pourrait être favorable au malade, et, le 16 juin, il reprend la route de Champrosay. Il y reste jusqu'au 14 juillet, mais ses forces s'épuisaient, sa maigreur était extrême et sa faiblesse aussi. Ce jour-là, il revint à Paris pour prendre la chaise longue et le lit d'où il ne devait plus se relever. "

Il expira le 13 août 1863, vers six heures du matin.

En lui s'éteignait le plus grand peintre des temps modernes.

Les regrets ne firent pas défaut au grand artiste. "Aucun des hommes appartenant de près ou de loin à la grande famille intellectuelle, dit M. Cantaloube, n'a manqué de rendre au maître les derniers et pieúx devoirs.

"Autour de la dépouille mortelle de l'homme se pressait un noble cortège d'admirateurs et d'esprits d'élite. Au premier rang figuraient les poètes qui ont depuis célébré sa gloire. Sur les bords de sa fosse, deux discours ont noblement ouvert pour la renommée de Delacroix une ère nouvelle. Un épisode touchant a terminé cette 
cérémonie funèbre. Comme autrefois en Italie, une jeune et gracieuse femme, artıste elle-même, une patricienne portant l'un des grands noms de la noblesse romaine (la duchesse Colonna), a déposé sur le cercueil du peintre-poète une couronne d'or. Auprès de ce mort, déjà ressuscité dans la vie idéale, nous avons ainsi pu rêver de Pétrarque et des triomphes du Capitole! »

Delacroix laissait un testament aux termes duquel MM. Pérignon, Dausatz, Carrier, Schwiter, Andrieu, Dutilleux et Burty étaient chargés de s'entendre avec M. Piron, légataire universel, et de classer ses dessins.

Nous n'avons pas à parler ici de ce testament autrement que pour mentionner la clause relative à son tombeau :

"Mon tombeau sera au cimetière du PèreLachaise, sur la hauteur et dans un endroit un peu écarté. Il n'y sera placé ni emblème, ni buste, ni statue. Mon tombeau sera copié très exactement sur l'antique, ou Vignole, ou Palladio, avec des saillies très prononcées, contrairement à tout ce qui se fait aujourd'hui en 
architecture. „) Ces prescriptions ont été fidèlement exécutées.

Une autre clause de ce testament cependant prescrivait que ses œuvres fussent mises en vente publique. On sait quel succès inattendu obtint cette vente, qui dura du mardi 16 février 1864 au lundi 29. "Il y eut, dit M. Burty, presque constamment vacation double, dans la journée et le soir, et presque tout le même public assista sans interruption à cette dispersion d'un œuvre qui offrait quelque morceau à tous les appétits délicats. Ce fut une réhabilitation et une ivresse. On vit, on aima Delacroix. La vente, estimée à l'origine à moins de cent mille francs, en produisit plus de trois cent mille.

Tableaux. . . . . . . 209,711 francs.

Dessins et aquarelles . . . 117,833 -

Eaux-fortes et lithographies . $\quad 5,719 \quad-$

Divers . . . . . . $\frac{3,963-}{337,226 \text { francs. }}$

“ Et la spéeulation qui devait faire plus tard de l'hôtel Drouot un terrain tellement redoutable ne s'était point encore organisée! Tout, tableaux, esquisses ou dessins, tout fut disputé, moins par 
les marchands que par des amateurs passionnés ou par des artistes. ")

Les dessins, les pastels, les aquarelles, les calques, les croquis au crayon ou à la plume, les eaux-fortes, les lithographies trouvés dans l'atelier de Delacroix emplissaient une trentaine de cartons. " Il y en avait au delà de six mille, dit encore M. Burty. Personne ne les avait jamais vus, sauf M. Andrieu, qui vivait depuis plusieurs années auprès dı maître et l'aidait dans ses travaux. Personne, même les plus intimes amis, n'avait jamais reçu la confidence de ce labeur énorme... Il avait à plusieurs reprises, dans sa vie, épuré ces cartons, brûlant ce qu'il jugeait indigne de lui survivre. Jamais il ne les avait vidés pour en tirer profit. Il voulait qu'après sa mort ses dessins vinssent, comme un argument solennel, protester contre les reproches amers d'improvisation et de facilité dont on l'avait poursuivi, et prouver qu'une " improvisation" aussi abondante et aussi solide que celle dont il avait fait preuve dans ses travaux décoratifs et ses tableaux, qu'une semblable " facilité » à exprimer par la forme et 
la coloration le sentiment et l'idée, à adapter l'esprit du dessin et l'éloquence de la couleur aux convenances du sujet choisi, eussent été, sans le secours préalable de l'étude la plus puissante et la plus méthodique, des phénomènes sans exemple dans l'histoire de l'art. ")

Il serait superflu et oiseux de résumer ici les opinions très diverses, excessives pour la plupart, que la critique a émises à différentes époques sur le maître que nous avons essayé de montrer à l'aide d'une sorte d'autobiographie posthume résultant de l'ensemble des choses qu'il a dites, écrites et pensées. Il nous a paru suffisant et plus utile d'emprunter à M. Chesneau la bibliographie des ouvrages où “ le génie du grand artiste romantique a été l'objet d'une ardente discussion ». On pourra ainsi aller aux sources. Cette bibliographie, on la trouvera plus loin. Il n'entrait pas non plus dans le cadre de ce volume de parler en particulier des œuvres de Delacroix, fût-ce des plus importantes, ni de relater la très mince partie anecdotique qui s'y rattache. Cela nous eût entraîné trop loin; mais qu'on nous 
permette, en terminant, de substituer à notre opinion pleinement admirative, dont le public n'a cure, celle de l'homme qui a le mieux jugé et compris Delacroix, du critique éminent et du poète incomparable dont la plume incisive et pénétrante a su le plus sagacement, à notre sens, mettre en relief les traits particuliers du génie de ce maître, aujourd'hui incontesté.

Dès 1845, à propos du Salon où Delacroix exposait la Madeleine dans le désert, les Dernières paroles de Marc-Aurèle, une Sibylle qui montre le rameau d'or et le Sultan du Maroc entouré de sa garde, Baudelaire écrit : “Delacroix est décidément le peintre le plus original des temps anciens et des temps modernes. Cela est ainsi, qu'y faire? Aucun des amis de Delacroix, et des plus enthousiastes, n'a osé le dire simplement, crûment, impudemment comme nous. »)

En 1846 : “ Le romantisme et la couleur me conduisent droit à Eugène Delacroix. J'ignore s'il est fier de sa qualité de romantique; mais sa place est ici, parce que la majorité du public l'a clepuis longtemps, et même dès sa première 
œuvre, constitué le chef de l'école moderne..... Ses curres sont des poèmes, et de grands poèmes naïvement conçus, exécutés avec l'insolence accoutumée du génie.... poèmes dans lescuels il ouvre de profondes avenues à l'imagination la plus voyageuse....

“ Delacroix part de ce principe qu'un tableau doit avant tout reproduire la pensée intime de l'artiste, qui domine le modèle comme le créateur la création.

“...Pour Eug. Delacroix, la nature est un vaste dictionnaire dont il roule et consulte les feuillets avec un œil sûr et profond; et cette peinture, qui procède surtout du souvenir, parle surtout au souvenir. L'effet produit sur l'âme du spectateur est analogue aux moyens de l'artiste. Un tableau de Delacroix laisse toujours une impression profonde dont l'intensité s'accroît par la distance. Sacrifiant sans cesse le détail à l'ensemble, et craignant d'affaiblir la vitalité de sa pensée par la fatigue d'une exécution plus nette et plus calligraphique, il jouit pleinement d'une originalité insaisissable qui est l'intimité du sujet. » 
“ L'exercice d'une dominante n’a légitimement lieu qu'au détriment du reste. Un goout excessif nécessite les sacrifices, et les chefs-d'œuvre ne sont jamais que des extraits divers de la nature. C'est pourquoi il faut subir les conséquences d'une grande passion, quelle qu'elle soit, accepter la fatalité d'un talent et ne pas marchander avec le génie. C'est à quoi n'ont pas songé les gens qui ont tant raillé le dessin de Delacroix. - Delacroix est le seul aujourd'hui dont l'originalité n'ait pas été envahie par le système des lignes droites : ses personnages sont toujours agités, et ses draperies voltigeantes. Au point de vue de Delacroix, la ligne n'est pas; car, si ténue qu'elle soit, un géomètre taquin peut toujours la supposer assez épaisse pour en contenir mille autres; et pour les coloristes qui veulent imiter les palpitations éternelles de la nature, les lignes ne sont jamais, comme dans l'arc-en-ciel, que la fusion intime de deux couleurs. D'ailleurs, il y a plusieurs dessins comme plusieurs couleurs : exacts ou bêtes, physionomiques et imaginés.

“ Le premier est négatif, incorrect à force de 
réalité, naturel mais saugrenu; le second est un dessin naturaliste, mais idéalisé, dessin d'un génie qui sait choisir, arranger, corriger, deviner, gourmander la nature; enfin, le troisième qui est le plus noble et le plus étrange peut négliger la nature : il en représente une autre analogue à l'esprit et au tempérament de l'auteur. Le dessin de création est le privilège du génie. La grande qualité du dessin des artistes suprêmes est la vérité du mouvement, et Delacroix ne viole jamais cette loi naturelle.

“ Un des caractères principaux du grand peintre est l'universalité. Delacroix est universel; il a fait des tableaux de genre pleins d'intimité; des tableaux d'histoire pleins de grandeur. Lui seul peut-être, dans notre siècle incrédule, a conçu des tableaux de religion qui n'étaient ni vides et froids comme des œuvres de concours, ni pédants, mystiques ou néo-chrétiens, comme ceux de tous ces philosophes de l'art qui font de la religion une science d'archaïsme, et croient nécessaire de posséder avant tout la symbolique et les traditions primitives pour remuer et faire chanter la corde religieuse. 
"Cela se comprend facilement, si l'on veut considérer que Delacroix est, comme tous les grands maitres, un mélange admirable de science et de naïveté, c'est-à-dire un homme complet.

“ En général Delacroix ne peint pas de jolies femmes, au point de vue des gens du monde toutefois. Presque toutes sont malades et resplendissent d'une certaine beauté intérieure. Il n'exprime point la force par la grosseur des muscles, mais par la tension des nerfs. C'est non seulement la douleur qu'il sait le mieux exprimer, mais surtout - prodigieux mystère de la peinture - la douleur morale! cette haute et sérieuse mélancolie brille d'un éclat morne, même dans sa couleur large, simple, abondante en masses harmoniques, comme celle de tous les grands coloristes, mais plaintive et profonde comme une mélodie de Weber.

“ En fait de gestes sublimes, Delacroix n'a de rivaux qu'en dehors de son art. Je ne connais guère que Frédérick Lemaître et Macready.

“ C'est à cause de cette qualité toute moderne et toute nouvelle que Delacroix est la dernière expression du progrès dans l'art. Héri- 
tier de la grande tradition, c'est-à-dire de l'ampleur, de la noblesse et de la pompe dans la composition, et digne successeur des vieux maîtres, il a de plus qu'eux la maîtrise de la douleur, la passion, le geste! c'est vraiment là ce qui fait l'importance de sa grandeur. En effet, supposez que le bagage d'un des vieux illustres se perde, il aura presque toujours son analogue qui pourra l'expliquer et le faire deviner à la pensée de l'historien. Otez Delacroix, la grande chaîne de l'histoire est rompue et s'écroule à terre.

" A quoi bon relever des fautes de détail et des taches microscopiques? L'ensemble est si beau, que je n'en ai pas le courage. D'ailleurs la chose est si facile et tant d'autres l'ont fait! N'est-il pas plus nouveau de voir les gens par leur bon côté? Les défauts de Delacroix sont parfois si visibles qu'ils sautent à l'œil le plus exercé. On sait que les grands génies ne se trompent jamais à demi, et qu'ils ont le privilège de l'énormité dans tous les sens. ”

En 1855, Delacroix apparaît avec trentecinq tableaux qui inspirent à Baudelaire les 
réflexions suivantes de critique générale : "Delacroix a traité tous les genres; son imagination et son savoir se sont promenés dans toutes les parties du domaine pittoresque. Il a fait (avec cuel amour, avec quelle délicatesse!) de charmants petits tableaux, pleins d'intimité et de profondeur; il a illustré les murailles de nos palais, il a rempli nos musées de vastes compositions.

“ Nul, après Shakespeare, n'excelle comme Delacroix à fondre dans une unité mystérieuse le drame et la vérité...

Delacroix, lac de sang, hanté des mauvais anges, Ombragé par un bois de sapins toujours vert, Oì, sous un ciel chagrin, des fanfares étranges, Passent comme un soupir étouffé de Weber.

“ Du dessin de Delacroix si absurdement, si niaisement critiqué, que faut-il dire, si ce n'est qu'il est des rérités élémentaires complètement méconnues; qu'un bon dessin n'est pas une ligne dure, cruelle, despotique, immobile, enfermant une figure comme une camisole de force; que le dessin doit être comme la nature, vivant et agité; que la simplification dans le dessin est une monstruosité; que la nature nous 
présente une série infinie de lignes courbes, fuyantes, brisées, suivant une loi de génération impeccable, où le parallélisme est toujours indécis et sinueux, où la concavité et la conrexité se correspondent et se poursuivent; que M. Delacroix satisfait admirablement à toutes ces conditions et que, quand même son dessin laisserait percer quelquefois des défaillances et des outrances, il a au moins cet immense mérite d'être une protestation perpétuelle et efficacc contre la barbare invasion de la ligne droite, cette ligne tragique et systématique dont les ravages sont déjà immenses dans la peinture et la sculpture? Une autre qualité très grande, très vaste du talent de M. Delacroix et qui fait de lui le peintre aimé des poètes, c'est qu'il est. essentiellement littéraire. Non seulement sa peinture a parcouru, toujours avec succès, le champ des hautes littératures; non seulement elle a traduit, elle a fréquenté Arioste, Dante, Byron, Walter Scott, Shakespeare, mais elle sait révéler des idées d'un ordre plus élevé, plus fines, plus profondes que la plupart des peintures modernes. Et remarquez bien que ce n'est 
jamais par la.grimace, par la minutie, par la tricherie de moyens, que M. Delacroix arrive à ce résultat; mais par l'ensemble, par l'accord profond, complet, entre son sujet, sa couleur, son dessin et par la dramatique gesticulation de ses figures.

“ Edgard Poe dit, je ne sais plus où, que le résultat de l'opium pour les sens est de revêtir la nature entière d'un intérêt surnaturel qui donne à chaque objet un sens plus profond, plus volontaire, plus despotique. Sans avoir recours à l'opium, qui n'a connu ces admirables heures, véritables fêtes du cerveau, où les sens plus attentifs perçoivent des sensations plus retentissantes, où le ciel d'un azur plus transparent s'enfonce comme un abîme plus infini, où les sons tintent musicalement, où les couleurs parlent, où les parfums racontent des mondes d'idées? Eh bien! la peinture de Delacroix me paraît la traduction de ces beaux jours de l'esprit. Elle est revêtue d'intensité et sa splendeur est privilégiée. Comme la nature aperçue par des nerfs ultra-sensibles, elle révèle le surnaturalisme. 
“Que scra M. Delacroix pour la postérité? Que dira de lui cette redresseuse de torts? Il est déjà facile de l'affirmer sans trouver trop de contradicteurs. Elle dira comme nous qu'il fut un accord unique des facultés les plus étonnantes; qu'il eut comme Rembrandt le sens de l’intimité et la magie profonde, l'esprit de combinaison et de décoration comme Rubens et Le Brun, la couleur féerique comme Véronèse, etc., mais qu'il eut aussi une qualité sui generis, indéfinissable et définissant la partie mélancolique et ardente du siècle, quelque chose de tout à fait nouveau, qui a fait de lui un artiste unique, sans générateur, sans précédent, probablement sans successeur, un anneau si précieux qu'il n'en est point de rechange, et qu'en le supprimant, si une pareille chose était possible, on supprimerait un monde d'idées et de sensations, on ferait une lacune trop grande dans la chaîne historique. » 


\section{BIBLIOGRAPHIE D'EUGÈNE DELACROIX}

EMPRUNTÉE A M. C HESNEAU

D'Arpentigny. - Catalogue avec préface de l'Exposition qui eut lieu en 1864 au boulevard des Italiens, après la vente posthume du maître. In-18, 66 pages. Paris, Claye, 186'

Philippe Burty. - Catalogue avec préface de la vente posthume du maître. In-18, 104 pages. 1864. - Maîtres et Petits Maîtres. In-18, 387 pages. Paris, Charpentier, 1877. (Eugène Delacroix, p. 51-70.)

Charles Baudelaire - Curiosités esthétiques. Euvres complètes. 3 vol. in-12. Paris, Michel Lévy. (Eugène Delacroix, p. 311-393.)

AuÉdÉE Cantaloube. - Eugène Delacroix, l'homme et l'artiste, ses amis et ses critiques. 1 vol. in-12, 100 pages. Paris, Dentu, 1864.

Ernest Chesneau. - Les Chefs d'école. La Peinture au XIx ${ }^{\mathrm{e}}$ siècle. In-12. Paris, Didier, 1862. - L'Art et les Artistes modernes en France et en Angleterre. In-12, 358 pages. Paris, Didier, 1864. (Eugène Delacroix, p. 312-392.) 
Cir. Clénent. - Étude sur les Beaux-Arts en France. In-12, 392 pages. Paris, Michel Lévy, 1865. (Eugène Delacroix, p. 175-190.)

H. Ducleuziou. - L'Euvre de Delacroix. In-12, 72 pages. Paris, Marpon, 1865.

Ch. Coligny. - Les Grands et les Petits Personnages du jour. In-18, 16 pages. Paris, Poupin-Delaroche, 1861.

Th. Coutan. - Méthode et entretiens d'atelier. In-18, 382 pages. Paris, 1867. (Eugène Delacroix, p. 194-203.)

H. Deraborde. - Éloge d'Eugène Delacroix. In $-4^{\circ}, 31$ pages. Paris, F. Didot, 1876.

V. Frond. - Panthéon des illustrations françaises au $X I X^{\mathrm{e}}$ siècle. Livraison in-folio, 2 pages avec portrait et fac-similé; dessins. Paris, A. Pilon, 1865.

JAL. - Entretiens sur le Salon de 1824.

Ch. Lenormant. - Les Artistes contemporains. Salons de 1831 et 1833 .

H. de la Madeleine. - Eugène Delacroix à l'Exposition du boulevard des Italiens. In- $8^{\circ}$, 32 pages, orné de 18 vignettes sur bois, plus un portrait et un autographe. Paris, F. Didot, 1864. 
Ad. Moreau. - Eugène Delacroix et son œuvre. In- $8^{\circ}, 328$ pages. Paris, Jouaust, 1873.

G. Planche. - Portraits d'artistes, peintres et sculpteurs. In-12, 372 pages. Paris, Michel Lévy, 1853. (Eugène Delacroix, p. 25-49.)

Piron. - Eugène Delacroix, sa vie et ses cuvres. In- $8^{\circ}, 542$ pages. Paris, Claye, 1865.

G. SAND. - Histoire de ma vie (passim). Paris, Michel Lévy.

Th. Silvestre. - Histoire des artistes vivants. In-18, 375 pages. Charpentier, 1878. Documents nouveaux. Michel Lévy, 1864. Catalogue de la galerie Bruyas de Montpellier. (Eugène Delacroix, p. 270-415.)

Il faudrait consulter aussi :

Les comptes rendus des Salons, par L. Vitet, dans la Revue des Deux-Mondes; les articles de M. Ch. Blanc dans la Gazette des BeauxArts, ceux de M. E. Feydeau dans la Revue internationale, de M. Darcel dans l'Illustration, de M. Paul de Saint-Victor dans la Presse, les Salons de Th. Gautier et de Thoré, la préface si importante du Catalogue de la vente F. Villot (1865) et les notes renfermées dans bien d'autres 
catalogues, vente Laurent Richard, Michel de Tretaigne, Paturle, San Donato, Wilson, Carlier, Faure, Dutilleux, etc.

Rechercher :

Les Causeries faites par A. Dumas père dans le local même de l'Exposition posthume du maître, en décembre 186't, et parues en feuilleton dans le journal la Presse.

Les articles intéressants parus dans le Magasin pittoresque à diverses époques. Il en est de date ancienne qui sont écrits par E. Delacroix lui-même avec des vignettes sur bois et facsimilés de ses dessins.

Feuilleter le Monde illustré, le Journal illustré, l'Art, le Musée des Familles, l'Autographe, l'Artiste, le Constitutionnel, etc., où l'on trouverait des articles signés : Thiers, Stendhal, H. Heine, A. de Musset, Mérimée, J. Janin, Delescluze, Sainte-Beuve, N. Roqueplan, Ch. Blanc, de Chennevières, J. Buisson, P. Mantz, Adrien Dauzats, E. About, Taine, comte de Viel-Castel, Jeanron, A. Decamps, Laviron, Ch. Haussard, A. Karr, Gavarni, Proudhon, de la Fizelière, L. Biris, Geogglau, 
H. Rochefort, Lady Eglé Charlmont, baron Rivet, F. Sabatier, Nugher, P. Petroz, A. Robaut, Ménard, Tardieu, E. Véron, Castagnary, J. J. Guiffrey, A. Bruyas, Bergerat, G. Colin, Champfleury, Z. Astruc, Delphine Gay, A. Sensier, Ars. Houssaye, L. Lagrange, F. de Lasteyrie, C. de Sault, Gonzague Privat, Marius Vachon, de Gisors, de Jolly, Ernest Fillonneau, J. Raymond, Ol. Merson, Tabar, Fromentin, Montrosier, F. Clément, Sezerat, Ch. Royer, Vergniaud, Eug. Barbier, Mercey, L. Viardot, C. Rousset, A. Vacquerie, P. Meurice, L. Peisse, R. de Beauvoir, V. Schœlcher, R. Galbacès, de Mirecourt, Antony Béraud, Landon, Trim, F. Wey, Ch. Asselineau, Ch. Talot, F. Pigeory, J. Lefort.

Voir enfin la Galerie Durand-Ruel, 1878, in- $4^{\circ}, 61$ pages de texte et trente livraisons de dix planches gravées chacune; l'Exposition universelle, portraits nationaux, 1878, et un curieux volume : Lettres de Real-Delcroix, par Marie Desyles. In-18, $40 b^{3}$ pages. Paris, Didier, éditeur. (Eugène Delacroix, p. 151, 156-158, 326-327.) 


\section{TABLE DES MATIERES}

Pages.

Généalogie . . . . . . . . . . 5 5

Portrait de Delacroix . . . . . . . . . . . . . 11

Amour de Delacroix pour la musique. . . . . . . . . . . 23

Pourquoi Delacroix se fit peintre. Entrée à l'atelier . . . . 28

Relations avec Gros. Son admiration pour le maître . . . . 31

La santé . . . . . . . . . . . . . . . . . . . . . . 55

Sacrifices à l'art. Amitié . . . . . . . . . . . . . . 47

Affection de Delacroix pour sa bonne. Ses conséquences. . 59

Amour. . . . . . . . . . . . 66

Critique et esthétique. Idéal et réalisme. . . . . . . . . 74

Appréciation de certains maîtres . . . . . . . . . . 85

Pensées philosophiques et critiques. . . . . . . . . . 123

Mélancolie, amertume et doute. . . . . . . . . . . . 131

Voyage en Angleterre . . . . . . . . . . . . . . . 147

Voyage au Maroc . . . . . . . . . . . . . . . 157

Voyage en Belgique. Il ne voit pas I'Italie . . . . . . 166

Son opinion sur lui-même . . . . . . . . . . . 172

Mépris pour la critique. . . . . . . . . . . . . . 177

Critique des autres. Aspirations et préceptes. Manière de procéder................. 183

Candidature ì l'Institut . . . . . . . . . . 195

La fin. Le testament. Le tombeau. La vente. . . . . . . 203

Bibliographie d'Eugène Delacroix, empruntée à M. Ches-

FIN DE LA TABLE DES MATIÉRES. 
PARIS. - IMPRIMERIE DE L'ART

E. MÉNARD ET J. A UGRY, 4I, RUE DE LA VICTOIRE 


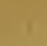

$-2=$

1
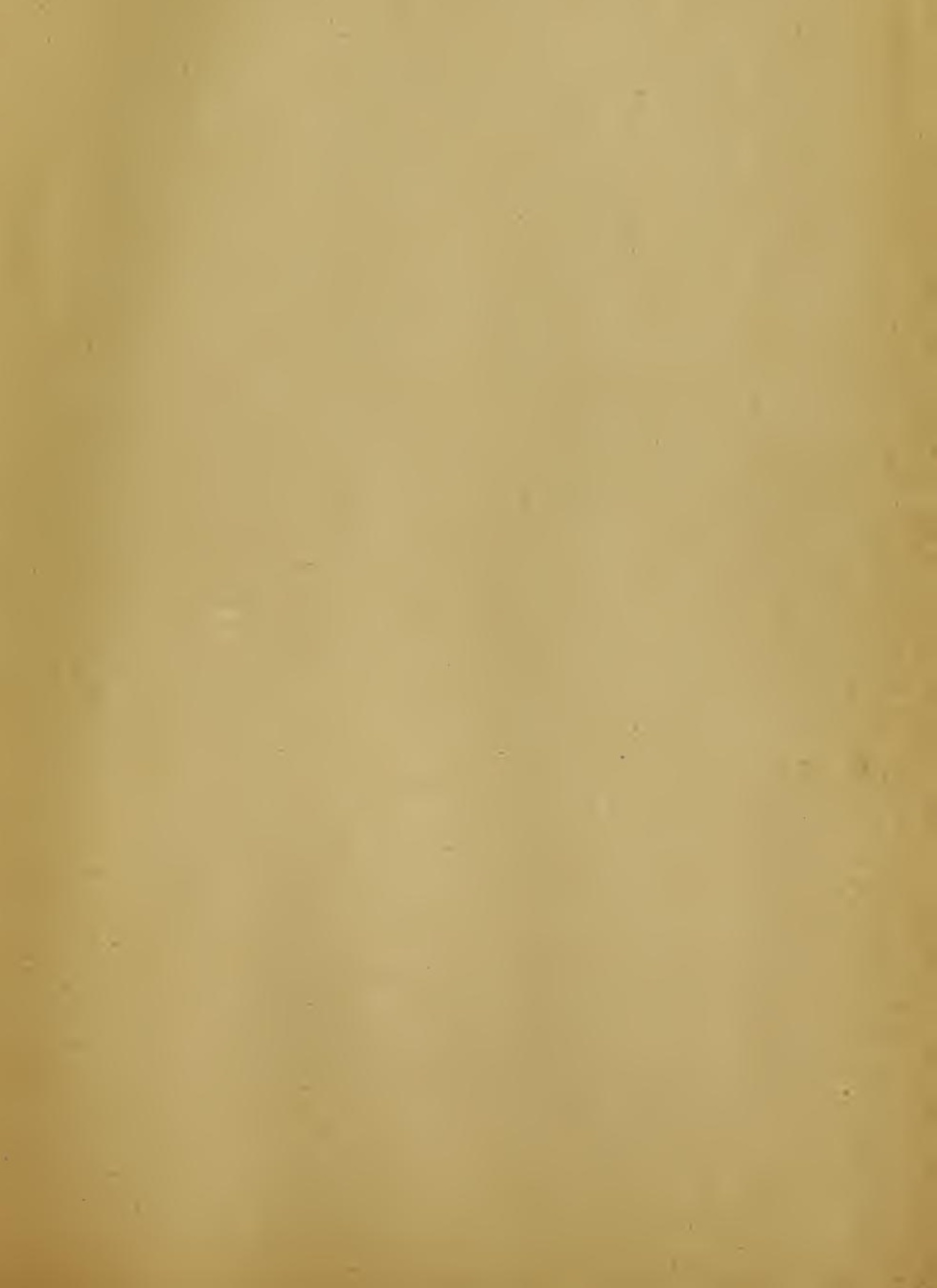

LIBRAIRIE DE L'ART

JULES ROUAM, ÉDITEUR 29, CITÉ D'ANTIN, PARIS

\section{EXTRAIT DU GATALOGUE}

\section{PUBLICATIONS PÉRIODIQUES}

\section{ONZIĖME ANNÉE T, A RT ONZIĖME ANNÉE $1885 \backsim 1885$}

REVUE BI - MENSUELLE ILLUSTRÉE

Direction générale et Rédaction en chef : M. Eugène VE்R0N Secrétaire de la Rédaction : II. Paul LEROI

Direction artistique : II. Léon GAUCHEREL

Peinture, Sculpture, Architecture, Archéologie Art dramatique, Salons, Expositions Musées, Galeries publiques \& particulières

\section{ÉDIJION ORDINAIRE}

Chaque numéro, accompagné d'une eau-forte au moins, tiré sur beau papier teirté, se compose de 20 pages in $-4^{\circ}$ grand colombier, avec nombreuses illustrations dans le texte et hors texte.

I'ART forme, par année, deux volumes de 300 pages environ chacun, non compris les eaux-fortes et les gravures hors texte.

PRIX DE L'ABONNEMENT

Paris, Départements, Algérie et Alsace-Lorraine :

Un an, 60 fr.; six mois, 30 fr.

PAYS DE L'UNION POSTALE :

Un an, 70 fr.; six mois, 35 fr.

On s'abonne sans frais dans tous les Bureaux de poste et chez tous les principaux libraires. 
Librairie de l'Art, J. ROUAM, Editeur, 29, cite d'Antin, Paris.

\section{PRIX DES ANNÉES PARUES}

1875. -3 volumes . . . . . . . . . $120 \mathrm{fr}$. 1876 et 1877 . (Presque épuisées). - 4 vol. par annee, chacune $150 \mathrm{fr}$. I 878,1879, I 880, I881, I 882, I883. - 4 vol. par année, chacune $120 \mathrm{fr}$. 1884. -2 volumes.................. $60 \mathrm{fr}$.

\section{Un Numéro spécimen : 2 fo. 50}

\section{ÉDIJIONS DE GRAND IUUXE}

L'ART publie deux éditions de grand luxe : la première, à 100 exemplaires avec le texte sur papier de Hollande, est accompagnée de 2 séries de planches avec la lettre et avant la lettre sur papier du Japon; la seconde, à 5 exemplaires avec le texte sur papier vélin, accompagnée de 4 séries de planches : sur Hollande, avec la lettre, sur Japon, sur parchemin et sur whatman avant la lettre. Ces éditions sont soigneusement numérotées, et les planches avant la lettre portent la signature des artistes.

Édition à 100 exemplaires : par an, 200 fr. Édilion à 5 exemplaires : par an, 600 fr.

Les livraisons des deux éditions tirćes à 5 et à 100 exemplaires ne se vendent pas séparément.

On ne peut s'abonner aux éditions de luxe pour moins d'une année.

Les Abonnés de L'ART reçoivent GRATUITEMENT le COURRIER DE L'ART

\section{COURRIER DE L'ART}

Chronique Hebdomadaire des Ateliers

des Musées, des Expositions, des Ventes publiques, etc.

PARAISSANT TOUS LES VENDREDIS

PRIX D'ABONNEMENT:

France et Colonies, 12 fr. par an.

Pays compris dans l'Union postale, 14 fr. par an.

On s'abonne sans frais dans tous les Bureaux de poste.

\section{LE NUMÉRO : 25 CENTIMES}

Le Commier de $\boldsymbol{l}$ Art se compose de 12 pages in-8 grand colombier.

Le Cominier de $\boldsymbol{l} \boldsymbol{A} \boldsymbol{A} \cdot \boldsymbol{t}$ publie les informations relatives aux ateliers, aux expositions, aux collections, aux ventes publiques, aux musées; les comptes rendus des livres illustrés, et tout ce qui de près ou de loin intéresse le développement des arts en France et chez les autres nations.

Les Abonnés de L'ART reçoivent gratuitement le COURRIER DE L'ART. 
Librairie de l'Art, J. ROUAM, Éditeur, 29, cité d'Antin, Paris.

\section{L'ART ORNEMENTAL}

PARAISSANT TOUS IES SAMEDIS

Directeur et Rédacteur en chef: G. DARGENTY

Paris et Départements : un an, 5 Fr ; Six mois, 2 Fr. 50 UNiON POSTALE : UN AN, 8 Fr.; SIX MOIS, 4 Fr.

Le Numéro : 10 centimes.

Le but que se propose L'Art Ornemental est de procurer, pour un prix insignifiant, à toutes les industries d art des modèles qu'elles ne peuvent trouver ailleurs, et de leur constituer une collection unique qui deviendra une source inépuisable de renseignements à consulter.

\section{On s'abonne sans frais dans tous les Bureaux de poste.}

Chaque année de L'Art Ormemental forme un beau volume in $-4^{\circ}$ jésus illustré de plus de 300 gravures, avec titres et tables, aux prix suivants : Broché, 6 fr. Elégamment relié en percaline rouge, avec le titre frappé en or sur le plat et au dos, $10 \mathrm{fr}$. L'administration de l'Art Ornemental tient à la disposition de ceux de ses abonnés ou acheteurs au numéro, qui voudraient faire relier sur place leur volume, un emboitage, toile rouge, avec titre frappé en or sur le plat et sur le dos, au prix de $3 \mathrm{fr}$.

\section{GUIDES DU COLLECTIONNEUR}

E. Molinier, attaché à la Conservation du Musée du Louvre. Dictionnaire des Émailleurs, Biographies, Marques et Monogrammes. Un volume in-8 sur papier vergé, 5 fr., 12 exemplaires sur papier du Japon, $15 \mathrm{fr}$.

\section{OUVRAGES DE LA MÂME SÉRIE EN PRÉPARATION :}

Dictionnaire des Fondeurs et des Ciseleurs, par M. DE Champeaux, inspecteur des Beaux- $\Lambda$ rts à la Préfecture de la Seine. - Dictionnaire des Ébénistes, par le même. - Dictionnaire de la C'éramique. Marques et Monogrammes, par M. Edouard GARN1ER. - Dictionnaire des Monogrammes et Marques de graveurs, par M. Georges Duplessis, conservateur adjoint du département des Estampes à la Bibiiothèque nationale, et M. Boucнот, attaché au même département. - Dictıonnaire des Monogrammes et Marques de collectionneurs et d'amateurs, par M. A. W. Thibaudeau. - Les Bronzes de la Renaissance. Catalogue des Plaquettes italiennes et francaises, par M. E. MoLinier, attarhé à la Conservation du Musée du Louvre. Dictionnaire des Peintres de l'Ecole francaise. - Dictionnaire des Peintres des Ecoles flamande et hollandaise. - Dictionnaire des Peintres de l'Ecole italienne. - Catalogues des Médailles françaises et allemandes de la Renaissance.-Etc., etc. 
Librairie de l'Art, J. ROUAM, Editeur, 29, cité d'Antin, Paris.

\title{
BIBLIOTHÈQUE INTERNATIONALE DE L'ART
}

\author{
PUBLIÉE SOUS LA DIRECTION DE
}

M. EUGE $\mathbf{N E ~ M U ̈ N T Z ~}$

PREMIĖRE SÉRIE. - VOLUMES IN-4ำ

OUVRAGES PUBLIÉS :

I. Eugìne Müntz, conservateur du Musée, des Archives et de la Bibliothèque à l'École nationale des Beaux-Arts. - Les Précurseurs de la Renaissance. Prix : broché, 20 fr. ; relié, 25 fr. 25 exemplaires sur papier de Hollande, $50 \mathrm{fr}$.

II. Edmond Bonnaffé. - Les Amateurs de l'ancienne France. Le Surintendant Foucquet. Il ne reste plus de cet ouvrage que quelques exemplaires reliés, à $15 \mathrm{fr}$., et quelques exemplaires sur papier de Hollande, à 25 fr.

1II. Davillier (le baron). - Les Origines de la porcelaine en Europe. Les Fabriques italiennes du XVe au XVIIe siècle. Il ne reste plus de cet ouvrage qu'un très petit nombre d'exemplaires qui sont réservés aux acheteurs de la collection. Prix : broché, $20 \mathrm{fr}$; relié, $25 \mathrm{fr}$ - -25 exemplaires sur papier de Hollande, $40 \mathrm{fr}$.

IV. Ludovic Lalanne, sous-bibliothécaire de l'Institut. - Le Livre de Fortune. Recueil de deux cents dessins inédits de Jean Cousin, d'après le manuscrit conservé à la Bibliothèque de l'Institut. Prix: broché, 30 fr.; relié, 35 fr. -25 exemplaires sur papier de Hollande, $50 \mathrm{fr}$.

V. Henri Delaborde (le vicomte), secrétaire perpétuel de l'Académie des Beaux-Arts, Conservateur du Département des Estampes à la Bibliothèque nationale. - $I_{a}$ Gravure en Italie avant Marc-Antoine. Prix : broché, 25 fr. ; relié, 30 fr. -25 exemplaireș sur papier de Hollande, $50 \mathrm{fr}$.

VI. Mark Pattison ( $\left.\mathrm{M}^{\mathrm{me}}\right)$, auteur de "The Renaissance in France". - Claude Iorrain, sa vie et ses ceuvres, d'après des documents nouveaux. Prix: broché, $30 \mathrm{fr} . ;$ relié, $35 \mathrm{fr} .-25$ exemplaires sur papier de Hollande, $50 \mathrm{fr}$. 


\section{BIBLIOTHEQUUE POPULAIRE DES ECOLES DE DESSIN}

PUBLİEE FAR

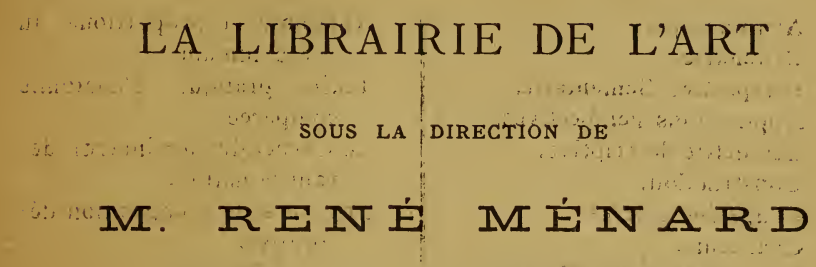

- Professeur à l'École nationale des Arts décoratifs.

Les nations étrangères font depuis plusieurs années des efforts considérables pour conquérir la suprématie que la France a conservée jusqu'à ce jour dans les industries qui relèvent de l'art. De son côté, notre pays cherche à élever le niveau des études artistiques, en créant partout de nouvelles écoles de dessin et en donnant à celles qui existaient déjà une direction plus éclairée et plus méthodique.

La Librairie de l'Art, désireuse de seconder ce mouvement national, a résolu de publier une série de petits volumes illustrés, traitant de toutes les matières qui se rattachent à l'enseignement artistique, et dont le prix soit à la portée des plus petites bourses.

La BIBLIOTHĖQ̨UE POPULAIRE DES ÉCOLES DE DESSIN comprend trois séries de volumes : $1^{\circ}$ Enseignement technique; $-2^{\circ}$ Enseignement professionnel; - 30 Enseignement général.

I'REMIÈre SÉrIE. - Enseignement technique. - Les volumes qui composent cette série suivent le programme de l'enseignement spécial qui se donne dans nos écoles de dessin. Ils comprennent tout l'ensemble des cours oraux, depuis ceux qui s'adressent aux enfants les plus jeunes qui ne savent absolument rien, jusqu'aux cours des adultes ou des hommes faits, qui se préparent aux examens pour le diplôme de professeur. La rédaction de ces petits volumes a été demandée principalement à des professeurs, que leur situation met à même de connaître les besoins des élèves. Ces petits traités sont 
conçus de manière à mettre tous les élèves à même de répondre aux examens de fin d'année, ou aux examens définitifs pour lesquels on décerne les diplômes.

Les volumes de cette série sont accompagnés de dessins démoustratifs intercalés dans le texte. Nous avons actuellement en préparation et nous pourrons, très prochainement, livrer au public les volumes suivants :

Arithmétique.

Géométrie.

Perspective élémentaire.

Applications perspectives.

Géométrie descriptive.

Construction.

Coupe des pierres.

Charpente.

Les Ordres et les Moulures.
Anatomie et proportions du corps humain.

Traité pratique d'anatomie comparée.

Le Carnet du dessinateur de vant la nature.

Principes de composition décorative.

Etc., etc.

DEUXIÈME sÉRIE. - Enseignement professionnel. - Les volumes qui composent cette série complètent l'enseignement spécial des écoles et s'adressent à toutes les professions se rattachant aux écoles de dessin.

Des livres de ce genre existent déjà, mais pour la plupart dans des conditions de prix qui en font des ouvrages de luxe plutôt que des livres usuels. Les nôtres conservent le format et le prix adopté pour la série technique; car nous voulons que désormais chaque élève, chaque apprenti puisse avoir dans sa poche un petit volume qui contiendra l'histoire de sa profession, accompagnée de gravures reproduisant les plus grands chefs-d'œuvre que l'art a produits dans cette profession, depuis les temps les plus reculés jusqu'à nos jours. Les volumes en ce moment en préparation comprennent :

Le Papier peint et les Éventails. Les Tissus et la Décoration des tissus.

La Tapisserie.

La Verrerie et les Cristaux de roche.

Les Émaux.
L'Ornementation des livres.

Les Ivoires.

Les Meubles.

La Ferronnerie.

Les Armes et Armures.

L'Orfèvrerie.

La Bijouterie.

Etc., etc.

Troistème sérIe. - Enseignemcnt général. - Les volumes formant cette série s'adressent aux gens du monae, en mêmc temps quaux producteurs et aux élèves. Ils ont pour but de leur montrer, à l'aide de nombreuses gravures, les transformations du goût à travers les âges, de facon à les mettre à même de discerner 
Librairie de l'Art, J. ROUAM, Éditeur, 29; cité d'Antin, Paris.

VII. J. Cavallucci, professeur à l'Académie des Beaux-Arts de Florence, et E. Molinier, attaché à la Conservation du Musée du Louvre. - Les Della Robbia, leur vie et leur œuvre. Prix : broché, $30 \mathrm{fr}$.; relié, $35 \mathrm{fr}$. -25 exemplaires sur papier de Hollande, $50 \mathrm{fr}$.

VIII. Henri Hrmans, conservateur à la Bibliothèque Royale de Belgique, membre correspondant de l'Académie Royale des Sciences, des Lettres et des Beaux-Arts, professeur à l'Académie Royale des Beaux-Arts d'Anvers. - Le Livre des Peintres de Carel van Mandir, Vie des peinlres flamands, hollandais et allemands. Deux volumes in $-4^{\circ}$ raisin avec un grand nombre de portraits. Prix des deux volumes : brochés, $100 \mathrm{fr}$.; reliés, $120 \mathrm{fr}$.

25 exemplaires sur papier de Hollande.

Prix des deux volumes ............. . $150 \mathrm{fr}$.

\section{SOUS PRESSE :}

\section{Émile Michel. - Les Musées d'Allemagne.}

Charles Perkins, Direcieur du Musée de Boston. - Ghiberti et son École.

Kondakoff. - Histoire de la Miniature byzantine.

\section{DEUXIĖME SÉRIE. - VOLUMES IN-80}

I. Eugìne Müntz. - Ies Historiens et les Critiques de Raphael. Essai bibliographique pour servir d'appendice à l'ouvrage de PASSAVANT, avec un choix de documents inédits ou peu connus. Un volume illustré de quatre purtraits de Raphael. Il ne reste de cet ouvrage qu'un très petit nombre d'cxemplaires qui sont réservés aux acheteurs de la collection. Quelques exemplaires sur papier de Hollande, $25 \mathrm{fr}$.

II. Henry Cros et Charles Henry. - I'Encaustique et les autres procédés de peinture chez les anciens. Un volume illustré de 30 gravures. Prix : broché, 7 fr. 50. Quelques exemplaires sur papier de Hollande, $15 \mathrm{fr}$. 
Librairie de l'Art, J. ROUAM, Éditeur, 29, cité d'Antin, Paris.

III. Georges Duplessis, conservateur du Département des Estampes à la Bibliothèque nationale - Les Livres à gravures du XVIo siècle. Les Emblèmes d'Alciat. Un volume illustré de I I gravures. Prix : broché, $5 \mathrm{fr}$. Quelques exemplaires sur papier de Hollande, $10 \mathrm{fr}$.

IV. Louis DE Ronchaud, Directeur des Musées nationaux et de l'École du Louvre. - Ia Tapisserie dans l'antiquité. Ie Péplos ¿'Athéné Parthénos. Un volume illustré de 16 gravures. Édition sur papier ordinaire, $10 \mathrm{fr}$. Quelques exemplaires sur papier de Hollande, $20 \mathrm{fr}$.

\section{BIBLIOTHÈQUE D'ART MODERNE}

Jean Rousseau. - Camille Corot. Suivi d'un appendice par Alfred Robaut. Avec le portrait de Corot et 34 gravures sur bois et dessins reproduisant les œuvres du maitre. In- $4^{\circ}$ écu. Prix : broché, 2 fr. 50.

Charles Yriarte, inspecteur des Beaux-Arts. - J. F. Millet. Un volume in $-4^{\circ}$, illustré de nombreuses gravures. Prix : 2 fr. 50 .

Charles de la Rounat. - Études Dramatiques. Le Théâtre-Français. $\mathrm{M}^{\mathrm{me}}$ Arnoud-Plessy, MM. Régnier, Got, Delaunay. Nombreuses illustrations par P. Renouard. In- $4^{\circ}$ écu. Prix : broché, 3 fr.

\section{BIBLIOTHÈQUE DES MUSÉES}

Émile Michel. - Le Musée de Cologne. Suivi d'un catalogue alphabétique des tableaux de peintres anciens, exposés au Musée de Cologne. Illustré de nombreuses gravures dans le texte. In- $4^{\circ}$ écu. Prix : broché, 3 fr.

\section{BIBLIOTHÈQUE D'ART ANGIEN}

Jean Rousseau. - Fans Holbein. Un volume in-4 illustré de nombreuses gravures. Prix : 2 fr. 50 . 
aisément le style particulier à chaque époque, et de mettre ainsi à profit les visites qu'ils pourront faire dans les collections publiques ou particulières. Ils n'appartiennent pas directement à l'éducation artistique, mais ils en sont le complément indispensable. Nous préparons en ce moment les volumes suivants qui auront le format et le prix des ouvrages des autres séries:

Leçons d'histoire générale professées à l'École nationale des Arts décoratifs.

Histoire du Costume.

Histoire de la Sculpture française.

Histoire de l'Architecture.

Promenades au musée du Louvre.

Promenades au musée de Cluny:
La Décoration en Égypte.

$\begin{array}{ll}\text { - } & \text { en Grèce. } \\ \text { - } & \text { à Rome. } \\ \text { - } & \text { au Moyen-Ase. } \\ \text { sous la Renais- } & \text { sance. } \\ \text { - } & \text { au xvile siècle. } \\ \text { - } & \text { au xville siècle. } \\ \text { - } & \text { au xixe siècle. }\end{array}$

Etc., etc.

L'ensemble de notre bibliothèque constituera donc un tout bien complet, et parfaitement homogène, malgré la diversité apparente des sujets traités. L'artiste et le fabricant, l'homme du monde et l'ouvrier, l'élève des écoles ou des lycées et l'apprenti des ateliers, pourront y puiser également, et sous les formes les plus variées, les connaissances artistiques qu'ils ont le désir ou le besoin d'acquérir:

\section{OUVRAGES DÉJA PARUS :}

René Ménard. - L'Orfèvrerie. La Décoration en Égypte. La Décoration en Grèce (1re partie) : Architecture et Sculpture. La Décoration en Grèce ( $2^{\mathrm{e}}$ partie) : Meubles et Vêtements. La Décoration au $X V I$ e siècle : le Style Henri II. La Décoration au $X V I I$ e siecle : le Style Louis XIV. La Décoration au XVIIIe siècle: le Style Louis XV. La Décoration au XVIIIe siècle : le Style Louis XVI. Les Emblemes et Attributs des Grecs et des Romains. Les Villes du Vésuve. Excursion dans une cité antique.

Ch. Genurs. - Constı uction, Maçonnerie. (2 volumes.)

Christian Clopet. - La Perspective. L'Arithmétique (nombres entiers. L'Arithmétique (nombres premiers). Géométrie descriptive. 
Librairie de l'Art, J. ROUAM, Editeur, 29, cité d'Antin, Paris.

\section{MAGNIFIQÙE CHOIX}

D E

\section{GRAVURES AU BURIN \& A L'EAU-FORTE \\ Avant la lettre $\left\{\begin{array}{rr}\text { Tirées sur } & \text { Chine. } . . \\ - & \text { sur Japon. } \\ - & \text { sur parchemin. }\end{array}\right\}$ Montées Sur Bristol}

Avec la letTre, tirées sur beau papier, grandes marges.

GRAVURES SUR BOIS TIRÉES SUR CHINE, MONTÉES SUR BRISTOL

Ces gravures, exécutées par les premiers artistes, reproduisent les œuvres les plus célèbres des Maitres anciens et modernes. - Envoi franco du Catalogue.

\section{Publications diverses de la Librairie de l'Art}

Eugène Véron. - La Troisième Invasion (Juillet $1870-$ Mars $187 \mathrm{I}$, avec les eaux-fortes d'après nature, par Auguste Lançon. - Cet ouvrage comprend deux magnifiques volumes in-folio, colombier. 500 exemplaires numérotés, texte sur papier vélin et eaux-fortes tirées sur papier de Hollande; les deux volumes, $400 \mathrm{fr}$. 50 exemplaires numérotés, texte sur papier de Hollande et eaux-fortes tirées sur papier du Japon; les deux volumes, $800 \mathrm{fr}$. Edition populaire : deux volumes in $-8^{\circ}$, avec 86 gravures dans le texte et 16 cartes d'après les cuivres du Dépôt de la Guerre : les deux volumes brochés, $20 \mathrm{fr}$.; reliés toile, $24 \mathrm{fr}$.; reliés demi-chagrin, $28 \mathrm{fr}$.

RENÉ MÉNARD. - Entretiens sur la peinture, avec traduction anglaise. sous la direction de Philip Gilbert Hamerton. Un volume grand in $-4^{\circ}$, avec 50 eaux-fortes par les premiers artistes. $75 \mathrm{fr}$.

PhilipPe Burty. - Les Eauz-fortes de Jules de Goncourt. 200 exem. plaires, les eaux-fortes tirées sur papier de Hollande, $100 \mathrm{fr}$.; Ioo exemplaires numérotés, les eaux-fortes tirées sur papier du Japon, $200 \mathrm{fr}$.

Walter Armstrong. - - Alfred Stevens, a biographical study. Un volume illustré, in-4 $4^{\circ}$ colombier, relié en parchemin, $15 \mathrm{fr}$.

E. E. Viollet-LE-Duc. - Ia Décoration appliquée aux édifices. Fascicule orné dé 2 I gravures. Prix : $8 \mathrm{fr}$.

Son Altesse Impériale l'Archiduc Ronolphe, prince héritier d'Autriche. - Voyage en Orient. Un superbe volume grand in $-4^{\circ}$ enrichi de 37 eaux-fortes et de nombreuses gravures sur bois, d'après les dessins originaux de Françols DE PaUsingtr. Prix : broché, $80 \mathrm{fr}$.; riche reliure, $90 \mathrm{fr}$.

Paris. Imp, de l'Art. E. Ménard et J. Augry, 41, rue de la Victoire. 


\section{EN PRÉPARATION}

\section{EUGENE DELACROIX}

DEVANT SER CONTEMPORAIN'S

$$
\text { PA R }
$$

\section{MAURICE TOURNEUX}

